\title{
Die Pluralbildung im Deutschen - ein Versuch im Rahmen der Optimalitätstheorie
}

\author{
Heide Wegener (Potsdam)
}

Die Pluralbildung im Deutschen ${ }^{1}$ ist nicht chaotisch, aber komplex. Unabhängig davon, ob man für die Pluralbildung Regeln, Schemata oder die Wortstruktur als Erklärungsmodell benutzt, bleibt die Tatsache einer beachtlichen Zahl miteinander konkurrierender Formen zu erklären. Dies gilt schon deshalb, weil die Variation unter den Pluralformen wohl mit dazu beiträgt, dass trotz der Arbeiten von Mugdan 1977 und Köpcke 1987, 1993, der klaren Darstellung des Pluralsystems in vielen Grammatiken, z.B. Eisenberg 1986, 1989, 1998 noch immer bisweilen die Meinung besteht, die Pluralbildung im Deutschen sei arbiträr².

Im Folgenden soll gezeigt werden, dass das Pluralsystem des Deutschen nach Beschränkungen aufgebaut ist, die morphologischer und silbenphonologischer Natur sind und sich im Rahmen der Optimalitätstheorie (OT) beschreiben lassen. Die OT nimmt an, dass Wortformen universalen Beschränkungen (Constraints) unterliegen, und dass diese prinzipiell verletzbar sind. Ich werde zunächst die für die Pluralbildung relevanten Beschränkungen definieren, dann an heimischen Pluralformen und -varianten ihr Zusammenwirken zeigen und schließlich den Assimilationsprozess von Fremdwörtern mit Hilfe dieser Beschränkungen und der Beschränkungshierarchien zu erklären versuchen. Daran werden schließlich Überlegungen zu Verarbeitung und Lernbarkeit der Pluralformen geknüpft.

\subsection{Die Varianten der Pluralbildung}

Als Pluralvarianten gelten hier alle Pluralformen, die zu einem bestimmten Singularstamm gebildet werden können, zunächst unabhängig von dessen Eigenschaften wie Genus, Semantik und/oder Wortklasse. Von völlig undurchsichtigen, nur mit Hilfe etymologischen oder fremdsprachlichen Wissens interpretierbaren Formen wie Aposteriori, Fundus, Examina, Atlanten, Kommata sehe ich hier ab. Sie werden in der vorliegenden Arbeit nicht behandelt. Diese Formen sind ohne Zweifel im Lexikon gelistet, die Singularform kann ohne spezielles Wissen nicht erschlossen, die Pluralform nicht nach einer Regel, einem Schema oder einem "Wortdesign" (Neef 1998) gebildet werden. Formen wie Muttis, Gene, Laptops, Computer werden dagegen hier behandelt, auch wenn sie nur teilweise dem deutschen Pluralsystem entsprechen. Sie sind gerade für die Frage interessant, welche Beschränkungen im heutigen Deutsch gelten und die Assimilierung von Fremdwörtern an das Forminventar des nativen Wortschatzes regeln.

Für jeden Variationstyp führe ich hier nur einige Beispiele an und verweise auf den Anhang. Die konkurrierenden Formen sind für eine Beschreibung im Rahmen der OT interessant, da diese annimmt, dass Beschränkungen für die Bildung bestimmter Formen, darunter Flexionsformen, prinzipiell verletzbar und untereinander hierarchisiert sind, cf. Archangeli 1997, Russell 1997, Féry 1997. Ferner geht die OT davon aus, dass auch die Regelhierarchien

\footnotetext{
${ }^{1}$ Für wertvolle Hinweise danke ich Barbara Menzel und Stefanie Haberzettl.

${ }^{2}$ Schon Mugdan 1977: $113 \mathrm{f}$ beklagt, dass hinsichtlich der Substantivflexion Systemlosigkeit "immer wieder ernstlich behauptet" werde, dass die Darstellungen entsprechend "tatsächlich mehr oder minder regel- und systemlos sind", und fragt, "ob das allein an der Sprache liegt". Eine Frage, die heute umso berechtigter ist.
} 
nicht stabil sind, sondern variieren und sich im Lauf der Sprachgeschichte verändern können. Aus OT-Sicht ist Variation also zu erwarten und erklärbar.

\section{Semantisch motivierte Variation:}

1a) Die Varianten dienen synchron zur Unterscheidung von Homonymen: Muttern-Mütter, Banken-Bänke, Schilde-Schilder.

Die Varianten können häufig durch Flexionsklassenwechsel erklärt werden. Etwa war Bank ('Sitzmöbel') maskulin und wurde im Sog des aus Italien importierten Wortes für das Geldinstitut feminin, behielt aber seinen Plural bei. Die auch im Singular für Feminina phonologisch auffälligen Nomen Mutter und Hand gehen auf untergegangene Flexionsklassen zurück. Eine solche diachrone Erklärung soll hier aber nicht im Vordergrund stehen, was nicht ausschließt, dass sich aus der Diachronie wichtige Hinweise zur Entstehung und Funktionalität der synchronen Formen ergeben.

1b) Die Varianten dienen zur Unterscheidung von Appellativen bzw. Produktnamen und Eigennamen: Männer-Manns, Holzmänner ${ }^{3}$ - Holzmanns, Schmiede-Schmieds, Opel-Opels, Duden-Dudens, Vögel-Vogels, Katzen-Katzens, Schulzen-Schulzens.

Die s-Formen sind Familiennamen, die nativen Formen Appellativa, darunter Produktnamen und Bezeichnungen für Firmenangehörige. Die Produktnamen insbesondere befinden sich im Übergangsbereich zwischen Eigennamen und Appellativa.

\section{Stilistische Variation:}

Die Varianten, die nur teilweise bedeutungsdifferenzierend sind, gehören unterschiedlichen Sprachschichten $^{4}$ an: Grabmale-Grabmäler, Worte-Wörter, Bande-Bänder.

\section{Diastratische Variation:}

Die Varianten beruhen auf regionalspezifischen Beschränkungen, die Unterschiede zwischen dem Süden und dem Norden sowie zwischen dem Osten und dem Westen des deutschen Sprachgebiets aufzeigen. Sie machen deutlich, dass in der jeweiligen Sprachvarietät andere Beschränkungen gelten bzw. dass diese anders gewichtet sind, und sind deshalb für die vorliegende Untersuchung besonders interessant.

a) Süden ${ }^{5}$ - Norden: Skier-Ski, Beiner-Beine, Bröter-Brote, Wägen-Wagen, Onkeln-Onkel, Pärke ${ }^{6}$ - Parks, Karusselle-Karussells, Onkel-Onkels, Jungen-Jungs.

b) Osten - Westen: Parke-Parks, Pointe-Points, Taxen-Taxis, LPGen-LPGs

\section{Diachrone Variation:}

Die Varianten sind bedingt durch a) Veränderungen im deutschen Flexionssystem, die die Ausbildung eines neuen Pluraltyps erforderten, b) den Abbau dieses Notplurals und Anpassung von dessen Formen an die Norm, c) die Anpassung von Fremdwörtern an das deutsche Flexionssystem (cf. Paul 1917, Curme 1922), hier einige von zahlreichen Belegen:

\footnotetext{
${ }^{3}$ Inforadio 01.12.1999.

${ }^{4}$ In diesen Fällen ist der er-Plural die jüngere Form (siehe unten), die ältere gilt als erhaben. Zum Teil ist die ältere Form noch in Ortsnamen erhalten: Niederlande, Burghausen, Rheinfelden.

${ }^{5}$ Schwäbisch, bairisch.

${ }^{6}$ Schweizerisch.
} 
a) (Ebers)Walde-Wälder, Lichte-Lichter, Gesichte-Gesichter, Manne-Männer

b) Sträußer-Sträuße, Dinger-Dinge, Rester-Reste, Wichter-Bösewichte, RegimenterRegimente

c) Lazaretter-Lazarette, Testamenter-Testamente, Generals-Generäle ${ }^{7}$, Onkels-Onkel, Balkons-Balkone, Lifts-Lifte, Fracks-Fräcke, Kostüms-Kostüme ${ }^{8}$, Defizits-Defizite, VilleVillas, Pizze-Pizzas, Motti-Mottos, Celli-Cellos

Themata-Themas, Kommata-Kommas

Mensas ${ }^{9}$-Mensen, Basilikas-Basiliken, Divas-Diven, Villas-Villen, Pizzas-Pizzen, SchemasSchemen, Themas-Themen, Astas-Asten ${ }^{10}$

Kontos-Konten, Freskos-Fresken, Risikos-Risiken

Sozis-Sozen, Taxis-Taxen

Globusse-Globen, Albums ${ }^{11}$-Alben

Keks-Kekse, Straps-Strapse

\section{Synchrone Variation:}

Bei folgenden Formen ist unklar, ob es sich um Formen handelt, die a) relativ neu entlehnt sind, erst am Beginn des Nativierungsprozesses stehen, also eine native Pluralform erst ausbilden müssen, oder ob b) eine native Pluralform durch eine andere Pluralform ersetzt wird: Jungen-Jungens, Onkel-Onkels, Mädel-Mädels, Bräutigame-Bräutigams, Lifts-Lifte, Labors-Labore, Scheichs-Scheiche.

\subsection{Der Ansatz der OT}

Die Formvarianten in 1 sind semantisch motiviert und dürften dadurch relativ stabil sein. Auch die Formen in 5 bestehen teilweise schon lange: Paul 1917:182 führt Bubens, Briefleins, Mädchens u.a. von Goethe, Pfarrers von Schiller an. Die Formen in 3 sind innerhalb eines Teilgebiets der deutschen Sprache relativ stabil, obwohl sie dem Druck der standarddeutschen Norm ausgesetzt sind. Für beide stellt sich die Frage, welche Beschränkungen dafür verantwortlich sind, 1. dass überhaupt unterschiedliche Formen entstehen, 2. dass genau diese Formen gebildet werden, und 3. welchen Rang die Beschränkungen haben.

Alle Formen sind also für die Frage, welche Beschränkungen für die Pluralbildung im heutigen Deutsch gelten, interessant. Wenn die Formen in 4 und 5 dadurch erklärt werden können, dass sie relativ neu entlehnt sind, so wäre zu erwarten, dass sie in mehr oder weniger kurzer Zeit eine native Pluralform ausbilden, und es fragt sich, welche das sein wird. Interessant ist dann, welche Beschränkungen für die jetzige Form und welche für die Bildung der neuen, der nativen Form gelten, welche folglich einen höheren Rang auf der Hierarchie der Beschränkungen einnehmen.

\footnotetext{
${ }^{7}$ Nach Paul 1917 waren die jeweils ersten die Pluralformen im 18. Jahrhundert. Dabei ist Generals nicht aus dem Französischen entlehnt (généraux), sondern in Deutschland entstanden.

${ }^{8}$ Diese Form und die folgenden Pluralformen noch bei Curme 1922: 93.

${ }^{9}$ Sachs/Villatte 1900, Wahrig 1968 auch: Mensae.

${ }^{10}$ Zum maskulinen (!) Akronym für Allgemeiner Studentenausschuß, Zeitungsbelege bei Harnisch 1994: 107, Fn 11.

${ }^{11}$ Sachs/Villatte 1900.
} 
Des Weiteren erhebt sich dann die Frage, welche Ursache der Veränderung in der Beschränkungshierarchie zugrunde liegt. Wenn für diese Formen gilt, dass eine native Form durch eine andere bzw. durch -s ersetzt wird, dass es sich folglich um bloße Schwankungen handelt, so stellt sich ebenfalls die Frage, welche Beschränkungen die jeweiligen Formen regeln und was das für die Neubildung der Formen und für die Hierarchie der Beschränkungen besagt. Die konkurrierenden Formen zeigen, dass die Pluralbildung im Deutschen komplexer als im Englischen oder Spanischen ist. Das bedeutet weder, dass sie arbiträr ist noch dass es nur einen Regelplural, nur einen Defaultwert gibt und dass alle anderen Formen irregulär sind, wie einige Vertreter der kognitiven Linguistik annehmen (so Wiese 1996, Clahsen et al. 1992, 1995, Wunderlich/Fabri 1995, Marcus et al. 1995). Die wichtigsten Prinzipien der Pluralbildung sind seit langem bekannt (cf. z. B. Bech 1963, Wurzel 1970, Mugdan 1977, Eisenberg 1986, 1989, 1995, Wegener 1991, 1992, 1995, Bornschein/Butt 1987). Sie lassen sich im Rahmen der OT mit Hilfe silbenphonologischer und morphologischer Beschränkungen (siehe unten) teilweise präziser erfassen und anschaulich darstellen.

Als Merkmale oder Kriterien, die für die Pluralbildung eine steuernde Rolle spielen, kommen im Deutschen in Frage:

die Zahl und Form der Pluralsuffixe,

kategoriale Eigenschaften des Singularstamms wie die Zugehörigkeit zur Klasse der Eigennamen, Stoffnamen, Kurzwörter, Onomatopoetika, Substantivierungen anderer Wortarten, Appellativa,

phonologische Eigenschaften wie unmarkierte vs markierte phonologische Struktur, die Flexionsklassenzugehörigkeit,

die Genusklassenzugehörigkeit des Singularstamms,

der Fußakzent,

der Wortakzent der Pluralform,

Treuebeschränkungen zwischen Singularform und Pluralform, universale Beschränkungen zur Silbenstruktur.

\subsubsection{Die Pluralsuffixe und die Pluralformen}

Für die Pluralbildung stehen im heutigen Deutsch vier Pluralsuffixe zur Verfügung, und zwar (e), (e)n, er, s. Die beiden ersteren bilden Allomorphe mit und ohne Schwa, die phonologisch bedingt und strikt komplementär verteilt sind. Die Wahl zwischen $\varnothing$ und -e (+/- Umlaut) einerseits, die zwischen -n und -en andererseits ist vorhersagbar. Seit Curme 1922, Bech 1963, Wurzel 1970, Mugdan 1977, Kloeke 1982, Eisenberg 1986, Wegener 1995 wird dies als Schwa-Tilgung erklärt: Das -e des Pluralflexivs wird getilgt, wenn es auf eine schwahaltige Silbe folgt, wobei diese offen oder geschlossen sein kann, in letzterem Fall aber nur durch einen Liquid oder Nasal geschlossen sein darf. ${ }^{12}$ Da der er-Plural regelhaft umlautet, stellt auch er nur ein Pluralsuffix dar.

Wir haben es also mit folgenden fünf Pluralformen zu tun:

\footnotetext{
${ }^{12}$ Während der Zusammenhang zwischen -n und -en allgemein anerkannt wird, wird der ebenso phonologische Zusammenhang zwischen $\varnothing$ und -e immer wieder übersehen und führt zu umständlichen, widersprüchlichen oder falschen Darstellungen, die von mehr als 4 Pluralsuffixen ausgehen, wobei bis zu 8(!) Suffixe angenommen werden, die lexikalistisch gespeichert, also irregulär seien. Das ist etwa so sinnvoll, wie für die Bildung der Partizipien 4 verschiedene Suffixe anzusetzen: $t$, et, n, en (gesagt, geredet, gehaun, gekommen).
} 


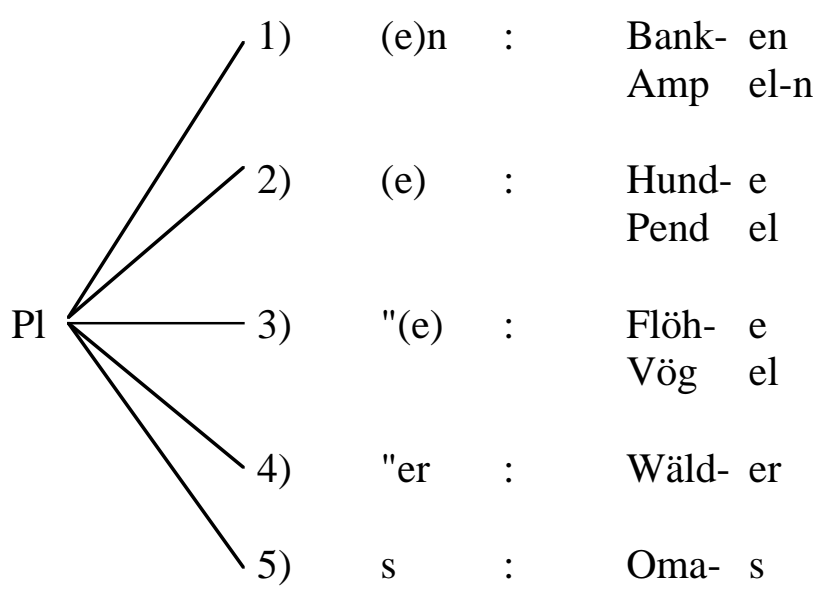

Schwa-Tilgung erfolgt nicht, wenn das Wort auf eine schwere Silbe mit -e oder eine Silbe mit einem anderen Vokal auslautet. Soweit erfasst die Annahme von Schwa-Tilgung sämtliche nativen Pluralformen, ${ }^{13}$ die zweisilbigen Hunde, Engel, Käse, Ampeln ebenso wie die dreiund viersilbigen: Abende, Gegenden, Barbaren, Nachfahren, Doktoren, Leichname, Bräutigame, Nachtigallen vs Kartoffeln.

Neef 1998 schlägt stattdessen die Annahme einer Reduktionssilbe vor, die ein Schwa als Kern enthält und infolgedessen nicht betonbar ist. Das erfordert als Zusatzannahme für Substantive wie Abend, Gegend, dass die Reduktionssilbe auf einen Sonoranten auslautet, weil sonst Schwa-Epenthese wie bei Hunde erfolgt: Abende, Gegenden. Die Annahme von SchwaTilgung kommt dagegen ohne eine solche Zusatzannahme aus und ist folglich als einfacher vorzuziehen. Wiese 1996:136 ff schlägt Schwa-Epenthese vor, geht also von Basismorphemen 0 bzw. $-n$ aus, die durch Epenthese zu $-e$ bzw. - en erweitert werden. Diese Annahme setzt einen sehr weiten Epenthesenbegriff voraus, denn als Epenthese gilt i. a. (cf. Bußmann 1990) die automatisch erfolgende, phonotaktisch bedingte Ein- oder Anfügung eines Segments.

Nun lässt sich für Schulden vs Ampeln nicht klar entscheiden, ob Epenthese oder SchwaTilgung erfolgt, aber bei Formen wie Knie, Feen, in denen kein Konsonant vorhanden ist, der die Epenthese auslösen könnte, erscheint der Epenthesenbegriff fragwürdig (cf. hierzu auch Kloeke 1982, Eisenberg 1991). Im Vergleich mit der traditionellen Annahme von SchwaTilgung ist auch nicht zu erkennen, inwiefern die Schwa-Epenthesenlösung die weniger aufwendige sein soll, denn beide Verfahren führen zum selben Ergebnis, einer Reduktion der Pluralsuffixe auf vier. Zudem wird die Epenthesenlösung den empirischen Fakten nicht gerecht: Wenn -n die Grundform des Flexivs -en ist, so wäre zu erwarten, dass Pluralformen wie *Oman, *Villan, *Konton gebildet werden, für die in Sultan, Kaftan, Kanon Muster vorliegen. Wenn außerdem, wie gerade Wiese 1996 annimmt, der s-Plural der Defaultplural des Deutschen ist und Epenthese als das günstigste und am wenigsten aufwendige Verfahren bereit steht, so fragt sich, warum wir dann nicht genau wie im Englischen, nach dessen Modell die Pluralbildung des Deutschen von Wiese 1996 beschrieben wird, die Pluralformen *Bosses und *Busses haben, und bei Familiennamen (für die Namen Groß, Kunz) die Formen *Großes, *Kunzes. Sie sind im Deutschen aber als Pluralformen ungrammatisch. Ich halte deshalb an der Annahme von Schwa-Tilgung fest.

Die einzigen Ausnahmen für die Annahme von Schwa-Tilgung sind auch für die SchwaEpenthese ein Problem: Bei Nachbar, Ungar tritt $-n$ auf, obwohl die Endsilbe ein a und kein e

\footnotetext{
${ }^{13}$ Eine Ausnahme sehe ich nicht im veralteten Kirmes-sen, wo der Plural dem Simplizium Messe folgt.
} 
enthält. Diese Ausnahme kann dadurch erklärt werden, dass das Endsilben-er (Bauer, Vetter) besonders in Norddeutschland wie der hintere Zentralvokal artikuliert wird (cf. König 1989:118) und damit dem a in Nachbar sehr ähnlich ist. Im Unterschied zu Nachfahren ist die erste Silbe nicht lang, könnte also bei *Nachbaren keinen eigenen Fuß bilden.

Ziel der Pluralbildung mit Schwa-Tilgung ist ein (mindestens) zweisilbiges Wort, idealiter ein Trochäus, womit "die kanonische Struktur mit betonter und unbetonter Silbe" erreicht wird (Eisenberg 1991:48, Féry 1997). Allerdings entstehen dadurch neue Verletzungen hinsichtlich der Morphemgrenzen:

Die nativen Pluralsuffixe lauten stets vokalisch an, haben darin ein gemeinsames Merkmal, das sie außerdem mit Derivationssuffixen teilen, welche vorzugsweise vokalisch anlauten. Das bewirkt nach den Silbenbaugesetzen Vennemanns 1988, dass sie "phonologisch mit der Basis verschmelzen können. Die resultierende Morphemgrenze des suffigierten Stamms fällt dann nicht mit der Silbengrenze zusammen" (Fuhrhop 1998:93). Die Pluralformen unterscheiden sich dadurch phonologisch nicht von Singularformen, wie Reimpaare zeigen (Hunde - Runde, Hallen - Ballen, Löcher - Köcher), ja sie realisieren den unmarkierten Fuß des Deutschen in idealerer Weise als diese, da es außer beim s-Plural keine einsilbigen Formen gibt.

Die Pluralformen sind trotzdem funktional, da sie innerhalb ihrer Flexionsklasse nicht mit gleichlautenden Singularformen konkurrieren. In Klasse 1 und 2, bei den Feminina und den schwachen Maskulina, gibt es keine Singularformen auf -en, in Klasse 3, der starken Flexion, gibt es fast keine auf - $e$ (Ausnahme: Käse, Gebirge), und fast keine Neutra auf -er (Ausnahme: Fenster). Pluralformen wie Hunde, Jacken, Jungen, Kinder sind daher innerhalb ihrer Flexionsklasse distinkt. Das Deutsche erreicht also mit geringem Aufwand durchaus distinkte Pluralformen. Die unmarkierte Silbenstruktur der Pluralformen hat neben Vorteilen jedoch auch Nachteile.

Ein Nachteil liegt in der Verschmelzung der Morphemgrenzen von Singularstamm und Pluralsuffix und der damit verbundenen Verschiebung der Silbengrenze: Hund. - Hun.de, Kind. - Kin.der, Poet.- Poe.ten. Die Transparenz zwischen Singular und Plural ist dadurch beeinträchtigt, und dies hat Auswirkungen auf die Pluralisierung von Neologismen. Bei Ableitungen kann die Singularform aus den hochfrequenten Ableitungssuffixen erschlossen werden: Frei.hei.ten < Frei.heit. Nur für Substantive auf Pseudosuffix, das ja Schwatilgung im Pluralsuffix bewirkt, ist dagegen hohe Transparenz gesichert, die bis zur Identität gehen kann: Engel, Fenster. Hohe Transparenz wird also durch geringe bis nichtexistierende Distinktivität erkauft.

In OT-Untersuchungen ist es üblich, sämtliche denkbaren Formen (Kandidaten) durch die Beschränkungen zu überprüfen, die dann den optimalen Kandidaten auswählen. Es liegt also nahe, eine Beschränkung ST für Schwa-Tilgung anzunehmen und durch sie Formen wie *Engele, *Engelen, *Ampele, *Ampelen etc herausfiltern zu lassen. Da diese Regel aber von deutschen Pluralformen nie verletzt wird, würde durch sie die Darstellung nichts gewinnen und nur unnötig redundant. Ich führe daher diese Beschränkung und die Kandidaten, deren Scheitern durch die Schwatilgungsregel vorhersagbar ist, i.a. nicht an.

Da es im Deutschen drei Genusklassen und eine weitere Flexionsklasse für schwache Maskulina gibt, wären mit den vier Pluralsuffixen + Umlaut, der nur bei -e unrestringiert ist, theoretisch 20 verschiedene Pluralklassen bildbar. Jedoch sind keineswegs in jeder Flexionsklasse alle diese Formen möglich (siehe unten). 


\subsubsection{Die Flexions- und Genusklassen}

\section{a) Flexionsklassen}

Ich gehe von der Annahme aus, dass sich die Pluralform aus Merkmalen des Singularstamms ableiten lassen muss, und setze voraus, dass die Flexions- und/oder Genusklassenzugehörigkeit dafür eine Rolle spielt: Wenn eine Sprache sich den Luxus leistet, ihren Wortschatz in unterschiedliche Flexionsklassen einzuteilen, so muss sie dafür Sorge tragen, dass diese Klassenausprägung gelernt und von Generation zu Generation weiter gegeben werden kann. Eine Möglichkeit hierfür bietet die Pluralbildung. Tatsächlich ist die Verteilung der vier Pluralsuffixe und des Umlauts nach Flexionsklassen geregelt, wie die statistische Verteilung zeigt.

Die Zahl der für die Pluralbildung relevanten Flexionsklassen ergibt sich aus der Genitivbildung, der einzigen Kasusform im Singular, die noch folgende Suffixe aufweist: (e)s (einschließlich -ens) für starke Maskulina und Neutra, -(e)n für schwache Maskulina und $\varnothing$ für Feminina. Ob der Genitiv auf -s, -es oder -ens (Herzens) gebildet wird, ist ein Problem der Kasusflexion, nicht der Pluralbildung, und bleibt hier folglich unberücksichtigt. Abgesehen von unterschiedlicher Präferenz für den Umlaut und für den er-Plural (siehe unten), unterscheiden sich die Maskulina und Neutra der starken Flexion nicht, daher lassen sich die Pluralformen in zwei Genusklassen einteilen, in Feminina und Nichtfeminina. Es gibt jedoch eine weitere, für die Pluralbildung relevante Klasse, die zudem absolut reguläre Pluralbildung aufweist, die schwachen Maskulina, die an dem semantischen Merkmal der Belebtheit und/oder dem Auslaut auf Schwa-Silbe oder betonter Endsilbe erkennbar sind: Junge - Student.

Für die Pluralbildung sind für das heutige Deutsch also drei Flexionsklassen anzunehmen:

Klasse 1: Feminina

Klasse 2: schwache Maskulina

Klasse 3: starke Maskulina und Neutra.

Meine Einteilung beruht auf der Überlegung, dass die Pluralformen relevant für die Flexionsklassen und durch diese determiniert sind, dass also zwischen der Flexionsklasse, erkennbar am Genitiv Singular, und der Pluralform ein implikatives Verhältnis besteht (cf. Wurzel 1984:174).

Zwei Pluralsuffixe sind strikt flexionsklassenspezifisch: -er tritt nur in Klasse 3 auf. Wenn wir den Umlaut berücksichtigen, gilt dies auch für den $\varnothing$-Plural, der ohne Umlaut ebenfalls nur in dieser Klasse auftritt.

Rein statistisch gesehen kann für jede Flexionsklasse ein eindeutiger Defaultwert festgestellt werden, diesen betrachte ich als den unmarkierten oder regulären Plural dieser Klasse, siehe Tabelle $1 .^{14}$

\footnotetext{
${ }^{14}$ Die Werte dieser Tabelle sind gewonnen aus der relativ neuen Auszählung in Pavlov 1995, aus dessen Angaben ich die Werte pro Flexionsklasse errechnet habe. Tabelle 1 beruht auf der Auswertung eines Wörterbuchs (Wahrig 1968/75 , Buchstabe A bis G), gibt also die Typefrequenzen an ( $\mathrm{N}=6505$ ), Tabelle 2 beruht auf der Auszählung eines Textkorpus (vorwiegend literarische Texte nach 1945, N = 13587).
} 
Tabelle 1: Plural und Flexionsklassen nach Wörterbucheinträgen $=$ Typefrequenz, $\mathrm{N}=6505$ (Pavlov 1995:44ff)

\begin{tabular}{|c|c|c|c|c|c|c|c|c|c|}
\hline \multicolumn{3}{|c|}{ Fem (2726) } & sw & $\begin{array}{l}\text { M (458) } \\
\text { (e)n }\end{array}$ & \multicolumn{2}{|c|}{ st MN (3321) } & "(e) & "er & $\mathrm{S}$ \\
\hline \multirow[t]{2}{*}{96,6} & \multirow[t]{2}{*}{1,1} & \multirow[t]{2}{*}{1,7} & \multirow{3}{*}{\multicolumn{2}{|c|}{100}} & 3,3 & 70,2 & 7 & 1,5 & \multirow[t]{3}{*}{16,3} \\
\hline & & & & & & \multicolumn{3}{|c|}{78,7} & \\
\hline & \multicolumn{2}{|c|}{$99,4^{15}$} & & & \multicolumn{4}{|c|}{$98,3^{16}$} & \\
\hline
\end{tabular}

Die Zahlen für die Typefrequenz bestätigen meine Annahme, dass es für jede Flexionsklasse (FK) eine vorhersagbare reguläre Pluralbildung gibt, das ist -(e)n für die Feminina und die schwachen Maskulina sowie -(e) für die starken Maskulina und Neutra. Darüber hinaus gibt es in Klasse 1 und 3 jeweils konkurrierende Formen in Nebenklassen, zwei in Klasse 1 und vier in Klasse 3, aber keine in Klasse 2. Insofern haben wir insgesamt 9 Pluralklassen,drei für die Feminina, eine für die schwachen Maskulina und fünf für die starken Maskulina und Neutra.

Die FK-Spezifik der Pluralformen geht aus der folgenden Graphik hervor:

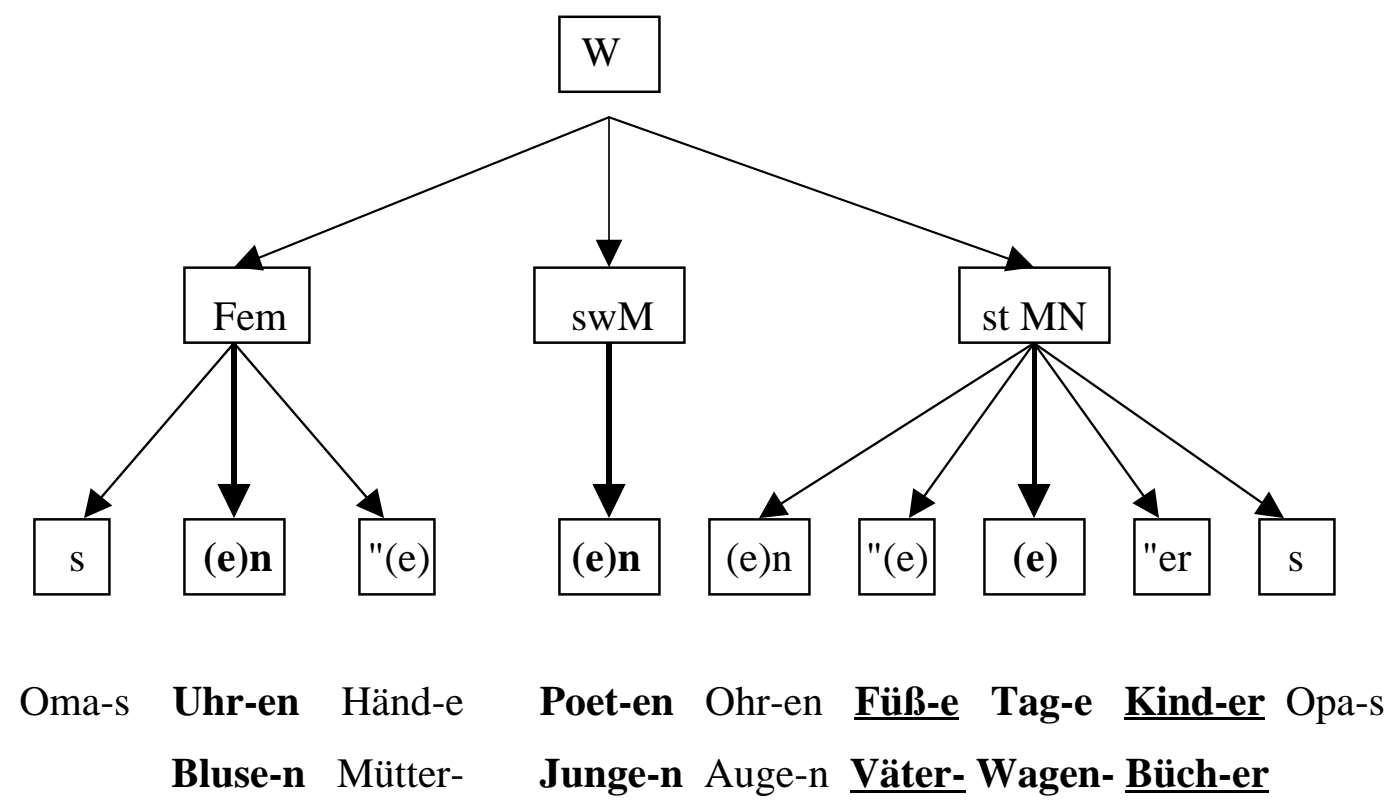

Feminina bilden ihren Plural zu 96,6 \%, die schwachen Maskulina zu $100 \%$ auf -(e)n, starke Maskulina und Neutra zu $70 \%$ auf -(e). Da -"e und -er flexionsklassenspezifisch sind, bilden $78,7 \%$ dieser Klasse einen für sie typischen Plural.

Der Rest verteilt sich bei den Feminina auf -"(e) und zu einem ganz geringen Teil auf -s. Bei den Feminina werden Formen wie Villen unbeschadet ihrer Stammflexion zum Regelplural gezählt und nicht als eigene Klasse angesehen (zur Tilgung des auslautenden -a, siehe unten). Die "(e)-Formen sind bei den Feminina klar eine Ausnahme, da sie nicht vorhergesagt werden können. Sie umfassen umgelautete sowie die wenigen nichtumgelauteten Formen der

${ }^{15} 0,6 \%$ : Anopheles etc.

${ }^{16} 1,7 \%$ : Fundus, Aposteriori etc. 
Ableitungen auf -nis, einem Suffix, das vorwiegend Neutra ableitet, Kenntnisse. Da diese nicht umlautfähig sind, stellen sie keine Ausnahme innerhalb dieser Klasse dar, genausowenig wie die nicht umgelauteten er-Pluralformen vom Typ Kinder eine Ausnahme zu den umgelauteten (Bücher) bilden. Dass die ersteren keinen Umlaut bilden, braucht nicht extra gelernt zu werden, insofern besteht hier keine Irregularität. ${ }^{17}$ Allerdings kann daraus keine nichtzirkuläre Regel abgeleitet werden, da sich für die Umlautbereitschaft keine unabhängige Evidenz etwa aus der Diminutivbildung ergibt: Hündchen - Hunde, Ührchen - Uhren.

Bei den Maskulina und Neutra ist das Bild heterogener, außer dem Regelplural -(e) gibt es Formen mit (e) + Umlaut und mit -er, die jedoch auch flexionsklassenspezifisch sind. Die Formen auf -(e)n (Augen, Ohren, Betten, Muskeln), die im Singular nicht schwach flektieren, sind dagegen hier klar eine Ausnahme, auch statistisch: 3,3\%.

Die Formen auf -s sind, wie die Zahlen für die Typefrequenz zeigen, in ebenso starker Weise genusgesteuert wie die anderen, und könnten danach auch als typische Pluralformen für Klasse 3 gewertet werden. Auch der s-Plural ist offensichtlich flexionsklassengesteuert (daran ändert auch die heutige i-Ableitung nichts Wesentliches: Unter den von Féry 1997 untersuchten Bildungen sind nur 12\% Feminina.): Von den 586 s-Pluralen im Wörterbuch gehören 92,3 \% zu Klasse 3, und nur 7,7 \% zu Klasse 1. Im Textkorpus ist das Verhältnis noch krasser: 96,2 \% gehören zu Klasse 3, nur 3,8 \% zu Klasse 1. Der s- Plural wäre dann nur bei den Feminina als Ausnahme anzusehen. Jedoch nehme ich nicht an, dass der s-Plural ein weiterer genusspezifischer Plural für starke Maskulina und Neutra ist. Wie die Zahlen für die Tokenfrequenz in Tabelle 2 und die Unterschiede zwischen Types und Token zeigen, ist der s-Plural einerseits hoch produktiv, andererseits in hohem Maße instabil. Zum Sonderstatus des s-Plurals siehe 2.4.

Tabelle 2: Plural und Flexionsklassen nach Textkorpus = Tokenfrequenz, $\mathrm{N}=13587$ (Pavlov 1995:48)

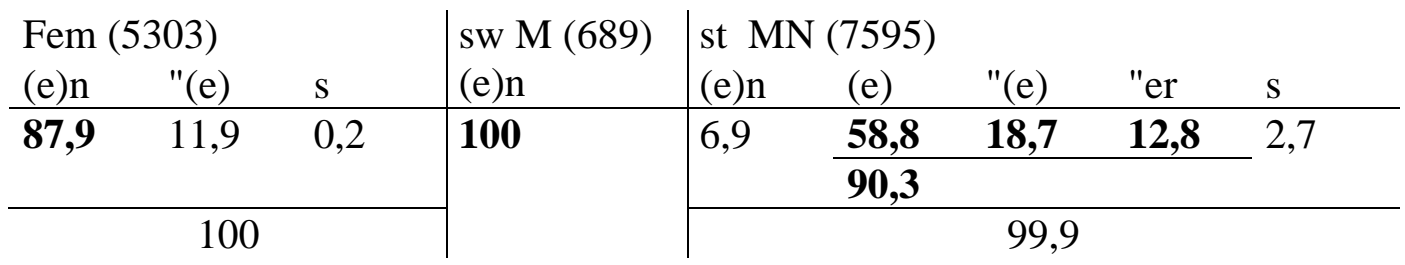

Die Tokenfrequenzwerte halte ich in Bezug auf Spracherwerb, Sprachentwicklung, Exemplarität der Pluralformen für die wichtigeren. Die Wörterbuchliste enthält auch Fremdwörter sowie hochspezialisierte Fachwörter und gewichtet diese ebenso stark wie hochfrequente native Pluralformen. Die Typewerte geben über das tatsächliche Vorkommen der Plualformen daher ein falsches Bild.

Der Unterschied zwischen den Type- und den Tokenwerten ist in den meisten Fällen beeindruckend und zeigt, dass die "irregulären" Pluralformen hochfrequent sind. Beim femininen "(e)-Plural ist das Verhältnis von Type zu Token fast 1:11, bei den er-Pluralen 1:8, beim Umlautplural in Klasse 3 noch 1:2,7, bei -(e)n in dieser Klasse beträgt er 1:2. Die Relation zwischen Type und Token geht aus Tabelle 3 hervor:

\footnotetext{
${ }^{17}$ Die wenigen nicht umgelauteten Feminina auf -sal (Drangsal, Mühsal, Labsal, Trübsal, Wirrsal) sind, wie meine Informanten (ca. 30 Potsdamer Studenten) bestätigen, nicht mehr pluralfähig. Sie werden hier nicht berücksichtigt.
} 
Tabelle 3: Type-Token-Quotient:

\begin{tabular}{lllllllll} 
Fem & \multicolumn{9}{c}{ sw M } & \multicolumn{2}{c}{ st MN } \\
(e)n & "(e) & s & (e)n & (e)n & (e) & "(e) & "er & s \\
\hline 0,9 & $\mathbf{1 0 , 8}$ & 0,1 & 1 & $\mathbf{2}$ & 0,8 & $\mathbf{2 , 7}$ & $\mathbf{8 , 1 5}$ & 0,16
\end{tabular}

Diese Zahlen für den TT-Quotienten lassen vermuten, dass die nicht dem Regelplural entsprechenden Formen trotz ihrer Nichtvorhersagbarkeit dann relativ leicht gelernt werden, wenn sie eine hohe Tokenfrequenz aufweisen, was für -"(e) bei Feminina und für -(er) durch Spracherwerbsdaten bestätigt wird (siehe unten).

\section{b) Genusklassen}

Klasse 3 enthält zwei Genusklassen, Maskulina und Neutra, die sich nicht völlig gleich verhalten. Der Umlaut beim (e)-Plural und der er-Plural leisten innerhalb dieser Klasse eine Binnendifferenzierung, wie folgende Werte zeigen:

"(e) : 93,9\% Types, 69,2\% Tokens sind Maskulina,

"er : $\quad 85,4 \%$ Types, $74,4 \%$ Tokens sind Neutra.

Ein umgelauteter (e)-Plural schließt also Neutra fast vollständig aus, ein er-Plural schließt Feminina definitiv aus und ist ein starkes Indiz für Neutra. Innerhalb der Klasse 3 lassen die Maskulina und die Neutra also unterschiedliche Präferenzen für entweder den umgelauteten (e)-Plural oder den er-Plural erkennen.

Die Pluralsuffixe -e, -"(e), -(e)n, -s treten zwar bei allen Genera auf:

$\begin{array}{llll}\text { e: } & \text { F: Kenntnisse, } & \mathrm{N}: \text { Boote, } & \text { M: Hunde, } \\ \text { "e: } & \text { F: Hände, } & \mathrm{N}: \text { Flöße, } & \text { M: Hüte, } \\ \text { "Ø: } & \text { F: Mütter, } & \mathrm{N}: \text { Klöster, } & \text { M: Väter, } \\ \text { en: } & \text { F: Frauen, } & \mathrm{N}: \text { Ohren, } & \text { M: Menschen, } \\ \text { n: } & \text { F: Ecken, } & \mathrm{N}: \text { Enden, } & \text { M: Erben, } \\ \text { s: } & \text { F: Muttis, } & \mathrm{N}: \text { Autos, } & \text { M: Opas, }\end{array}$

jedoch in statistisch sehr unterschiedlicher Verteilung, wie die Tabellen zeigen, manchmal nur durch ein bis zwei Nomen belegt (Flöße, Klöster, Mütter/Töchter, Kenntnisse). Das bloße Vorkommen bei mehreren Genusklassen ist also keine Besonderheit des s-Plurals ${ }^{18}$, bedeutet andererseits aber nicht, dass das Genus für die Pluralbildung keine Rolle spielt - die meisten Pluralformen sind genus- bzw flexionsklassengesteuert. Nur Klasse 2 korreliert zwar eindeutig mit nur einer Pluralform, die anderen beiden Klassen zeigen aber eindeutige Präferenzen für -(e) bzw. -(e)n, so dass ein "Dschungel" (so Neef 1998) hier keineswegs vorliegt. Die Pluralformen des Deutschen sind über die Substantive keineswegs verteilt wie Rosinen über einen Kuchen.

Die hohe Gewichtung der Genus- und Flexionsklassenzugehörigkeit zeigt sich auch an Flexionsklassenwechseln, die manche Substantive selbst um den Preis eines $\varnothing$-Plurals vornehmen: die Gruppe Funke, Gedanke etc. mit Erweiterung des Singulars, Stiefel, Ziegel mit Abbau des overten (e)n-Plurals; siehe unten zu Veränderungen im heutigen Deutsch.

\footnotetext{
${ }^{18}$ Wie Clahsen et al. 1992, Marcus et. al. 1995 behaupten.
} 
Für die Abhängigkeit der Pluralformen von der Genus- bzw. Flexionsklasse des Substantivs nehme ich die Beschränkungen GK bzw FK an:

FK: Die Pluralform korrespondiert mit der Flexionsklasse des Singularstamms.

GK: Die Pluralform korrespondiert mit der Genusklasse des Singularstamms.

Eine Pluralform erfüllt FK, wenn sie in Klasse 1 und Klasse 2 auf -(e)n, in Klasse 3 auf -(e) oder -er lautet. Sie erfüllt in Klasse 1 und 2 dann zugleich GK. In Klasse 3 erfüllt sie darüber hinaus GK, wenn sie bei Maskulina auf -"(e), bei Neutra auf -er lautet, wenn sie die Genusklasse also anzeigt. Insofern ist GK in Klasse 3 eine engere Beschränkung als FK, in Klasse 1 und 2 fällt sie mit FK zusammen.

Die Beschränkung FK erklärt, warum wir Gabeln, aber Löffel, Messer haben, Rosen, aber Schuhe, Boote, die Beschränkung GK erklärt, warum wir Vögel, Füße bei den Maskulina, Bücher, Kinder vor allem bei den Neutra haben. Umlaut und er-Plural sind also nicht einfach irregulär, sondern GK-spezifisch: Füße ist ein typischerer Plural für Maskulina als Schuhe, Kinder ein besserer für Neutra als Pendel. Unter den Feminina ist Bänke dagegen eine Ausnahme, die jedoch nicht nur historisch erklärt werden kann (dazu siehe unten.). Die Beschränkungen FK und GK vereinfachen die Pluraldarstellung erheblich, sie befreien von der Annahme allzu vieler irregulärer Formen, die als im Lexikon gelistet vorgestellt werden, und von zirkulären Annahmen wie der, dass Amseln einen Plural auf - $n$ bilde, weil es damit eine Beschränkung "N-Plural" erfülle (Neef 1998:260, Wunderlich 1999:13f). Nach meiner Darstellung haben Jagd, Amsel nicht deshalb einen Plural auf -(e)n, weil sie einer Beschränkung "N-Plural" folgen, sondern weil sie Feminina sind, entsprechendes gilt für Trecker, Engel, Hund. Diese bilden nicht den (e)-Plural, weil sie einer Beschränkung "RSP" (Reduktionssilbenplural) folgen, sondern weil sie maskulin sind.

Auch erübrigt sich die Annahme, dass die Pluralsuffixe durch Ableitungssuffixe lizensiert sind: Freiheit, Freundin, Zeitung bilden den en-Plural, weil sie Feminina sind, Lehrling, Kellner den (e)-Plural, weil sie starke Maskulina, Student, Germanist, Biologe den (e)nPlural, weil sie schwache Maskulina sind. Eine Auflistung der Ableitungssuffixe belastet die Grammatik unnötig und erübrigt sich also.

Wenn der Umlaut bei Maskulina, der er-Plural bei Neutra aus GK folgen, so sind die entsprechenden Formen nicht einfach irregulär, und Umlaut bzw. er-Plural brauchen nicht als idiosynkratische Merkmale im Lexikon angenommen zu werden. Sie sind allerdings nicht vorhersagbar, sondern präferierte Formen, die unter bestimmten Bedingungen realisiert werden (dazu siehe unten).

Die Beschränkungen GK und FK sind außerdem unabhängig motiviert: Flexions- bzw. Genusklassenspezifik liegt auch bei der Adjektivflexion, bei der Kasusflexion und bei der Wortbildung vor (Wortbildungssuffixe wie -heit, -ling, -ist bilden genusspezifische Substantive wie Krankheit, Lehrling, Terrorist). Ich vermute, dass die Beschränkung GK/FK universal gilt in Sprachen, die Genus- bzw. Flexionsklassen haben.

\subsubsection{Silbenphonologische Beschränkungen}

Wie die Graphik oben zeigt, lassen sich die Pluralformen zwar weitgehend, aber nicht kategorisch aus Genus und/oder Flexionsklasse erklären - wir hätten in diesem Fall höchstens einen Pluraltyp pro Genus und Flexionsklasse. Für die abweichenden Fälle müssen also andere Kriterien herangezogen werden. Diese Kriterien können aus Merkmalen des 
Singularstammes wie Auslaut und Silbenzahl, Zugehörigkeit zu einer markierten Wortklasse (Eigennamen, Onomatopoetika ), Tokenfrequenz bzw. Bekanntheitsgrad, sie können aber auch aus der phonologischen Form der zu bildenden Pluralform gewonnen werden. Die Beschränkung auf nur eine zusätzliche Reduktionssilbe lässt sich als Beschränkung auf eine bestimmte Fußstruktur erfassen (zum Trochäus allgemein cf. Eisenberg 1991, 1998):

FUSS: Die Pluralform realisiert den unmarkierten Fuß der Sprache,

d.i. im Deutschen 1. der Trochäus, 2. der Daktylus. Die Beschränkung liegt also als FUSS/TR und als FUSS/DA vor. Der Trochäus ist im Deutschen eindeutig der kanonische Fuß (Eisenberg 1991), der "unmarkierteste Fuß" (Féry 1997). Er ist gegenüber dem Daktylus präferiert, wird z.B. mit Hilfe von Schwa-Tilgung erreicht. Die Beschränkung FUSS kann geradezu als das die Schwa-Tilgung auslösende Prinzip angesehen werden. Deshalb werde ich, um die Darstellung nicht unnötig redundant zu machen, nur einen Daktylus näher spezifizieren. FUSS bedeutet also im Folgenden: die Pluralform realisiert einen Trochäus.

Einsilbige Stämme bilden in ihren Pluralformen Trochäen (Hunde), zweisilbige heimische Stämme unterliegen der Schwa-Tilgung und pluralisieren dann mit -n oder $\emptyset$ (Ampeln, Engel) oder sie haben einen s-Plural wie Autos. Alle diese Formen erfüllen die Beschränkung FUSS. Die einzigen Ausnahmen unter den Simplizia sind Substantive mit schwerer schwa-haltiger Endsilbe wie Abend, die im Plural Daktylen ausbilden: Abende, Gegenden. Einen daktylischen Fuß realisieren auch die Ableitungen mit konsonantisch auslautendem Suffix: Freundinnen, Freiheiten, Zeitungen. Diese erfüllen FUSS/DA.

Die Präferenz für den Trochäus gegenüber dem Daktylus zeigt sich bei der Pluralisierung dreisilbiger Wörter. Hat das dreisilbige Wort den Akzent auf der Paenultima wie Forelle, Bazillus, so wird durch Stammflexion, d.h. nach Kappen der Auslautsilbe e- bzw. -us, ein Trochäus mit Auftakt gebildet: Forellen, Bazillen. In einigen Fällen wird ein Trochäus durch Akzentverlagerung hergestellt, so dass Singular und Plural jeweils einen Trochäus, im Plural einen Trochäus mit vorgeschalteter Auftaktsilbe realisieren: 'Doktor, Dok'toren. Die Annahme einer Beschränkung auf trochäische Füße erfasst also auch die nicht durch SchwaTilgung erklärbaren Fälle Nachbarn, Konsuln und erklärt zugleich den Akzentwechsel bei Dok'toren, Profes'soren < 'Doktor, Pro'fessor.

Nur wenn keine betonbare Paenultima vorliegt und wenn keine Schwa-Silbe hinzutreten kann, ohne einen Hiat auszulösen, wird ein Daktylus realisiert: *Kameraen, 'Kameras, 'Kopulas. Im Gegensatz zu Villa > Villen würde Stammflexion in diesen Fällen zu zwei aufeinander folgenden unbetonten Silben führen und ist deshalb nicht möglich: *Kameren.

Für viersilbige Wörter kann eine Beschränkung Wortakzent angenommen werden, die zu einer Wortstruktur mit zwei Füßen führt (cf z.B. Müller 1997). Da es Füße mit mehr als drei Silben im Deutschen nicht gibt (cf. Eisenberg 1998:133), wird bei einem viersilbigen Wort ein Nebenakzent eingeführt, so dass ein zweifüßiges Wort entsteht: 'Nach.ti.gàl.len. Für die Pluralisierung von dreisilbigen Wörtern kann das Probleme darstellen (siehe unten). Ich nehme jedoch keine zusätzliche Beschränkung "Wortakzent" an, sondern betrachte FUSS als erfüllt, wenn eine Struktur entsteht, die dank des Nebenakzents zwei Trochäen bzw. einen Trochäus und einen Daktylus wie 'Cafeterien hat.

FUSS scheint in der Hierarchie der Beschränkungen sehr hoch gerankt zu sein: sämtliche nativen und die meisten nicht-nativen Pluralformen erfüllen diese Beschränkung in der Ausprägung als Trochäus oder als Daktylus. Nur einsilbige und endbetonte s-Pluralformen 
verletzen sie, und dies dürfte einer der wesentlichen Faktoren dafür sein, dass der s-Plural hier wieder abgebaut wird und nur eine Übergangslösung darstellt: 'Lifts > 'Lifte, Bal'kons > Bal'kone etc.

Die Beschränkung auf trochäische Füße kann natürlich nicht universal sein, wie Sprachen mit jambischen Füßen wie das Französische zeigen. Sie gilt im Deutschen aber nicht nur für die Pluralbildung, sondern auch in anderen Bereichen der Flexion und Derivation (Infinitive: lächeln, Adjektive: eklig, Diminutive: Kätzchen), ebenso für die Bildung von Kurzformen wie Mutti, von Kompositionsformen wie Hundehütte, Eierschale (cf. dazu 3.) und sogar für die Bildung von Binomialen wie fix und fertig (cf. Féry 1997, Müller 1997). Die Beschränkung ist also unabhängig motiviert. Universal dürfte aber für akzentzählende Sprachen eine Beschränkung gelten, die Flexionsformen auf den unmarkierten Fuß dieser Sprachen festlegt. Insofern kann die Beschränkung FUSS als universal gelten. ${ }^{19}$

\subsubsection{Treuebeschränkungen}

Außer diesen silbenphonologischen Beschränkungen nehme ich die in der OT üblichen Treuebeschränkungen an. Durch die Treuebeschränkungen wird die Transparenz zwischen korrespondierenden Formen gewährleistet, was gerade bei markierten Substantiven und Fremdwörtern eine erhebliche Rolle spielt, wie wir sehen werden.

Die OT nimmt für korrespondierende Formen, zu denen Plural- und Singularformen zweifellos gehören, ${ }^{20}$ Treuebeschränkungen folgender Art an (cf. Féry 1997:474):

Treuebeschränkungen für korrespondierende Formen:

$$
\begin{aligned}
& \text { Input }=\mathrm{f}_{1} \mathrm{e}_{2} \mathrm{n}_{3} \mathrm{~s}_{4} \mathrm{t}_{5} \mathrm{e}_{6} \mathrm{r}_{7}\left(=\mathrm{S}_{1}\right) \\
& \text { Output }=\mathrm{f}_{1} \mathrm{e}_{2} \mathrm{n}_{3} \mathrm{~s}_{4} \mathrm{t}_{5} \mathrm{e}_{6} \mathrm{r}_{7}\left(=\mathrm{S}_{2}\right)
\end{aligned}
$$

MAX: $\quad$ Jedes Segment von $S_{1}$ hat einen Korrespondenten in $S_{2}$.

DEP: $\quad$ Jedes Segment von $S_{2}$ hat einen Korrespondenten in $S_{1}$.

IDENT(F): Korrespondierende Segmente haben identische Werte für das Merkmal F.

MAX verhindert das Tilgen, DEP das Hinzufügen, IDENT das Verändern eines Segments. ØPluralformen wie Fenster erfüllen alle drei Treuebeschränkungen. Hätte das Deutsche aber nur Pluralformen wie Fenster, so hätte es keinen morphologischen Plural. Ich nehme daher als zusätzliche Beschränkung ein Distinktheitsgebot an, das verlangt, dass Pluralformen sich von Singularformen unterscheiden. Es ist klar, dass DIST in Widerspruch zu den Treuebeschränkungen steht und mit diesen konkurriert.

DIST: Pluralformen sind distinkt von Singularformen.

Eine gute Pluralform erfüllt idealiter zwei gegensätzliche Forderungen. Sie ist 1. transparent, zeigt den Zusammenhang zwischen der Pluralform und der Singularform an, ist der

\footnotetext{
${ }^{19}$ Die Präferenz für trochäische oder daktylische Füße wird in Golston/ Wiese 1995: 151 mit einer Beschränkung -FIN erfasst, die besagt, dass die Endsilbe flektierter Wörter nicht betont sein darf. Diese Beschränkung ist, wie die Autoren zugeben, nicht universal, sie sei aber nicht sprachspezifisch, da sie auch im Latein, Hindi und Altgriechischen vorkomme. Die weiter gefasste Beschränkung FUSS dürfte tatsächlich universal für akzentzählende Sprachen gelten.

${ }^{20}$ Pluraletanta und Pluralformen mit eigener Bedeutung sind hier natürlich ausgenommen.
} 
Singularform also möglichst ähnlich, sie ist 2. distinkt, zeigt Pluralität deutlich an, ist der Singularform also möglichst unähnlich. Es ist klar, dass diese beiden miteinander konkurrierenden Forderungen nie vollkommen erfüllt werden können.

Um das Distinkheitsgebot zu erfüllen, müssen Pluralformen also mindestens eine der Treuebeschränkungen verletzen, entweder ein Suffix hinzufügen (DEP) oder den Vokal ändern. Da Pluralformen im Deutschen ikonisch oder nicht-ikonisch, aber niemals kontraikonisch sind, scheidet die bloße Tilgung eines Segments (MAX) zur Pluralbildung aus; sie tritt aber in Kombination mit DEP auf und führt dann zur Stammflexion, siehe 2.4.3. In jedem Fall entstehen aber noch weitere Änderungen.

Native Pluralflexive führen in mehreren Fällen zu negativen Konsequenzen für die Transparenz der Pluralformen. Sie führen zu Hiatbildungen wie Schuhe, Seen, die bei unbetonten Silben ungrammatisch sind: *Oma.en, *Auto.e, oder sie führen zur Verschiebung der Silben- bzw der Morphemgrenze: Termin. - Termi.ne. Sie können darüberhinaus zur Änderung des auslautenden Konsonanten und/oder zur Umlautung des Vokals führen, also zu Prozessen, die die Transparenz der Pluralform erheblich beeinträchtigen: Hund [t] - Hunde, Hand [t] - Hände, Vogel - Vögel, Buch - Bücher.

Die Pluralformen lassen sich durch Beschränkungen, die in Untersuchungen zur Silbenphonologie des Deutschen erarbeitet wurden (Vennemann 1988, 1991, Eisenberg 1991, 1998, Féry 1997, Müller 1997) und der im Rahmen der OT ermittelten Hierarchien dieser Beschränkungen präziser beschreiben. Wegener 1995:23 weist darauf hin, dass bestimmte Pluralflexive bei bestimmten Substantiven zu unnatürlichen Formen und zur unerwünschten Verschiebung der Silbengrenze führen würden. Dies lässt sich mit Hilfe der o.g. Beschränkungen erfassen: FUSS verhindert die Hiatbildungen bei unbetonten Silben und löst bei Substantiven, die auf eine Schwa-Silbe enden, Schwa-Tilgung aus; die Treuebeschränkungen verhindern Veränderungen des Singularstamms, die die Transparenz der Pluralform beeinträchtigen könnten, und erzwingen in bestimmten Fällen einen s-Plural, (siehe unten).

Die Verletzungen der Treuebeschränkungen zugunsten von DIST werden durch die drei Constraints IDENT erfasst:

IDENT V wird verletzt, wenn der Vokal des Singularstamms umgelautet wird: Vogel - Vögel, IDENT K wird verletzt, wenn der Endkonsonant des Singularstamms in der Pluralform sonorisiert wird wie in Hund [t] - Hunde oder wenn er palatalisiert wie in Buch [X] - Bücher [ç]

IDENT $\boldsymbol{\mu}$ wird verletzt, wenn die Morphemgrenze des Singularstamms verschoben wird, Termin. - Termi.ne, oder wenn das Morphem verletzt wird wie bei Villa - Vill.en. Diese Tilgung eines Segments der Inputform wird außerdem durch MAX erfasst. Beide Beschränkungen sind jedoch nicht identisch: IDENT $\mu$ erfasst die Verschiebung der Morphemgrenze, MAX darüberhinaus das Kappen eines Segments.

Alle Verletzungen der Treuebeschränkungen können kombiniert auftreten: bei Hän.de, Bü.cher wird der Vokal umgelautet, der Konsonant sonorisiert bzw. palatalisiert und die Morphemgrenze verschoben. Eine Beschränkung gegen Redundanz nehme ich daher nicht an (so Wunderlich 1999), denn gerade im Kernwortschatz sind redundante Formen präferiert. 
Da bei Ros-en und Gart-en nicht eindeutig ist, ob Stammflexion vorliegt, werde ich für diese Pluralformen keine Verletzung von MAX vorsehen, da das die Arbeit nur aufblähen würde, sondern nur für Vill-en zu Villa, Rit-en zu Ritus, Kont-en zu Konto etc.

DEP ist natürlich sehr niedrig gerankt, die meisten Pluralformen sehen eine Suffigierung vor, um das Distinktheitsgebot zu erfüllen. Auch DEP unterscheidet sich von IDENT $\mu$ : Ersteres wird auch durch -n und -s verletzt, die jedoch die Morphemgrenze integer lassen. Nur der ØPlural verletzt keine der Treuebeschränkungen, aber natürlich DIST.

Für an sich wohlgeformte, aber ungrammatische Pluralformen wie *Schale, *Baren zu Schal, Bar ist es nötig, ein Homonymenverbot anzunehmen:

-HOM: Homonyme Formen sind zu vermeiden.

Das universale Silbenstrukturgesetz "Onset No Coda" gilt natürlich auch für Pluralformen. Sein Coda-bezogener Teil kann ein entscheidendes Kriterium für die Wahl des optimalen Kandidaten und für die Sprachentwicklung sein:

NC: Eine Silbe hat einen Anfangsrand, aber keine Coda: No Coda.

Bei Schwa-Silben muss bei Feminina NC verletzt werden, um Haplologie zu vermeiden: Ampeln, Kammern. Das Verbot von Haplologie, das durch die Schwa-Tilgung erfüllt wird, ist also höher gewichtet als NC. Auch FK ist höher gewichtet als NC: Uhren/*Uhre bei Feminina, Poeten $/ *$ Poete bei schwachen Maskulina haben eine Coda. NC-Verletzung wird im nativen Wortschatz aber nur bei unbetonten Silben und nur dann toleriert, wenn dadurch Haplologie vermieden und/oder ein FK-spezifischer Plural realisiert werden kann. Bei markierten Wörtern wie Onomatopoetika, Familiennamen und Fremdwörtern wird NC dagegen massiv verletzt. Hier ist IDENT so hoch gewichtet (genauer siehe unten.), dass NC verletzt werden kann und Konsonantencluster bei betonten Silben entstehen: Lifts, Kiosks. Ist NC nicht durch Haplologievermeidung oder FK motiviert, wird diese Struktur repariert, indem eine native silbische Pluralform gebildet wird: Lifte, Kioske. Es fragt sich aber, ob es sinnvoll ist, das n-Suffix überhaupt als Verstoß gegen NC zu werten, da diese Endsilben auf einen Sonoranten auslauten und damit dem idealen vokalischen Silbenauslaut sehr nahe kommen. Golston/Wiese 1995 und Neef 1998 nehmen entsprechend "SON" als Beschränkung für den Endrand von Flexionssilben an. Pluralformen auf -(e)n betrachte ich daher nicht als Verletzungen von NC.

Schließlich kann durch die Annahme, dass in Pluralformen nur paradigmische Flexive verwendet werden dürfen, erklärt werden, dass im Deutschen zwar das Stammbildungssuffix er ( $<$ ahd ir) und das Genitivsuffix -s bzw -ens zur Anzeige von Pluralität dienen können und somit zu Pluralsuffixen werden konnten, aber nicht das griechische Suffix -ta: nach dem Muster von Themata kann eben nicht eine Pluralform wie *Pizzata gebildet werden. Ebenso scheidet $-n$ aus, das es als Flexionssuffix nur durch Schwa-Tilgung gibt, deshalb *Pizzan.

PAR: Als Pluralsuffix dienen nur paradigmische Flexive

Auch diese Beschränkung ist nicht pluralspezifisch, sondern gilt im Deutschen z.B. auch für Fugenelemente (cf. Fuhrhop 1998). Flexionssuffixe fallen nicht vom Himmel, wenn eine Sprache sich vor die Notwendigkeit gestellt sieht, neue Flexive auszubilden, so schafft sie entweder durch Grammatikalisierung von Inhaltswörtern neue Flexive (z.B. geht das Präteritalsuffix -te auf die Verbform tat zurück) oder sie greift auf im Paradigma vorhandene 
Suffixe zurück und interpretiert sie um. Das schließt nicht aus, dass diese Suffixe dann auch auf andere Paradigmen übertragen werden können.

Die für die Pluralbildung relevanten Beschränkungen sind also:

MAX: Jedes Segment von $S_{1}$ hat einen Korrespondenten in $S_{2}$. (= keine Tilgung)

DEP: Jedes Segment von $S_{2}$ hat einen Korrespondenten in $S_{1}$. (= keine Erweiterung)

IDENT(F): Korrespondierende Segmente haben identische Werte für das Merkmal F. $\mathrm{F}=\mathrm{V}$ (Vokal des Kerns) und / oder K (Konsonant im Auslaut) und / oder $\mu$ (Morphem(grenze))

DIST: $\quad$ Pluralformen sind distinkt von Singularformen.

FUSS: $\quad$ Die Pluralform realisiert den unmarkierten Fuß der Sprache, das ist im Deutschen 1. der Trochäus, 2. der Daktylus.

FK: $\quad$ Die Pluralform korrespondiert mit der Flexionsklasse des Singularstamms.

GK: Die Pluralform korrespondiert mit der Genusklasse des Singularstamms.

-HOM: Homonyme Formen sind zu vermeiden.

NC: $\quad$ Eine Silbe hat keine Coda.

PAR: $\quad$ Als Pluralsuffix dienen nur paradigmische Flexive. 


\section{Eine Analyse im OT-Rahmen}

\subsection{Der unmarkierte Fall}

Das Zusammenwirken der Beschränkungen soll nun an einem einfachen Beispiel vorgeführt werden, für das ich ein heimisches und ein relativ junges, aber sehr verbreitetes Fremdwort, das im 18. Jahrhundert entlehnt wurde, verwende: Vogel vs Onkel.

\begin{tabular}{|l|l|l|l|l|l|l|l|l|l|}
\hline \multirow{2}{*}{ Onkel M } & \multirow{2}{*}{ FUSS } & \multicolumn{2}{|c|}{ IDENT } & NC & FK & GK & DIST & DEP \\
\cline { 3 - 9 } & & $\mathrm{V}$ & $\mathrm{K}$ & $\mu$ & & & & & \\
\hline Onkele & & & & & & & $*$ & $*$ & \\
\hline Onkels & & & & & $*$ & $*$ & $*$ & & $*$ \\
\hline Onkeln & & & & & & $*$ & $*$ & & $*$ \\
\hline Onkelen & $* !$ & & & $*$ & & $*$ & $*$ & & $* *$ \\
\hline Onkeler & $* !$ & & & $*$ & & & $*$ & & $* *$ \\
\hline Önkel & & $! *$ & & & & & & & \\
\hline
\end{tabular}

\begin{tabular}{|l|l|l|l|l|l|l|l|l|l|}
\hline Vogel M & FUSS & NC & FK & GK & DIST & \multicolumn{2}{|l|}{ DEP } & \multicolumn{3}{|c|}{ IDENT } \\
\cline { 6 - 10 } & & & & & & & V & K & $\mu$ \\
\hline Vogel & & & & $*$ & $*$ & & & & \\
\hline Vogele & $*$ & & & $*$ & & $*$ & & & $*$ \\
\hline Vogels & & $*$ & $*$ & $*$ & & $*$ & & & \\
\hline -Vögel & & & & & & & $*$ & & \\
\hline Vogeln & & & $*$ & $*$ & & $*$ & & & \\
\hline
\end{tabular}

Für das alte native Wort erweist sich die umgelautete Form als optimal: Sie ist distinkt, zeigt Genus- und Flexionsklasse an, bildet einen Trochäus, aber kein Konsonantencluster, allerdings verletzt sie, um distinkt zu sein, eine der Treuebeschränkungen, die Beschränkung hinsichtlich des Vokals.

Bei dem noch relativ jungen Wort Onkel ist Vokaländerung nicht zugelassen, weshalb es zu einer Ø-Pluralform kommt. Da das Wort eine Schwa-Endsilbe hat und maskulin ist, ist ein overter nativer Plural nicht möglich. Die Ø-Pluralform ist ein wohlgeformter Trochäus, ist FK-konform, verletzt aber DIST und zeigt das Genus nicht deutlich an. 
Daraus lässt sich für das native Wort folgende Hierarchie der Beschränkungen im Standarddeutschen ableiten:

DIST ist offensichtlich nicht die höchste Beschränkung, sondern FUSS und FK, DIST ist aber höher gerankt als IDENT/V. Diese Beschränkung darf durch den Umlaut verletzt werden, um eine distinkte Pluralform zu bilden, nicht aber NC.

Hierarchie für den Regelplural : FK/GK, FUSS >> NC >> DIST, IDENT

Für die regulären Pluralformen der Klasse 1 (Banken) und Klasse 2 (Jungen) gelten exakt die selben Beschränkungen und die selbe Beschränkungshierarchie. Die jeweilige Pluralform ergibt sich aus FK. Zu Bänke siehe unten.

Die Verletzung von DIST wird in Subvarietäten des Deutschen nicht toleriert, weshalb es zur Kompensation des durch FUSS und FK bedingten $\varnothing$-Plurals kommt. Interessant ist, dass verschiedene Varietäten des Deutschen hier unterschiedliche Lösungen für die Reparatur einer nicht präferenten Struktur wählen:

österr.: Onkeln, ebenso: Spiegeln, Spargeln, Madeln

norddt: Onkels, ebenso: Jungens, Jungs, Mädchens ${ }^{21}$

In den Substandards ist DIST höher gerankt, wofür bei einem Substantiv auf Pseudosuffix Verletzung von FK und in Norddeutschland auch von NC in Kauf genommen wird, indem entweder -n oder -s an das Pseudosuffix gefügt wird. Die Pluralformen dieser Wörter weisen also unterschiedliche Beschränkungshierarchien auf: Keine Varietät verletzt die SchwaTilgungsregel oder FUSS, aber beide sind nicht FK-konform, die s-Formen verletzen NC.

Versuche, den Ø-Plural zu kompensieren, gibt es, wie Belege aus dem 18. Jh zeigen (cf. Belege in 1., cf. Paul 1917), offenbar schon sehr lange, sie sind auch aus der Kindersprache bekannt. Zu einer generellen Verbreitung des s- oder (e)n-Plurals hat das bisher nicht geführt, wie Tabelle 2 zeigt.

Kompensatorisch wird in süddeutschen Dialekten auch der Umlaut eingesetzt:

schwäb, bair.: Wägen, Bögen, Ärm, Täg, Kästen, Krägen, Läger, Mägen, Pölster

Da die Beispiele alle Maskulina sind, erfüllen die Formen GK und somit auch FK, sind meistens trochäisch und stellen, da sie NC nicht verletzen, bessere Outputformen dar als die zu Onkel vorliegende Variante Onkels.

Hat der Stamm aber keinen umlautfähigen Vokal, so wird im süddeutschen Sprachgebiet, wo ein e-Plural aufgrund der e-Apokope nicht zur Verfügung steht, statt dessen ein er-Plural gebildet, der hier noch relativ produktiv ist, wie Skier ${ }^{22}$ beweist: Beiner, Steiner, Hemder, Rösser. Der er-Plural verdankt seine Entstehung überhaupt einer Kompensationsstrategie (siehe unten).

\footnotetext{
${ }^{21}$ Nach Paul 1917 sind solche Formen schon zahlreich bei den Klassikern im 18. Jahrhundert belegt.

${ }^{22} \mathrm{Da}$ Ski im Norwegischen 0-Plural hat, ist der er-Plural sicher erst in Süddeutschland entstanden, nicht erstaunlich, wenn man bedenkt, wo die Schneebretter v.a. gebraucht werden. Im Norden Deutschlands hieße es vermutlich Skis.
} 


\subsection{Der er-Plural}

Der er-Plural ist in der Geschichte des Deutschen relativ jung, der unmittelbare Vorgänger des s-Plurals. Er verdankt seine Entstehung der Tatsache, dass nach Verfall der mhd Flexionsklassensuffixe die Substantivflexion zusammenbrach und Pluralformen nicht mehr erkennbar waren (Wegera 1987), cf. Luther: die Wort, noch Th. Storm: die Kind. Die Miniklasse der neutralen s-Stämme (lat. genus, generis), die im Ahd nur ca. 10 Wörter umfasst, darunter Tierbezeichnungen, die kollektiv interpretiert werden können und somit eine Affinität zum Plural haben (Lämmer, Kälber, Hühner, Rinder), stellt das eigentlich stammbildende Suffix $-\mathrm{er}^{23}$ ( $<$ ir und deshalb umlautauslösend) zur Verfügung. Aus dieser Miniklasse entwickeln sich bis Ende des 18. Jahrhunderts zahlreiche Pluralformen auf -er, besonders süddeutsch, wo -e aufgrund von e- Apokope nicht zur Verfügung steht, auch für Maskulina: Äster, Bächer, Bäumer, Münder, Hälmer, Geschmäcker, Dinger, Türmer, Rester, Wichter, Stifter, Gerichter. Die alten, durch -er verdrängten Formen sind häufig in Ortsnamen belegt: Eberswalde,cf. Anhang. Zugleich stand im Deutschen damit auch ein Notplural zur Assimilation von Fremdwörtern zur Verfügung, wie zahlreiche Belege aus dem 18. Jahrhundert zeigen: Kabinetter, Lazaretter, Departementer, Regimenter, Kapitäler, Billeter, Publikümer, Lokäler, Complimenter, Präsenter, Offizierer, Kameler....

Die Schwankungen zwischen -e und -er erklären sich durch Verdrängung zunächst der alten e- durch die neue er-Form, die im Oberdeutschen funktionaler war und ist (siehe oben), dann durch Restitution des auslautenden -e, d.h. durch Abbau des -er und Rückübertragung des -e i.S. des von der Markiertheitstheorie vorhergesagten Abbaus kleiner Klassen. Teilweise halten sich die er-Formen in süddeutschen Dialekten, teilweise halten sie sich dank auseinander driftender Bedeutungsentwicklung wie bei Worte/Wörter, Schilde/Schilder, Bände/Bänder. Das folgende Tableau zeigt am Beispiel Wort, warum im Fnhd. die Form Wörter der optimale Kandidat ist: Das auslautende -e von Worte war der Lautentwicklung zum Opfer gefallen, damit entstand ein Ø-Plural, der DIST verletzt und kompensatorisch durch -er ersetzt wird. Spiralenförmige Abläufe sind beim Sprachwandel keine Seltenheit, die hier zu beobachtende Entwicklung ist ein typisches Beispiel für die beiden sich gegenseitig aufhebenden Prinzipien des Sprachwandels nach Lüdke $1980^{24}$.

Der s-Plural hat also einen Vorgänger, und es fragt sich, ob er nicht ebenfalls nur eine Übergangslösung darstellt oder wie im Englischen das Pluralsystem des Deutschen insgesamt verändert, indem er zum einzigen Regelplural wird. Dass ein Außenseiter zum Regelplural werden kann, beweist nicht nur das Englische mit -s, sondern auch die skandinavischen Sprachen, in denen der er-Plural ein hochproduktiver Regelplural ist.

Die Pluralform Wörter erfüllt für ein Neutrum die Beschränkungen ebenso optimal wie Vögel für ein Maskulinum (siehe oben). Zur genusspezifischen Verteilung von Umlaut und -er, cf. 1.3.2. Diese Form ist hochgradig distinkt, erfüllt FUSS, FK und im Gegensatz zu Worte sogar GK sowie NC, verletzt aber IDENT V, wie das Tableau zeigt. Das ist bei einem

\footnotetext{
${ }^{23}$ Stammbildend ist das Suffix noch im 17. Jahrhundert, wo ein Plural zusätzlich gebildet wird, besonders mnd: Kindere, Büchere, Dörfere, Rindere, nach Schottelius 1663 die Norm, deshalb auch in Komposita und Diminutiv: Hühnerei, Eierschale, Kinderchen.

${ }^{24}$ Nach Lüdtke 1980: 5 geht Sprachwandel zurück auf das "Streben des Menschen nach Optimierung", wobei aber immer zwei Prozesse auftreten, die sich gegenseitig aufheben:

A: der Arbeitsaufwand des Sprechers bei der Produktion wird minimiert, das System wird für Sprecher und Lerner ökonomischer, allerdings erhält der Hörer jetzt weniger Signale: Lautschwund.

B: der Arbeitsaufwand des Hörers wird minimiert, die Dekodierung wird dank zusätzlicher Signale leichter, allerdings muß der Sprecher jetzt mehr Signale produzieren: Kompensation.
} 
hochfrequenten Wort aber kein Problem (siehe unten). Für Wörter gilt daher die selbe Hierarchie wie für Vögel (siehe oben).

\begin{tabular}{|c|c|c|c|c|c|c|c|c|c|c|}
\hline \multirow[t]{2}{*}{ Wort $\mathrm{N}$} & \multirow[t]{2}{*}{ FUSS } & \multirow[t]{2}{*}{ FK } & \multirow[t]{2}{*}{ GK } & \multirow[t]{2}{*}{$\mathrm{NC}$} & \multirow[t]{2}{*}{ PAR } & \multirow[t]{2}{*}{ DIST } & \multicolumn{3}{|c|}{ IDENT } & \multirow[t]{2}{*}{ DEP } \\
\hline & & & & & & & V & K & $\mu$ & \\
\hline Wort & $*$ & & & & & $* * !$ & & & & \\
\hline$\Rightarrow$ Wor.te & & & $*$ & & & & & & * & * \\
\hline $\begin{array}{l}\text { Wort(e) } \\
\text { fnhd }\end{array}$ & $*$ & & $*$ & & & $* !$ & & & & \\
\hline Wör.ter & & & & & & $!$ & $*$ & & * & * \\
\hline Wor.ten & & $*$ & $*$ & & & & & & * & $*$ \\
\hline Wör.te & & & $*$ & & & & $*$ & & $*$ & $*$ \\
\hline Worts & $*$ & $*$ & $*$ & * & & & & & & $*$ \\
\hline
\end{tabular}

Die Frage ist, ob für die Entstehung eines neuen Pluraltyps im heutigen Deutsch, abgesehen vom Bedarf der Fremdwortassimilation, die Voraussetzungen gegeben sind, d.h. ob ein Bedarf danach besteht. Dieser könnte in den durch Schwa-Tilgung bedingten Ø-Pluralformen bestehen, die ihrerseits eine Erscheinung des Nhd sind. Beispiele wie Jungens, Mädchens könnten Anzeichen für eine Ausdehnung des s-Plurals in den heimischen Wortschatz sein (so Wunderlich 1999). Überprüfen wir daher die statistischen Werte für den Ø-Plural.

\subsection{Die markierten Pluralklassen}

\subsubsection{Der Ø-Plural}

Die Zahl der Ø-Plurale ist in Pavlovs Statistiken auffallend hoch, sie geht aus meiner Tabelle, die $\varnothing$ und -e zusammenfasst, nicht hervor. Nach Pavlov 1995:49 sind $22 \%$ der Tokens in Klasse 3, bei den Typewerten sogar $35 \%$ ohne formale Kennzeichnung (Lehrer, Fenster), das sind 13,3 \% sämtlicher Substantive im Textkorpus bzw. $20 \%$ der Wörterbucheinträge. Ein overtes Pluralzeichen ist für die Kommunikation offenbar nicht unbedingt notwendig, wenn Pluralmarkierung aus dem Artikel hervorgeht. Das bestätigt jedenfalls die Zahl nichtmarkierter Pluralformen bei den Feminina: Sie kommen nur bei Fremdwörtern vor und machen im Wörterbuch 0,6 \% aus, im Textkorpus kommt dieser Typ überhaupt nicht vor. Der Unterschied zwischen der Type- und der Tokenfrequenz, der hier negativ ist (siehe unten), könnte andeuten, dass nicht overte Pluralformen nicht optimal sind, cf. dazu das Beispiel Onkel und seine Kompensationsformen oben. Jedoch darf daraus kein Bedarf für den s-Plural abgeleitet werden, ehe nicht Frequenz und Funktion der Umlautplurale überprüft sind. 


\subsubsection{Die Umlautplurale}

Die noch heute existierenden Doppelfluralformen Wörter - Worte, Bänder - Bande, Bänke Banken, Männer - Mannen, Hände - (abhanden), Varianten zum selben Singularstamm, werfen die Frage auf, ob sich diese Variation auch synchron erklären lässt, ob der Umlaut eine Funktion hat. Wenn ja, müsste sich daraus für den Umlautplural eine Regel, wenigstens eine Tendenz ablesen lassen.

Die Umlautvarianten in den süddeutschen Dialekten Ärm, Wägen, die dann auftreten, wenn ohne Umlaut eine Ø-Form vorläge, zeigen, dass der Umlaut hier kompensatorische Funktion hat. Denkbar ist also, dass der Umlaut auch im Standarddeutschen der Kompensation des $\varnothing$ Plurals dient. Auf Funktionalität deutet auch die Tatsache hin, dass der Umlaut beim femininen e-Pluralsuffix, das süddeutsch nicht artikuliert wird, immer auftritt (die Händ), dagegen bei -(e)n und -s nie auftritt ${ }^{25}$ : Diese beiden Suffixe sind die einzigen, die auch bei eSynkope nicht tonlos werden können: die Fraun. Ein Umlaut ist also bei -(e)n ebenso wenig wie bei -s nötig und wäre hier afunktional.

Der Umlaut müsste dann bei Ø-Pluralformen häufiger auftreten als beim e-Plural. Beim erPlural ist der Umlaut phonologisch bedingt, aus dem alten ir-Flexiv ererbt. Eine funktionale Erklärung scheidet hier also aus, d.h. für den Vergleich kommen nur $\emptyset$ - und e-Formen infrage.

Bei den umgelauteten Pluralformen der Klasse 1 (Bänke, Mütter) und 3 (Wölfe, Bücher) Klasse 2 kennt keine Ausnahmen - weisen alle eine höhere Token- als Typefrequenz auf, cf. Tabelle 3. Für den $\varnothing$-Plural gilt genau das Umgekehrte: Seine Tokenfrequenz beträgt, bezogen auf den gesamten Wortschatz, nur 66,5\% der Typefrequenz.

Tendenzen und Entwicklungen im heutigen Deutsch lassen sich durch den Vergleich von Statistiken feststellen. Mit Mugdans statistischen Angaben, cf.Tabelle 4 unten, liegen Zahlen für Wörterbucheinträge von 1898 vor (cf. Mugdan 1977:97). Danach hatte der Ø-Plural am Ende des 19. Jahrhunderts keinen größeren, sondern einen geringeren Anteil am Gesamtwortschatz: 9,5\% der Token, 13, $3 \%$ der Types, mit einem TT-Quotienten von $71 \%$. Der Anteil des Ø-Plurals ist im heutigen Deutsch also bei Token von 9,5\% auf 13,3\%, bei den Types von 13,3\% auf $20 \%$ gestiegen. Der $\varnothing$-Plural wird also nicht abgebaut, er stellt offensichtlich für den Sprecher kein Problem dar, das er mit Hilfe des Umlauts oder des nbzw. s-Plurals zu lösen versucht.

Diese Zahlen widerlegen die Annahme, der Umlaut habe im Standarddeutschen kompensatorische Funktion, in eindeutiger Weise. Die hohe Zahl von Ø-Pluralformen mit umlautfähigem Vokal dürfte durch die zahlreichen Nomina agentis bedingt sein: Fahrer, Besucher. Für diese Ableitungen ist Transparenz, d.h. die Beschränkung IDENT/V sehr wichtig, um den Zusammenhang zum Verb nicht zu verdunkeln. IDENT ist daher hier höher gewichtet als bei Simplizia wie Hut, Stock, Bach. Die alten Verbableitungen, die lexikalisiert sind, lassen dagegen meistens Umlaut zu: Brände, Bünde, Gänge, Kämpfe, Käufe, Schläge, Schlüsse, Sprüche, Sprünge vs Halte, Funde, Rufe vs nichtmögliche morphologische Pluralformen wie Raubzüge, Ratschläge, Bauten, Danksagungen.

Gerade die hohe Tokenfrequenz der Umlautplurale weist auf eine andere Funktion des Umlauts hin. Diese wird deutlich, wenn wir die heutigen Frequenzwerte in Tabelle 1-2, die

\footnotetext{
${ }^{25}$ Mit der einzigen Ausnahme Werkstätten, die sich durch Kontamination von Werkstatt und Stätte erklären lässt.
} 
sich aus Pavlovs Auszählungen eines Wörterbuchs von 1977 bzw. eines Textkorpus ergeben, mit jenen vergleichen, die sich aus Mugdans Auszählung eines Wörterbuchs von 1898 bzw. der danach berechneten Häufigkeitsstatistik nach Meier 1964 ergeben, s. Mugdan 1977:95f. Die beiden Auszählungen bieten die Chance, die Entwicklung der Pluralformen im 20. Jahrhundert zumindest statistisch dokumentieren zu können. Die Tabellen zeigen die Zahlen für 1898 und für 1977 und darunter die Veränderungen in Prozent an.

Tabelle 4: Veränderung der Pluralfrequenzen (Types)

Typefrequenz, $\mathrm{N}=2307$ (Mugdan 1977:95ff = Kaeding 1898) bzw 6505 (Pavlov 1995:44ff = Wahrig 1975)

\begin{tabular}{|c|c|c|c|c|c|c|c|c|c|}
\hline \multicolumn{4}{|c|}{$\begin{array}{l}\text { M Fem (1245) } \\
\text { P Fem (2726) }\end{array}$} & $\begin{array}{l}\text { sw M (87) } \\
\text { sw M (458) }\end{array}$ & \multicolumn{5}{|c|}{ st MN (975) } \\
\hline & (e)n & "(e) & $\mathrm{S}$ & (e)n & (e)n & (e) & "(e) & "er & $\mathrm{S}$ \\
\hline 1898: & 96,4 & 2,6 & 0,3 & 100 & 2,46 & 64,7 & 19,8 & 5,5 & 5,74 \\
\hline$\underline{1975}$ & 96,6 & 1,1 & 1,7 & 100 & 3,3 & 70,2 & 7 & 1,5 & 16,3 \\
\hline $\mathrm{V}:$ & 102 & 42 & 566 & 100 & 134 & 108 & 35 & 27 & $284 \%$ \\
\hline
\end{tabular}

Tabelle 5: Veränderung der Pluralfrequenzen (Tokens)

Tokenfrequenz, $\mathrm{N}=386906$ (Mugdan 1977:95ff = Kaeding 1898) bzw 13587 (Pavlov $1995=$ Texte <1945)

\begin{tabular}{|c|c|c|c|c|c|c|c|c|}
\hline \multirow{2}{*}{$\begin{array}{l}\text { Fem (189329 } \\
\frac{\text { Fem }(5303)}{(\mathrm{e}) \mathrm{n}}\end{array}$} & & & \multicolumn{6}{|c|}{ sw M (5887) st MN (181690) } \\
\hline & & & SW N & st M & $\frac{(759)}{(0)}$ & & & \\
\hline $\begin{array}{l}(\mathrm{e}) \mathrm{n} \\
\text { 1898: } 96.6\end{array}$ & $\frac{(\mathrm{e})}{3}$ & $\frac{S}{0.05}$ & $\frac{(e) n}{100}$ & $\frac{(\mathrm{e}) \mathrm{n}}{105}$ & $\frac{(\mathrm{e})}{528}$ & $\frac{(\mathrm{e})}{27}$ & er & 187 \\
\hline 1975: 87,9 & 11,9 & 0,2 & 100 & 6,9 & 58,8 & 18,7 & 12,8 & 2,7 \\
\hline 90 & 396 & 400 & 100 & 65,7 & 111 & 67 & 200 & 144 \\
\hline
\end{tabular}

Tabelle 6: Veränderung des Type-Token-Quotienten:

\begin{tabular}{|c|c|c|c|c|c|c|c|c|c|}
\hline & (e)n & "(e) & $\mathrm{S}$ & (e)n & (e)n & (e) & "(e) & "er & $\mathrm{S}$ \\
\hline 1898: & 1 & 1,15 & 0,16 & 1 & 4,26 & 0,8 & 1,36 & 1,15 & 0,32 \\
\hline 1975: & 0,9 & 10,8 & 0,1 & 1 & 2 & 0,8 & 2,7 & 8,15 & 0,16 \\
\hline V: & 90 & 939 & 62,5 & 100 & 47 & 100 & 198 & 708 & $50 \%$ \\
\hline
\end{tabular}

Die Zahlen und die Veränderungen der Zahlen hinsichtlich der Typefrequenz bestätigen weitgehend, aber nicht vollständig die Annahme der Markiertheitstheorie, dass kleine markierte Klassen zugunsten großer homogener Klassen abgebaut werden.

Der feminine (e)-Plural ist auf $42 \%$, der umgelautete (e)-Plural in Klasse 3 auf $35 \%$, der erPlural sogar auf $27 \%$ seiner früheren Werte gesunken. Nur der markierte (e)n-Plural in Klasse 3 hat leicht zugenommen, auf $134 \%$. Stabilisiert haben sich wie erwartet die Regelplurale -(e)n bei Feminina und -(e) bei Nicht-Feminina. Den größten Anstieg (auf 284 
bzw. $566 \%$ ) erlebte der s-Plural, was die Annahme, der s-Plural sei der einzig produktive (siehe unten in 3.), zu stützen scheint.

Die Tokenfrequenzwerte zeigen jedoch, dass dieser Schluss verfrüht ist. Nach Tabelle 5 hat sich der Regelplural der Klasse 3 stabilisiert, der (e)n-Plural in Klasse 1 ist leicht gesunken, was angesichts seiner fast totalen Gültigkeit in dieser Klasse an seinem Status als Regelplural aber nichts ändert: Er beträgt auch im Text $90 \%$. Die Tokenfrequenz der markierten Plurale (e)n und "-(e) in Klasse 3 ist jeweils auf ca. 2/3 gesunken, hinsichtlich der Veränderung der Tokenfrequenz unterscheidet sich -(e)n also nicht vom Umlautplural in dieser Klasse. Die so viel höhere Token- als Typefrequenz erklärt sich hier durch Fremdwörter mit Stammflexion wie Konto-Konten, Ritus-Riten, Mythos-Mythen, Album-Alben (siehe unten).

Interessant für die Frage nach der Funktion des Umlauts sind gerade die kleinsten Klassen unter den nativen Pluralformen: -er in Klasse 3 (Bücher) und -"e in Klasse 1 (Hände). Ihre Tokenfrequenz ist nicht nur nicht gesunken, sondern um das zwei- bis vierfache gestiegen, auf 201 bzw. $396 \%$. Noch spektakulärer ist der Anstieg des Tokenquotieten, bei -"(e) hat er sich auf 2,7 verdoppelt, bei -er fand eine Zunahme um $708 \%$, beim femininen (e)-Plural um 939 \% statt! Diese beiden Klassen zeigen also einerseits Merkmale von Aussterben - ihr Typeanteil liegt zwischen 1,1 und 1,5\% pro Klasse -, andererseits zeigt ihre extrem hohe Gebrauchsfrequenz, dass hier ein Gesundschrumpfungsprozess stattgefunden hat. Diese Plurale treten bei hochfrequenten Wörtern auf, das sind Wörter, die zum lexikalischen Bereich des Nächstliegenden gehören, kurz Nahbereichwörter. Köpcke 1994:83 zeigt, dass der Umlaut bei Maskulina ${ }^{26}$ umso häufiger auftritt, je näher die Referenten dieser Wörter dem Menschen stehen, wobei ein Kontinuum im Sinne der Prototypentheorie besteht. Die folgenden Dubletten belegen eindeutig, welche der beiden Formen im Alltagswortschatz häufiger auftritt und dem Kind früher begegnet: Bänke - Banken, Mütter - Muttern, Bänder Bande, Wörter - Worte, Männer - Mannen. Wörter für den Nahbereich, die in vielen Sprachen besonders differenzierte Lexeme und Morphologie aufweisen, sind Bezeichnungen für Verwandte, ${ }^{27}$ Körperteile, Haustiere, Hausrat.

Bei diesen Wörtern ist häufig Suppletion zu finden, welche das Distinkheitsgebot am besten erfüllt, auch um den Preis irregulärer Formen. Man denke an die Flexion des Verbs sein mit vier Wurzeln (bin, ist, sind, war), die hohe Frequenz der starken Verben etc. Der Umlautplural ist zwar nicht suppletiv i.e.S., aber redundant, da Suffigierung + Vokaländerung erfolgt, er steht damit Suppletivformen am nächsten. Eine besonders hohe Differenzierung der Lexik des Nahbereichs findet sich in vielen Sprachen und ist funktional, da so die Unterscheidung der korrespondierenden Formen gesichert ist. Die Beschränkung DIST ist bei Nahbereichlexemen das höchste Constraint, höher als alle Treuebeschränkungen, sie bewirkt in Klasse 3, dass GK höher gewichtet ist als FK, und setzt bei Feminina sogar FK außer Kraft. Für den Spracherwerb stellen diese Formen dank ihrer hohen Frequenz kaum ein Problem dar, ${ }^{28}$ wie die Erwerbshierarchie der Pluralmarker (nach der Fehlerlosigkeit) beweist (cf. Wegener 1995a:202 mit Daten von DaZ lernenden Kindern, zum L1-Erwerb cf. Augst 1979, 230):

\footnotetext{
${ }^{26}$ Bei den Maskulina mit Umlaut ist der Unterschied zwischen Tokenfrequenzwerten und Typefrequenzwerten bemerkenswert, wie sich aus Pavlov 1995: 45, 48 errechnen läßt: Von 451 einsilbigen Maskulina mit umlautfähigem Vokal bilden 226 den umgelauteten e-Plural (Flöhe), das sind 8,5\% der Types, diese haben eine Tokenfrequenz von 21,6 \%, Quotient, 2,5. Von 179 Maskulina auf Pseudosuffix mit umlautfähigem Vokal bilden nur 6 den umgelauteten (e)-Plural (Vögel), das sind 0,2\% der Types, diese haben jedoch eine Tokenfrequenz von 3,9\%, Quotient 19,5!

${ }^{27}$ Cf. z.B. die germ. Klasse der Wörter auf -ter. Auch Lexeme des Nahbereichs sind jedoch nicht vor Aussterben geschützt, wie Base, Gevatter, Oheim zeigen, die durch die frz. Lehnwörter Cousine, Onkel ersetzt wurden.

${ }^{28}$ Dank ihrer hohen Frequenz ist aber auch der Genuserwerb bei diesen Wörtern kein Problem.
} 
Erwerbshierarchie der Pluralmarker: $-0>-$ er $>-e>-e n>-s>-n$.

Die hohe Tokenfrequenz bewirkt, dass insbesondere der er-Plural lexikalistisch gelernt, d.h. häufig unanalysiert gespeichert wird, siehe den Fehlertyp *ein Eier. Sie behindert auch das Erkennen und Klassifizieren von -er als Pluralflexiv und erklärt, warum dieser Plural fast nie übergeneralisiert wird. Die Umlautung des Stammvokals ist also nicht einfach arbiträr, sondern sie ist durch das besonders hoch gerankte Distinktheitsgebot für den Wortschatz im Nahbereich motiviert (cf. auch Köpcke 1994:83).

Alle Umlautvarianten erfüllen FUSS, die meisten auch FK, so dass sich eine unterschiedliche Hierarchie nur hinsichtlich DIST (und bei Feminina wie Hände sogar hinsichtlich FK ) ergibt, für alle Umlautvarianten ist IDENT/V niedrig gewichtet, cf. das Tableau für Wörter.

Bei Maskulina ist diese Klasse nicht unproduktiv (Fräcke, Gärten, Generäle), bei Neutra nicht völlig unproduktiv, besonders in Süddeutschland (Skier). Bei Feminina aber ist sie vermutlich unproduktiv. Der Abbau dieser Klassen überwiegt die Neuzugänge bei weitem, gerade die geringe Typefrequenz macht den Umlautplural ja zum geeigneten Plural für den Nahbereich. Für den Abbau der Klassen werden drei Verfahren angewandt: 1. Die "natürliche" Lösung besteht darin, dass die Wörter außer Gebrauch kommen. 2. einige Wörter wechseln die Flexionsklasse, 3. in einigen Fällen wird die Pluralform als Singularform reanalysiert.

Beispiele:

1. aussterbende Wörter (in Mugdan 1977:211ff noch aufgeführt, Auswahl):

F: Niß, Brunft, Brunst, Drangsal, Labsal, Trübsal

N: Aas, Wams, Reis, Gemach, Balg, Soll

M: Wanst, Trumm, Asch, Gauch, Schalk, Lackel, Fussel, Friesel, Brösel, Model, Stummel, Stoppel, Kaffer, Gevatter

2. Flexionsklassenwechsel zum Regelplural hin fand statt bei

F: Schlucht, Sucht ( -"e > en)

$\mathrm{N}$ : Brot, Mahl, Rest ( -er > -e)

M: Stiefel, Ziegel ( $-\mathrm{n}>0)$

sw M: Bayer, Pommer, Bauer ${ }^{29}$ ( -(e) > -n)

3. Reanalyse als Singular:

Knaul, Pl. Knäule > Knäuel, Funken, Gedanken, Schwaden u.v.a., cf. Wurzel 1985

Folgende Beschränkungshierarchien ergeben sich für die Pluraldubletten:

Wörter: FUSS, GK > FK, DIST, NC >> IDENT/ $\mu$, IDENT/V

Worte: FUSS, FK, IDENT/V, NC $>>$ DIST $>>$ IDENT/ $\mu$

Bänke: FUSS, DIST, NC $\gg$ FK, IDENT/V, IDENT/ $\mu$

Banken: FUSS, FK, NC, IDENT/V > DIST > IDENT/ $\mu$

${ }^{29}$ Die alte Genitivform ist in Bauersfrau erhalten. 


\subsection{Der s-Plural}

Für den s-Plural klaffen die Frequenzwerte noch stärker auseinander: Seine Tokenfrequenz beträgt in Klasse 1 nur $10 \%$, in Klasse 3 nur $16 \%$ der Typefrequenz. Offenbar kommen viele dieser Wörter im Alltagswortschatz nicht vor. Der Unterschied zwischen der Type- und der Tokenfrequenz, der hier extrem negativ ist, deutet schon an, dass der s-Plural einen Sonderstatus hat, und führt zu der Hypothese, dass ein Fremdwort, wenn es in den allgemeinen Wortschatz aufgenommen wird, was ja nur bei einem Bruchteil von ihnen überhaupt erfolgt, den s-Plural im Zuge der Assimilation an das deutsche phonologische und morphologische System durch ein natives Suffix (inklusive des Ø-Plurals) ersetzt. Assimilationen, die sich in mehreren Stufen vollziehen, sind besonders interessant für die Frage, welche Beschränkungen hier jeweils wirken.

Um die Funktionalität des s-Plurals zu zeigen, gehe ich von einer Klasse hochgradig markierter Wörter aus, den Onomatopoetika. Markierte und nichtnative Wörter reflektieren u.U. das phonologische und morphologische Wissen der Sprecher ganz unmittelbar, cf. hierzu Eisenberg 1991:42, Vennemann 1991. Die besondere Leistung des s-Plurals und die Bedingungen, die sein Auftreten begünstigen oder gar erzwingen, lassen sich an dieser Wortklasse besonders gut zeigen.

\subsubsection{Onomatopoetika}

Bei Wörtern, die in lautmalerischer Absicht gebildet (Kuckuck, Wauwau, Uhu) oder in lautmalerischer Absicht gebraucht werden, so bei Zitierformen und Substantivierungen anderer Wortklassen, insbesondere von Interjektionen, ist nur der s-Plural möglich: dieAchs, die Wenn undAbers, die A's, die Kuckucks, die Wauwaus, die Uhus. Die Unmöglichkeit eines nativen Plurals ergibt sich hier aus dem lautmalerischen Charakter dieser Wörter. Deren lautmalerische Struktur und Funktion würde durch ein hinzutretendes silbisches Pluralflexiv zerstört, weil dieses die Silbengrenze verschieben würde, insbesondere mit Umlaut wären sie keine Onomatopoetika mehr: *Kuckucke, *Kuckücke, *Wauwaue, die * Äche und Wehen statt die Achs und Wehs. Der -s Plural wird dagegen als einziges Pluralflexiv in den Silbenrand der Auslautsilbe integriert und führt so nicht zur Verschiebung der Silbengrenze.

Die Treuebeschränkungen IDENT hinsichtlich Vokal, Konsonant und Silbengrenze sind bei diesen Wörtern ganz hoch gewichtet und dürfen nie verletzt werden. Sie dürfen im Gegensatz zu Appellativa und Eigennamen selbst dann nicht verletzt werden, wenn das Onomatopoetikon auf -s auslautet, folglich kommt es zum Ø-Plural: die Los, los!, die S, die Würgs, Kotz und Grunz. ${ }^{30}$ Während ein Fremdwort in diesem Fall den e-Plural bildet (Bosse), verletzen Onomatopoetika hier das Distinkheitsgebot, um die Treuebeschränkungen zu erfüllen. Alle anderen Beschränkungen wie FK und NC sind hier außer Kraft gesetzt. FUSS wird häufig durch Reduplikation erreicht, ist aber nicht Bedingung, cf. die Beispiele oben. Für diese Wörter ist IDENT in jeder Form die höchste Beschränkung, die um den Preis eines $\varnothing-$ Plurals selbst gegen DIST durchgesetzt wird.

Bei Substantivierungen, die nicht in lautmalerischer Absicht gebraucht werden, besteht keine vergleichbare Restriktion, Substantivierungen von Verben z.B. werden daher wie normale Substantive flektiert, unter Berücksichtigung der Schwa-Tilgung und der Flexionsklasse: Die Schreiben, die Essen, die Modenschauen, die Käufe, die Kämpfe.

\footnotetext{
${ }^{30}$ Interjektionen der Comics.
} 
Auch für Zusammenrückungen wird nur dann der s-Plural gebildet, wenn sie Zitierformen sind oder Neologismen darstellen: die Rührmichnichtans, aber die Tunichtgute, die Vergissmeinnichte. $^{31}$

\subsubsection{Eigennamen}

Für Eigennamen gelten ähnlich strenge Treue-Beschränkungen wie für Onomatopoetika, insbesondere für Familiennamen gelten nicht nur juristisch, sondern auch sprachlich die Treuebeschränkungen in besonders strikter Weise. Familie Vogel $>*$ die Vögel, ebenso *die *Schmiede, die *Köche, sondern die Schmieds, die Kochs, die Vogels. Ein silbischer Plural scheidet aus, da er die Wortstruktur zu stark verändern und IDENT $\mu$ verletzen würde, ein $\emptyset$ Plural scheidet aus, da Familiennamen ja auch mit dem femininen Artikel für eine weibliche Person gebraucht werden können: die Meier wäre ambig, ebenso ein Plural auf -n: die Meiern weist in Norddeutschland noch schwache Flexion auf bzw geht auf die Meierin zurück (cf. Paul 1917), ist also Singular feminin.

Interessant ist nun, wie der Fall gelöst wird, der bei Onomatopoetika zum $\emptyset$-Plural führt: Lautet der Familienname auf -s oder -z aus, so wäre die Schulz ambig, könnte sich auf Frau Schulz oder Familie Schulz beziehen. Hier wird eine sonst nicht als Plural mögliche Form auf -ens gebildet, die aus dem Paradigma des entsprechenden Substantivs stammt: die Schulzens, Kunzens, Katzens, Großens, d.h. hier wird ein ursprüngliches Genitivsuffix ${ }^{32}$ verwendet, das qua Analogie dann auch an "feminine" Eigennamen treten kann. Die Sprache wendet hier genau das Verfahren an, das sie auch bei der Bildung der Fugenelemente benutzt, sie bedient sich der im Paradigma vorhandenen Formen und verwendet diese auch unparadigmisch.

Familiennamen sind die einzigen Substantive im Deutschen, die ausschließlich den s- bzw. ens-Plural bilden. Dies ist insofern funktional, als viele Familiennamen zugleich normale Appellativa sind, sodass es eines Sonderplurals bedarf, um Homonymien zu vermeiden: die Schmiede, die Katzen, die Braunen, die Wölfe wäre ambig, die Vogels, die Wolfs, die Brauns, die Schmids, die Katzens sind eindeutige Namen.

Ähnliches gilt für geographische Bezeichnungen: Hamburg ist keine Burg, daher *die Hamburgen. Geographische Bezeichnungen bilden einen s-Plural gerade dann, wenn ein nativer Plural zur Verfügung stünde: die Hamburgs, die Deutschlands, die beiden Berlins, und natürlich bei Auslaut auf Vollvokal, die Altonas, die Milanos. Eine Verschiebung der Silbengrenze wie bei Termi.ne wird also durch Berlins vermieden. Das Distinkheitsgebot gilt hier jedoch weniger strikt. Weist der geographische Name pluraltypische Züge auf, so ist der Ø-Plural möglich: Es gibt mehrere Italien / ?Italiens/, Niederlande/ *Niederlandes, 'Bremen/ ?Bremens, Paris/*Parise vs Frankreichs /*Frankreiche.

Auch bei Vornamen wird die Struktur des Namens so wenig wie möglich verletzt, wozu neben -s auch der $\varnothing$-Plural dient: die beiden Petras, aber die beiden Klaus/*Klausens, ??Klause, Andreas / ?Andreasse, Michaels, ?Peters, ?Dorisse(n), ??Lutze, *Lütze, Lutz. Lautet der Name auf -s aus, so wird ein silbischer Plural oder die -ens-Form meist abgelehnt, ein $\emptyset$ Plural vorgezogen.

Produktnamen stehen den Appellativa am nächsten, sie können zu solchen werden bzw. wie solche gebraucht werden und bilden folglich unmarkierte Pluralformen: die Diesel, Opel /

\footnotetext{
${ }^{31}$ Bei Paul 1917 noch mit s-Plural geführt.

${ }^{32}$ Der Familienplural ist aus einem Genitiv entstanden (cf. Curme 1922: 93), also bei Meiers Haus > bei Meiers. In süddt Dialekten wird noch häufig auf eine Familie mit $s^{\prime}$ Meiers statt die Meiers referiert.
} 
?Opels, Mercedes /?Mercedesse, Volvos, BMW, ?BMWs, die Duden, Dollar, Spiegel, Stern, Taz. Teilweise wird sogar ein silbischer Plural gebildet (am Kiosk): die drei Sterne, die Zeiten, die ?Tazen. Muss Homonymie vermieden werden, hat -s Vorrang: die Kadetts. Dagegen bezeichnen gerade die $\varnothing$-formen die Opel, die Duden das Produkt, die s-Formen die Familie.

Wie Vornamen werden auch Verwandschaftsbezeichnungen behandelt, die wie Eigennamen zur Anrede benutzt werden: die Omas, Opas, Mamas, Papas, Muttis etc. Im Gegensatz zu Villa ist für Oma daher kaum zu erwarten, dass es eingedeutscht wird, allenfalls in der Bedeutungsvariante 'alte Frau', dann mit offenem Vokal gesprochen: Omma, und dann auch schon als Diminutiv hörbar, ein Ömmchen.

Die Klassifizierung des s-Plurals als Notplural ist aber hier nicht ausreichend, denn in vielen Fällen könnte aus phonologischer Sicht ein nativer Plural gebildet werden, wie es auch bei Produktnamen und Bezeichnungen für Firmenangehörige geschieht: die Holzmänner. Bei Substantiven, die aufgrund ihrer phonologischen Struktur (Onomatopoetika) oder kategorialen Eigenschaft (Eigenname) Sonderfälle darstellen, ist -s funktional zur Bewahrung von IDENT $\mu$, somit ein Funktionsplural für phonologische bzw. kategoriale Spezialfälle.

Bei Familiennamen sind Verletzungen von DIST und IDENT fatal, FK/GK entfällt, bei Onomatopoetika ist IDENT höher als DIST gerankt, ansonsten gilt für beide Wortklassen dieselbe Hierarchie der Beschränkungen, die sich deutlich von der der Appellativa durch die Spitzenstellung von IDENT unterscheidet:

Kuckucks: IDENT $\mu>$ DIST $>>$ FUSS, NC $>>$ FK/GK

Kunzens: DIST, $-\mathrm{HOM}>$ IDENT $\mu>>$ FUSS, NC

Schmids: IDENT, DIST, -HOM $>>$ FUSS, NC

Das Tableau für das Lexem Land soll die unterschiedliche Gewichtung der Constraints je nach ihrer Funktion als Appellativum und als Eigennamen zeigen. Zugleich zeigt es die im Mhd noch mögliche, im Eigennamen erhaltene Form Lande. Da ich die Varianten in einem Tableau darstelle, um den Vergleich zu ermöglichen, ergeben sich die unterschiedlichen Hierarchien aus dem jeweils siegreichen Kandidaten:

Land - Appellativum vs Eigenname

\begin{tabular}{|l|l|l|l|l|l|l|l|l|l|l|}
\hline \multirow{2}{*}{ Land [t] N } & \multirow{2}{*}{ FUSS } & \multicolumn{3}{|c|}{ IDENT } & DEP & NC & FK & GK & PAR & DIST \\
\hline & & V & K & $\mu$ & & & & & & \\
\hline Land & $*$ & & & & & & & $*$ & & $*$ \\
\hline m(Nieder)Lan.de & & & $*$ & $*$ & $*$ & & & $*$ & & $*$ fnhd \\
\hline - Län.der & & $*$ & $*$ & $*$ & $*$ & & & & & \\
\hline Lan.den & & & & & $*$ & $*$ & $*$ & $*$ & & \\
\hline Län.de & & & $*$ & $*$ & $*$ & & $* !$ & $*$ & & \\
\hline
\end{tabular}


Das Tableau für das Lexem Duden soll die unterschiedliche Gewichtung der Constraints je nach ihrer Funktion als Produktname und als Familienname zeigen. Da ich die Varianten wiederum in einem Tableau darstelle, um den Vergleich zu ermöglichen, ergeben sich auch hier die unterschiedlichen Hierarchien aus dem jeweils siegreichen Kandidaten:

Duden - Produktname vs Familiennname

\begin{tabular}{|c|c|c|c|c|c|c|c|c|c|c|}
\hline \multirow[t]{2}{*}{ Duden $\mathrm{M}$} & \multirow[t]{2}{*}{ FUSS } & \multicolumn{3}{|c|}{ IDENT } & \multirow[t]{2}{*}{$-\mathrm{HOM}$} & \multirow[t]{2}{*}{$\mathrm{NC}$} & \multirow[t]{2}{*}{ FK } & \multirow[t]{2}{*}{ GK } & \multirow[t]{2}{*}{ DIST } & \multirow[t]{2}{*}{ DEP } \\
\hline & & $\mathrm{V}$ & $\mathrm{K}$ & $\mu$ & & & & & & \\
\hline -Du.den PN & & & & & & & & * & $*$ & \\
\hline Du.de.ne & * & & & * & & & & & & * \\
\hline Du.de.nen & * & & & * & & & * & $*$ & & $* *$ \\
\hline Dü.den & & * & & & & & & & & \\
\hline Du.dens & & & & & $* !$ & $*$ & * & $*$ & & * \\
\hline -Du.dens FN & & & & & & * & & & $!$ & * \\
\hline
\end{tabular}

Die Tableaus zeigen, dass beim Familien- und Ländernamen die Treuebeschränkungen höher gewichtet sind als bei den Appellativa, bei diesen dagegen die Constraints FUSS, NC und FK/GK. Der Produktname, der zum Appellativum übergeht, unterscheidet sich von diesem nur dadurch, dass eine zusätzliche Beschränkung, das Homonymenverbot, relevant wird. Da Familiennamen nicht auf ein Genus festgelegt sind, entfällt GK.

\subsubsection{Fremdwörter}

Bei Fremdwörtern ist zu unterscheiden zwischen Einsilbern und endbetonten Wörtern einerseits, die meist aus dem Französischen stammen, und Mehrsilbern mit Betonung auf der Paenultima andererseits.

\subsubsection{Fremdwörter mit Endsilbenbetonung}

Es dürfte nun klar sein, dass der s-Plural bei Fremdwörtern präferiert wird, weil er die Treuebeschränkungen besser erfüllt als die nativen Suffixe, weil er sozusagen besonders schonend mit dem Singularstamm umgeht. Für Fremdwörter aber ist es natürlich funktional, ja notwendig, dass sie zu Anfang ihres Gebrauchs im fremden Sprachgebiet in ihrer phonologischen Struktur so wenig wie möglich geändert werden, dass sie also transparent sind. Deshalb weisen v.a. die heute noch jungen Entlehnungen, die aus Einsilbern mit kurzem Vokal in geschlossener Silbe bestehen, meist s-Plural auf: dieTipps, Clubs, Stopps, Hits, Jobs. Ein e-Plural würde hier zur Verschiebung der Silbengrenze führen und die Wiedererkennbarkeit dieser noch nicht überall bekannten Wörter gefährden: *die Tippe, *Ticke, *Klubbe, *Stoppe, *Hitte, *Jobbe, zu denen es ja durchaus native Muster gibt: Tritte, Muffe, Robben.

Das s-Suffix ist das einzige, das dem Singularstamm keine Schwa-Silbe hinzufügt und folglich die Silben- und Morphemgrenze nicht verschiebt. Mit dem s-Plural wird also, weil er dem Singularstamm keine Silbe hinzufügt, die morphologische Struktur des Singulars am besten bewahrt, bleibt sie intakt. 
Ähnliches wie für Onomatopoetika und Eigennamen, insbesondere Familiennamen, die hinsichtlich ihrer phonologischen Struktur besonders schützenswert sind, gilt auch für Fremdwörter, solange sie fremd sind. Solange ein Fremdwort nicht allgemein bekannt ist, darf es seine morphologische Integrität nicht preisgeben. Die nativen Pluralflexive verschieben jedoch die Silbengrenze und damit die Morphemgrenze: Kin.der, Hun.de, Schul.den. Sie bewirken außerdem die Sonorisierung eines stimmlosen Endkonsonanten, verletzen also die Treuebeschränkungen IDENT $\mu$ und IDENT K. Um diese zu bewahren, d.h. um transparente Formen zu bilden, wird der s-Plural gebildet, der allerdings die Beschränkungen FUSS, NC und FK/GK verletzt, die offensichtlich hier niedriger gerankt sind.

Abgesehen von phonologischen Gründen ist es auch funktional, Fremdwörter zunächst morphologisch gesondert zu behandeln. Nach Heine 1982: 191, Corbett 1991:7ff ordnen afrikanische Klassensprachen Ableitungen und Fremdwörter häufig Sonderklassen zu. Im Deutschen erhalten aber nicht alle Fremdwörter automatisch den s-Plural, sondern die Pluralisierung erfolgt vorrangig nach phonologischen Kriterien und Beschränkungen. Fremdwörter hören irgendwann auf, Fremdwörter zu sein, sie werden assimiliert, und funktional ist es dann natürlich auch, sie an das deutsche Pluralsystem anzupassen.

Aufgrund der lautgesetzlichen Auslautverhärtung führt bei Simplizia, die auf einen Obstruenten auslauten, die native Pluralbildung zur Sonorisierung des Konsonanten, bei /ch/ zur Palatalisierung: ${ }^{33}$ Hund [t] - Hunde, Berg [k] - Berge, Korb [p] - Körbe, Buch [X] - Bücher [ç], wodurch die Distinktivität erhöht wird. Die korrekte Pluralbildung solcher Wörter setzt voraus, dass der Sprecher ein Phonembewusstsein hat, d. h. das zugrunde liegende Phonem und den tatsächlich gehörten Laut unterscheidet. Dieses Phonembewusstsein gewinnt er durch Formen wie Hündin, hündisch, bergig, Büchlein, die natürlich einen gewissen Verbreitungsgrad des Wortes voraussetzen. Für neu entlehnte Wörter wie Job, Kid, Bag gibt es aber womöglich noch keine Formen, an denen der Wechsel zwischen stimmhaftem und stimmlosem Auslautkonsonanten beobachtbar ist. Für Fremdwörter kann ein solches Phonembewusstsein daher nicht vorliegen, ein Adjektiv *jobig, *jobbig gibt es (noch) nicht, ${ }^{34}$ ein solches Phonembewusstsein kann hier aber auch durch die Schrift entstehen. Dass die Schrift bei der Herausbildung von Phonem- und Morphembewusstsein eine Rolle spielt, ist hier mit zu bedenken, denn eine solche Beeinflussung ist in einer Gesellschaft mit hoher Schreibkultur anzunehmen. Wenn die Orthographie eine Rolle bei der Assimilierung von Fremdwörtern spielt, wie Wunderlich 1999 annimmt, so müssten die Einsilber Tipp und Stopp, die seit der Orthographiereform mit Doppelkonsonant geschrieben werden, schneller assimiliert werden als Hit und Top und diese leichter als Kid und Job.

Erst wenn das Fremdwort einen gewissen Bekanntheitsgrad erreicht hat, erlaubt es die Bildung eines nativen Plurals, u.U. sogar mit Umlaut. Einige der bei Curme 1922, Mugdan 1977 noch mit s-Plural aufgeführten Belege weisen heute zumindest fakultativ e-Plural auf: Fräcke, Lifte. ${ }^{35}$ Im Gegensatz zum s-Plural verändert dieser nun die Silbenstruktur des Inputs: Defizits, Lifts, Jobs, aber Defizi.te, Lif.te, *Jo.be, *Job.be.

\footnotetext{
${ }^{33}$ Für das auslautende - $t$ wird im allgemeinen ein zugrunde liegendes Phonem /d/ angenommen, das im Auslaut verhärtet wird. Wenn ich jedoch vom Singular ausgehe und strikt oberflächennah beschreibe, gehe ich von der Form aus, die der Sprecher im Input vorfindet, das ist [t].

${ }^{34}$ Es gibt aber schon jobben, Kiddy und trendy.

${ }^{35}$ Der Duden 1989 gibt außerdem für folgende bei Mugdan mit s-Plural aufgeführten Wörter einen fakultativen e-Plural an: Dock, Biwak, Billett, Brikett, Haff, Heck, Jackett, Kaff, Klosett, Kornett, Korsett, Kotelett, Picknick, Relief, Wrack, Galopp, Park, Schock, Skunk, Spurt, Test, Trick, Tusch.
} 
Silben, die auf einfachen Konsonanten auslauten, verlangen vom Sprecher die Entscheidung, bei einem e-Plural die Silbengrenze vor den Konsonanten zu legen oder diesen als Silbengelenk zu benutzen. Im ersteren Fall könnte die dann offene Silbe gelängt, der Vokal gespannt werden, wie das bei Wege vs we geschehen ist und dann sogar über paradigmischen Längenausgleich zum Langvokal im Singular führte. Das Transparenzprinzip, das größtmögliche Korrespondenz zwischen Input und Output verlangt, erklärt also die Präferenz für den s-Plural besonders bei kurzen Silben.

Eine Alternative wäre nur der Ø-Plural, jedoch ist das Distinktheitsgebot auch bei Fremdwörtern hoch gerankt, das zeigen die Formen, die bei auslautendem -s des Singularstamms gebildet werden: Ein e-Plural wie Bosse, Busse ist völlig unproblematisch, obwohl die Pluralform zweisilbig ist und sich dadurch vom Singular stärker unterscheidet als die ebenfalls einsilbige Form Jobs von Job. Die Forderung DIST nach overter Pluralmarkierung ist hier im Gegensatz zu Onomatopoetika (siehe oben) offensichtlich die mächtigere Beschränkung.

Bei langem Vokal scheint der e-Plural leichter zu realisieren, bei Mugdan 1977 sind die folgenden Wörter noch mit s-Plural aufgeführt, die heute aber fakultativ oder obligatorisch ePlural realisieren: Clan, Dekor, Scheich, Labor, Myom. Curme 1922: 93 führt folgende Wörter auf, die heute nur noch e-Plural haben: Turban, Kaftan, Kostüm. Offensichtlich ist der s-Plural bei kurzer geschlossener Silbe zur Wahrung der Silbengrenze besonders notwendig. Bei langem Vokal bleibt der sanfte Schnitt der Silbe (cf. Vennemann 1991) in dieser Form erhalten und ermöglicht Pluralbildungen wie Myome, Balkone, Gene, Labore, Dekore, Module, Biotope, LPGen. ${ }^{36} \mathrm{Ob}$ die Assimilierung hier schneller erfolgt, ist eine offene Frage, die der genaueren Untersuchung bedarf. In einigen Fällen wird die Assimilation durch Homonymenvermeidung verhindert, zumindest verzögert, und der s-Plural bleibt stabil: die Models wegen die Model ('Backform'), Schals wegen Schale, Loks wegen Locken, Bars wegen Bahren.

In Ostdeutschland findet man mehr native Formen: Parke (für das es eine schweizerdeutsche Entsprechung Pärke gibt), Service-Pointe, LPGen - zusammen mit dem auch im Singular angeglichenen Datsche erlaubt das die Vermutung, dass sich heutiger Sprachwandel nicht nur von Süden nach Norden vollzieht (cf Wegera 1987:247 für den Umlaut im Fnhd, Wegener 1999 zu weil-Verbzweit-Sätzen), sondern auch von Ost nach West. Die Ostdeutschen sind hier also nur scheinbar konservativer, in Wirklichkeit aber progressiver als die Wessis. Allerdings stehen sie derzeit unter starkem Anpassungsdruck an deren Normen, was sich u. a. an der Ersetzung der Modalpartikel eben durch halt und der Konjunktion denn durch weil zeigt (Dittmar 1997:295f).

Die Frage ist also nicht nur, ob Job eine Pluralform Jobe oder Jobbe ausbilden wird, sondern auch, ob es vielleicht nach dem stimmlosen Auslautkonsonanten die Form Jope oder Joppe bildet (eventuell + Umlaut wie die meisten Einsilber: Pötte, Köpfe, Zöpfe ).

Jedoch zeigt die Entwicklung von Keks, das aus Englisch Cake entlehnt wurde, dass noch eine andere Entwicklung möglich ist. Der Duden von 1915 führt den Singular Kek mit der Pluralform Keks an, der Duden von 1934 Keks mit Ø-Plural, Wahrig 1975 Keks und Kekse als konkurrierende Pluralformen, ebenso der Duden 1989, was nicht mehr aktuell sein dürfte, jedenfalls von meinen Informanten abgelehnt wird, die nur Kekse akzeptieren. Hier wird also

\footnotetext{
${ }^{36}$ Paul 1917 führt außerdem folgende Substantive an, für die heute nur noch ein e-Plural möglich ist, und die sogar umlauten: Generäle, Pläne, Chöre, Märsche, Aktionäre, Kapitäne, Kostüme, Kalküle, Pläne, Rivalen, Kuriere, Memoiren u.v.a., cf. auch Köpcke (1993: 155).
} 
ein s-Plural als Silbenrand des Singularstammes fehlinterpretiert, so dass nun ein $\varnothing$-Plural entsteht, der dann kompensatorisch durch einen e-Plural ersetzt wird. Dieselbe Entwicklung liegt bei Strapse aus engl. strap vor. Die Verwendung eines s-Plurals als Singularform dürfte die notwendige Zwischenstufe bei diesem Prozess darstellen. Sie ist bei einigen Sprechern bei folgenden Wörtern heute gegeben: Pumps, Shrimps, Chips, Slips ${ }^{37}$ Damit ist bei diesen Wörtern der Weg für die Entwicklung eines e-Plurals frei. Auf ähnliche Weise sind aus Verbableitungen folgende heute unauffällige native Pluralformen entstanden: Knickse < Knicks < Knick < knicken, Knirpse, Klopse, Schlipse < nddt Slips < Slip, Schubse < Schubs $<$ Schub, Schnäpse < schnappen. Möpse < Mops < Mop < mobben, Klöpse < kloppen, Kläpse < Klaps < Klap < klappen, Schnäpse < schnappen, Kleckse $<$ Klecks $<$ Kleck $<$ klecken.

Die genaue Entstehungszeit dieser untergegangenen s-Plurale ist noch festzustellen. Die Grammatiker des 18. Jahrhunderts von Antesperg, Aichinger, Gottsched erwähnen den sPlural noch nicht (Schmidt-Wilpert 1980), das Grimm'sche Wörterbuch gibt für diese meist niederdeutschen Formen eine verstärkende Bedeutung (der ursprünglich lautmalerischen Singularformen) an,$^{38}$ was zur Pluralbedeutung passen würde, zumal der s-Plural im Nddt häufiger ist als im Oberdt.

Ich gebe für Keks die Entwicklung von 1915 bis 1968 und die jeweils relevanten Beschränkungen hier in einem Tableau an, um nicht allzu redundant zu werden. Die Gewichtung der Beschränkungen geht aus dem jeweils siegreichen Kandidaten hervor.

\begin{tabular}{|c|c|c|c|c|c|c|c|c|c|}
\hline \multirow[t]{2}{*}{ Keks M } & \multirow[t]{2}{*}{ FUSS } & \multirow[t]{2}{*}{ FK } & \multirow[t]{2}{*}{ GK } & \multirow[t]{2}{*}{ DIST } & \multirow[t]{2}{*}{$\mathrm{NC}$} & \multicolumn{3}{|c|}{ IDENT } & \multirow[t]{2}{*}{ DEP } \\
\hline & & & & & & V & K & $\mu$ & \\
\hline Kek - Kek & $*$ & & & $*$ & & & & & \\
\hline Kek - Ke.ke & & & & & & & & $* !$ & $*$ \\
\hline$=\rightarrow$ Kek - Keks 1915 & $*$ & $*$ & $*$ & & $*$ & & & & $*$ \\
\hline$\Rightarrow$ Keks - Keks 1934 & $*$ & * & * & * & $*$ & & & & \\
\hline Keks - Kek.se 1968 & & & & & & & & $*$ & $*$ \\
\hline
\end{tabular}

Im OT-Rahmen ist erklärbar, warum zum Singularwort Kek, das 1915 im Duden belegt ist, nicht direkt ein Plural *Keke ausgebildet wurde: Der stattdessen gebildete Plural Keks erfüllt die Treuebeschränkung hinsichtlich des Silbenrands, da er die Silbengrenze nicht verschiebt. Während dann bei Fräcke, Lifte, Parke (ostdt) u. a. Formen, besonders bei Mehrsilbern wie Balkone, Generäle, Barone etc, cf. Paul 1917, das s-Flexiv durch ein e-Flexiv abgelöst wurde, ist dies bei Keks und Straps nicht möglich, da hier die Pluralform auch in Singularkontexten verwendet wird und damit Singularbedeutung angenommen hat. Das -s, das ursprünglich als Notplural gebildet wurde, werden wir nun nicht mehr los. Eine native Pluralform wird nun zusätzlich gebildet, womit ein Wort entsteht, das diachron gesehen eine Doppelpluralform aufweist: Kek-s-e. Wie die Beispiele oben zeigen, ist Kekse kein Einzelfall, sondern stellt einen Pluraltyp im Assimilationsprozess dar. Im OT-Rahmen ist auch erklärbar, warum sich

\footnotetext{
${ }^{37}$ Harnisch 1994: 111 führt einen Beleg für Slipse auf.

${ }^{38}$ Cf. DWB, Bd 11, Knick, Knack bezeichneten demnach "einen knackenden Bruch", Kleck, Klack den "Sprung im Glas", die $s$-Formen dienen zur "Verstärkung der Klangwörter" (Sp.1054).
} 
dieser Typ gegen -s durchsetzt: alle Verletzungen der Beschränkungen, die Keks bewirkt, nämlich gegen FUSS, $\mathrm{FK}^{39}$ und $\mathrm{NC}$, werden durch Kekse repariert.

Interessant ist, dass das Flexiv -se bisweilen im Spracherwerb als Pluralsuffix auftaucht, cf. Ramge 1975:73, dessen Sohn im 3. Lebensjahr mehrere Formen damit bildet: Waggonse, Männerse, Kuchense, Papisse, Fliegerse. Haspelmaths Tochter bildet im 4. Jahr Flipse (p.M.).

Eine nicht unmögliche Entwicklung gibt daher das folgende Tableau für Shrimps ${ }^{40}$ an:

\begin{tabular}{|l|l|l|l|l|l|l|l|l|l|}
\hline Shrimp M & FUSS & FK & GK & NC & DIST & \multicolumn{3}{|c|}{ IDENT } & DEP \\
\cline { 5 - 9 } & & & & & & V & K & $\mu$ & \\
\hline Shrimp & $*$ & & & & $*$ & & & & \\
\hline Shrim.pe & & & & & & & & $*$ & $*$ \\
\hline s-Shrimps & $*$ & $*$ & $*$ & $*$ & & & & & $*$ \\
\hline Shrimps = Sg? & $*$ & $*$ & $*$ & $*$ & $* !$ & & & & \\
\hline - Shrimp.se & & & & & & & & $*$ & $*$ \\
\hline
\end{tabular}

Für Job ergibt sich damit auch die Möglichkeit eines Plurals Jobse oder Jöbse!

Zum derzeit als Fremdwort gebrauchten Wort Kids kann ergänzend (und schon fast anekdotisch) hinzugefügt werden, dass das Wort Kitz ('junges Tier') aus der selben Wurzel stammt wie das englische Kid und natürlich unser Kind. Die Entwicklung der Pluralform Kitze kann unschwer nachvollzogen werden. Für Kid ergibt sich demnach Kids > ?? ?Kidde oder?Kidse wie Kitz > Kitze, was durch Homonymenvermeidung dann blockiert sein könnte.

Im OT-Rahmmen ist also präzise erklärbar, warum schließlich doch ein e-Plural ausgebildet wird.

Die Ablösung des -s durch -e stellt nicht nur eine Anpassung ans deutsche Pluralsystem, an die Beschränkung auf flexionsklassentypische Pluralformen dar, sie kann auch durch die Restriktion auf trochäische Füße erklärt werden. Sie kann schließlich viel allgemeiner nach dem universalen Silbenbaugesetz NO CODA erklärt werden: Lif.te, Kek.se, Frä.cke, Ki.os.ke enthalten erheblich bessere Silben als Lifts, Keks, Fracks und erst recht als Kiosks.

\subsubsection{Fremdwörter mit unbetonter Endsilbe}

Enthält die Endsilbe eines Fremdworts ein Schwa, so ist native Pluralbildung am leichtesten zu erreichen und folgt den FK-Beschränkungen auch bei sonst fremd klingenden Wörtern, wir finden also - $\varnothing$ bei Maskulina und Neutra und -n bei Feminina: Computer, Synthesizer, Carrier, Broker, Examen - Oasen, Phasen, Devisen. Nur selten tritt bei Nicht-Feminina -s auf, um DIST zu erfüllen: Models, ?Genres, *Nomens.

\footnotetext{
${ }^{39}$ ) Bei einem nicht umlautfähigen Vokal entfällt die Unterscheidung FK/GK.

${ }^{40}$ Für die Form Shrimpse gibt es in Potsdam einen Hörbeleg (Christina Kauschke, p.M.), Kellnerin: "Wer kriegt die Shrimpse?".
} 
Enthält die Endsilbe des Fremdworts einen Vollvokal, so ist zu unterscheiden zwischen offener und geschlossener Silbe. Bei offener Endsilbe auf unbetonten Vollvokal würde ein natives Pluralflexiv hier zu einem Hiat führen: *Oma.en, *Opa.e, *Uni.en, *PKW.e, *Sozi.en. Die entsprechenden Substantive wählen folglich zunächst das Pluralflexiv -s: Omas, Opas, Sozis. Nur bei betontem auslautendem Vokal kann im Deutschen ein silbisches Pluralflexiv appliziert und damit eine zweisilbige Pluralform gebildet werden: Schu.he, Kni.e, Frau.en, Fe.en, bei unbetontem Auslautvokal ist ein somit entstehender Hiat dagegen verboten (Eisenberg 1998). Bei auslautendem unbetontem Vollvokal kann der -s Plural also als Strategie zur Vermeidung eines Hiats erklärt werden und ist somit ein Notplural.

Als Fremdwortplural ist er aber fest etabliert, was sich daran zeigt, dass andere, völlig fremde Pluralsuffixe durch -s ersetzt werden: Themata > Themas, Motti > Mottos. Die griechischen Formen Themata, Schemata, Kommata und die italienischen Formen Celli, Motti, Konti werden also zunächst durch "eindeutschende" Formen auf -s ersetzt: Themas, Schemas, Kommas, was sich hier auch durch die Präferenz für den Trochäus erklärt.

Ist die unbetonte vollvokalische Silbe geschlossen, so gibt es verschiedene Lösungen. Wie bei betonten Silben dient auch hier der s-Plural dazu, Verschiebung der Silbengrenze zu verhindern, IDENT zu erfüllen. Das führt zu Lösungen wie Albums ${ }^{41}$, Laptops, T-Shirts / $* T$ Shirte. Lautet die Endsilbe auf -s aus, wird dagegen -e gewählt: 'Krokusse, 'Zirkusse.

Die s-Formen bilden in diesen Fällen, d.h. bei zweisilbigen trochäischen Singularstämmen, bei vokalischem und bei konsonantischem Auslaut, trochäische Füße und erfüllen die Beschränkung FUSS also besser als native Plurale, die bei offener Silbe wegen Hiatbildung völlig ausscheiden und in jedem Fall zu Daktylen führen. Jedoch sind auch diese s-Plurale keineswegs stabil, sondern werden ihrerseits abgebaut.

Bei mehrsilbigen Wörtern auf -s wird im Gegensatz zum einsilbigen Bosse in etwa der Hälfte der Fälle, cf. Harnisch 1994:106, kein e-Plural gebildet, sondern es kommt zur Stammflexion: Ritus - Riten /*Ritusse, Globus - Globen, Mythos - Mythen. Stärker noch ${ }^{42}$ gilt das für Auslaut auf -is, -um, -on, -a: Daten/*Datums, Praxen /*Praxissen, Museen, Stadien, Themen. Alle diese Formen realisieren im Unterschied zu Zirkusse einen Trochäus, so dass gesagt werden kann, dass die Stammflexion hier durch die trochäische Struktur der Pluralform begünstigt wird.

Durch die trochäische Struktur erklären sich schließlich auch die Fälle dreisilbiger Stämme, die nicht zur Stammflexion übergehen, sondern ein e-Suffix anfügen wie Pfiffikusse. Die so entstehende viersilbige Struktur wird durch einen Nebenakzent in eine zweifüßige Wortform überführt. Das selbe gilt für Fremdwörter mit betonbarer Endsilbe, die einen zweifüßigen Plural dadurch ermöglichen, dass sie auf diese Endsilbe, die im Plural zur Paenultima wird, einen Nebenakzent legen: 'Hurrikàne, 'Professòren. In beiden Fällen wird die Beschränkung FUSS optimal erfüllt, denn durch Haupt- und Nebenakzent weist die entstehende Pluralform zwei trochäische Füsse mit regelmäßig alternierender Betonung auf. ${ }^{43}$

\footnotetext{
${ }^{41}$ Im Sachs/Villatte 1900 als Variante aufgeführt.

${ }^{42}$ Nach Harnisch 1994: 106 erfolgt Stammflexion bei $66 \mathrm{M}$ auf - us zu fast 50\%, bei $78 \mathrm{~N}$ auf -um zu fast $100 \%$, bei $26 \mathrm{~N}$ auf $-a$ zu mehr als 50\%, bei $69 \mathrm{~F}$ auf - $a$ zu mehr als $67 \%$ und bei $9 \mathrm{~F}$ auf -is zu $100 \%$.

${ }^{43}$ Der Nebenakzent führt jedoch zu einer Spaltung des Worts in zwei Füße: 'Bräutigàme. Da dies Wort nicht mehr als Kompositum verstanden wird, kann die zweifüßige Struktur als unangemessen gelten und von Sprechern gemieden werden. Sie kann nur durch ein nichtsilbisches Pluralflexiv verhindert werden, -n oder -s, hier nur -s. Damit liegt hier einer der wenigen Fälle vor, in denen ein nativer Plural durch ein -s fakultativ ersetzt wird und somit eine -s-Variante zum e-Plural entsteht: Bräutigams. Ebenso: Karussells.
} 
Die Abhängigkeit der Pluralbildung von den Akzentverhältnissen zeigt sich, wenn wir Wörter verschiedener Länge und Akzentstruktur vergleichen. Die Silbenzahl spielt keine Rolle, ebenso wenig Auslaut auf Vokal oder Konsonant, die Assimilierung ist allein von der Lage des Akzents abhängig.

Wird das Wort auf der letzten Silbe betont, tritt ein silbisches Pluralsuffix hinzu: 'Busse, Bal'kone, Ele'fanten, Bar'baren, 'Skier, Theo'rien, Karus'selle.

Wird das Wort auf der Paenultima betont, tritt Stammflexion auf, die letzte Silbe wird gekappt, durch das Pluralsuffix ersetzt: 'Globen, 'Riten, 'Stadien, Or'gasmen, Pleo'nasmen, 'Villen, Ve'randen, Pizze'rien, Cafete'rien,

Ist die letzte Silbe nicht betont, aber betonbar, so wird ein Trochäus durch Akzentverlagerung gewonnen: Dok'toren, Profes'soren.

Problematisch sind die Fälle, wo der Akzent auf der Antepaenultima liegt wie in 'Kamera. Wenn durch Stammflexion Haplologie entstünde, bleibt der s-Plural erhalten: 'Kameras $/ *$ Kameren $^{44}$. Im andern Fall wird durch eine Schwa-Silbe ein viersilbiges Wort gebildet und dieses durch einen Nebenakzent in zwei Trochäen gegliedert: 'Famulùsse, 'Hurrikàne (siehe oben). Ziel des Prozesses ist die kanonische Struktur des trochäischen Fußes mit reduzierter Endsilbe, die fast immer erreicht wird.

Wörter wie Laptop, Modem stellen insofern ein Problem dar, als sie kein Suffix haben, das gekappt werden kann. Ob sie den Assimilierungsprozess wie Doktor durch Akzentverlagerung bewältigen und Formen wie Biotope, Ödeme ausbilden, ist offen. Vermutlich ist -s hier deshalb ziemlich stabil.

Stammflexion setzt voraus, dass der Input in zwei Morpheme gegliedert wird, Stamm und Endung, die durch die Pluralendung -en ersetzt wird, um die Pluralbildung auf -en (wie italienisch -e, lateinisch -ae) zu ermöglichen.

Das Auftreten von -en ist mit anderen Worten abhängig davon, ob die Endsilbe des Fremdworts in der Quellsprache den Status eines Stammbildungssuffixes hat bzw. als solches von deutschen Sprechern auch tatsächlich so interpretiert wird. Ist dies der Fall, ${ }^{45}$ so ist Übergang zur Stammflexion möglich, sonst nicht: Albums > Alben, Geishas > *Geishen, Praxis > Praxen, Villas >Villen, Zebras > ZZebren, Kontos > Konten, Eskimos > *Eskimen. Stammflexion ist prinzipiell möglich, sofern das Wort aus einer klassischen, slawischen oder romanischen Sprache entlehnt wurde, tritt folglich ein bei -a, -is, -o, -on, -us, -um, aber nicht bei -u und -i, und zwar unabhängig von der Länge des Wortes: Gnus, Iglus, Zulus, Kakadus, Kängurus, Muttis, Ossis, Azubis.

Während bei Pluralformen wie Rosen nicht entscheidbar ist, ob der Sprecher Ros-en bzw. Rose- $n$ bildet, also ein Bewusstsein von der zweimorphemischen Struktur hat, die sich definitiv erst beim Diminutivum Röschen zeigt, setzt die Pluralform Villen ein solches Morphembewusstsein voraus. Auch dies kann bei Neologismen natürlich noch nicht vorliegen. Es kann allenfalls aus der Kenntnis der Quellsprache (Latein, Italienisch, Russisch)

\footnotetext{
${ }^{4} *$ Kameren würde durch Schwa-Tilgung zu Kammern - und damit einen Assimilierungsprozeß des schon einmal entlehnten Wortes wiederholen, ist hier also auch durch -HOM blockiert.

${ }^{45}$ Dass dies bei folgenden Nomen der Fall ist, zeigt die Bereitschaft meiner Studenten, Diminutive wie Villchen, Pizzchen, Dätschchen zu bilden. Die Pluralbildung Spaghettis spricht bei diesem Wort allerdings gegen ein Morphembewußtsein deutscher Sprecher. Für Firma liegt die Verbableitung firmieren vor.
} 
bezogen werden. Harnisch 1994 zeigt, dass tatsächlich auf -a, -um oder -us auslautende Wörter sehr viel häufiger und leichter zur Stammflexion übergehen, wenn sie aus dem Lateinischen oder Italienischen stammen, als wenn sie aus einer exotischen Sprache stammen wie Zebra, Geisha. Inwiefern die Verfügbarkeit von Wissen über Morphemgrenzen der Quellsprache bei nachlassenden Lateinkenntnissen die Assimilierung von Fremdwörtern beeinflusst, ist eine offene Frage.

Für -i und -o ist ein weiteres Kriterium relevant, und zwar der Status des auslautenden Vokals, d.h. ob dieser ein Ableitungssuffix ist oder zum Stamm des ursprünglichen Wortes gehört, das nun als Kurzwort vorliegt. Ableitungssuffixe liegen vor in: Realo, Kino ${ }^{46}$, Ossi, Mutti, Studi, Teil des ursprünlichen Wortes ist der auslautende Vokal dagegen in: Chauvi, Nazi, Sozi, Taxi $^{47}$, Touri,Uni. Ein Ableitungssuffix darf nicht gekappt werden (cf. Harnisch 1994:109), bei Mutti, Wessi etc ist daher kein Übergang zu -en möglich. Bei Kurzwörtern ist er dagegen möglich und taucht auch bisweilen auf: Taxis > Taxen, Sozis > Sozen ${ }^{48}$.

Die Stammflexion auf -en ist bei Klasse 3 genuswidrig, verletzt FK/GK. Indem sie auch bei unbelebten Substantiven auftritt, führt sie zur Stabilisierung der eigentlich markierten Klasse 3b. Sie kann bei nicht auf -s auslautenden Stämmen (Krokusse vs Riten) auch nicht nur durch die trochäische Zielstruktur erklärt werden, denn Villas, Kontos, Albums sind auch Trochäen. Es muss also noch eine stärkere Beschränkung geben, die für den Abbau des s-Plurals sorgt. Wir müssen also genauere Kriterien gewinnen, die erklären und möglichst vorhersagen, wann -s, wann -en auftritt bzw. wann es bei -s, bleibt, wann ein Übergang zu -en erfolgt.

Die Assimilierung der Fremdwörter in der Pluralbildung stellt häufig einen dreistufigen Prozess dar: Themata > Themas > Themen, der belegt, dass der s-Plural nur eine Übergangserscheinung ist. Wir müssen also nicht nur erklären, warum der s-Plural gebildet, sondern auch, warum er wieder abgebaut wird. Dies soll hier am Beispiel Pizza mithilfe der Beschränkungen der OT erfolgen.

Wahrig 1968 gibt für dieses Item, das erst kurz zuvor entlehnt worden ist, die italienische Pluralform Pizze an und vermerkt: "eindeutschend auch Pizzas". Curme 1922: 93 gibt noch für Villa die Pluralform Villas an. Der endgültige Schritt zur Assimilation ist dann mit Themen, Schemen, Pizzen und obligatorisch Villen, Firmen (Wahrig 1968 ) erreicht. ${ }^{49}$ Angesichts dieser dreistufigen Entwicklung stellt sich die Frage, warum das Deutsche von italienisch Ville, Pizze nicht direkt zu Villen, Pizzen überging, sondern die Übergangsformen Villas, Pizzas ausbildete.

\footnotetext{
${ }^{46}$ Kino $<$ Kinematograph.

${ }^{47}$ Taxi < französisch Taximètre.

${ }^{48}$ Derzeit ist ein Schwanken zwischen Sozis und Sozen zu beobachten, wobei das Letztere (laut PNN vom 17.11.1999, TAZ vom 3.12.1999) vor allem in CDU-Kreisen, aber auch von den Grünen gebraucht wird und leicht pejorative Bedeutung hat.

${ }^{49}$ Diese Entwicklung kann blockiert sein, wenn es zu Homonymien kommen würde, etwa bei Komma -

*Kommen durch den gleichlautenden Infinitiv.
} 


\begin{tabular}{|l|l|l|l|l|l|l|l|l|l|l|l|}
\hline Pizza F & FUSS & FK & GK & NC & PAR & \multicolumn{2}{|l|}{ DIST } & \multicolumn{2}{|l|}{ IDENT } & DEP & MAX \\
\hline Pizza & & & & & & & V & K & $\mu$ & & \\
\hline Pizze 1960 & & $*$ & $*$ & & & & & & $*$ & $*$ & $*$ \\
\hline =Pizzas 1970 & & $*$ & $*$ & $*$ & & & & & & $*$ & \\
\hline Pizzaen & $* !$ & & & & & & & & & $*$ & \\
\hline Pizzata & $*$ & $*$ & $*$ & & $* !$ & & & & & $*$ & \\
\hline - Pizzen 1999 & & & & & & & & & $*$ & $*$ & $*$ \\
\hline
\end{tabular}

Pizzen verletzt die Treuebeschränkung IDENT $\mu$, die hier nicht nur in Verschiebung der Silbengrenze, sondern sogar im Kappen des Auslautvokals besteht, also MAX, die beide von Pizzas bewahrt bleiben. Das macht die s-Form zum geeigneteren Übergangsplural für ein neu entlehntes Fremdwort, das ja erst noch bekannt werden muss. Sie ist dagegen nicht FKspezifisch, verletzt FK, außerdem NC, Beschränkungen, die von Pizzen erfüllt werden. Beide Formen erfüllen jedoch FUSS, Pizzas allerdings nur unvollkommen.

In Villas - Villen liegen zwar jeweils zwei geschlossene Endsilben, aber keine gleichwertigen Silben vor. Der Übergang von as > en erklärt sich durch die Präferenz für Schwa-Silben, d.h. generell durch die Forderung nach einer unbetonten Endsilbe in Flexionsformen. Diese Forderung wird von Villen mit der unbetonbaren Reduktionssilbe besser erfüllt als von Villas. Der Gegensatz zwischen der betonten Anfangs- und der unbetonten Endsilbe innerhalb des trochäischen Fußes wird durch die Schwa-Silbe besser realisiert als durch die Silbe mit Vollvokal. Es ist daher nur eine Frage der Zeit, bis wir neben Villen, Diven, Firmen auch Formen wie Pizzen, Pizzerien etc. haben. Denn es gibt keinen Grund für die Annahme, dass die Sprachentwicklung des Deutschen gerade auf der im Jahre 1999 erreichten Stufe stehen bleibt.

S-Plurale von Maskulina und Neutra (Saldos, Kontos, Albums) verletzen ebenso FK/GK, jedoch kann dies nicht das treibende Motiv für den Übergang zur Stammflexion sein, denn diese Beschränkung wird ja durch die en-Plurale ebenso verletzt: Salden,Konten, Alben. Das Motiv muss daher in der Verletzung der silbenphonologischen und prosodischen Beschränkungen durch die s-Plurale liegen.

Die s-Plurale verletzen NC stärker als die Reduktionssilben auf -n, weil sie nicht sonorant sind. Selbst wenn sie keine Konsonantencluster bilden wie bei Lifts, Kiosks, sondern auf Vollvokal folgen, stellen sie hochgradig markierte Silben dar. Sie sind die einzigen Silben des Deutschen, die nicht mit anderen Silben reimen, was daran liegt, dass ihr Vokal auch in der geschlossenen Silbe gespannt bleibt, man vergleiche die beiden folgenden Reihen:

Annas, Cafés, Amis, Kontos, Uhus, Atlas, Annes, Basis, Kosmos, Kultus.

Die Endsilbenvokale der oberen Reihe sind gespannt, obwohl die Silben geschlossen und kurz sind, die der unteren sind normgerecht ungespannt. Bei hoher Frequenz müssten die Vokale der s-Pluralsilben entspannt werden, denn für unakzentuierte Silben ist scharfer Schnitt das 
Normale (Vennemann 1991:95). Der Übergang zum en-Plural kann hier aber nicht durch Abschwächung und Entspannung des Vollvokals erklärt werden, was nach meiner Beobachtung nicht auftritt ${ }^{50}$ und außerdem den Übergang von -s bzw. -ms zu -n (Albums) nicht erklärt. Der Übergang erfolgt vielmehr abrupt, was voraussetzt, dass die Wörter einen Bekanntheitsgrad erreicht haben, der Stammflexion mit Verletzung von IDENT $\mu$ erlaubt, und der ein Morphembewusstsein für die Singularsuffixe -a, -is, -on, -o, -um, -us bei den Sprechern voraussetzt (siehe oben).

Für Fremdwörter gelten demnach folgende Hierarchien der Beschränkungen :

Lifts: IDENT $\mu$, DIST > FK, FUSS, NC, DEP

Lifte: FUSS, FK, NC, DIST >> IDENT $\mu$, DEP

Pizzas: IDENT, DIST, MAX, FUSS >> FK, NC, DEP

Pizzen: FUSS, FK, NC, DIST > IDENT/ $\mu$, DEP, MAX

Kontos: IDENT, DIST, MAX, FUSS >> FK, NC, DEP

Konten: FUSS, NC, DIST >> FK, IDENT/ $\mu$, DEP, MAX

Die s-Plurale der Fremdwörter weisen also im Wesentlichen die selbe Beschränkungshierarchie auf wie Onomatopoetika und Familiennamen, siehe oben zu Schmids, die (vorerst) endgültigen schwahaltigen Formen dagegen i.w. diejenige, die für native Wörter wie Vögel und Banken festgestellt wurde, siehe oben, mit der Ausnahme von FK-Verletzung durch Nicht-Feminina.

Denn da -en das einzige Pluralsuffix für Stammflexion ist, tritt es bei Substantiven aller drei Genera auf: Firmen, Mythen, Konten, und ersetzt die teilweise genustypischen Singularendungen -a, -is, -on, -os, -um, -us: Villen, Dramen, Praxen, Stadien, Mythen, Gymnasien, Gallizismen. Insofern liegt mit -en ein zweites Pluralflexiv zur Eindeutschung fremder Stämme vor, eines, das den nativen Suffixen sehr viel näher steht als -s, ein Notplural 2. Stufe gewissermaßen. Die Präferenz für -en dürfte an dessen absolut höchster Frequenz im Gesamtwortschatz liegen (die u. a. dadurch natürlich auch bewirkt wird), nach Pavlov 1995:45ff erreicht -(e)n 49,2 \% der Types, das ist fast die Hälfte aller deutschen Pluralformen, und 43,2 \% der Tokens. Diese unter den Pluralsuffixen mit Abstand höchsten Werte erklären, warum der (e)n-Plural beim Spracherwerb am häufigsten übergeneralisiert wird (s.u. in 3.2) und es besonders hier zu Fehlern wie viele Kuchen - ein Kuch kommt (s. Wegener 1995a:203), die zeigen, dass -en auch bei einmorphemigen Wörtern manchmal als Pluralsuffix fehlklassifiziert wird.

\subsection{Plural und Sprachentwicklung}

Der Übergang von -s zu einem der nativen Plurale -e und -en bewirkt keinen Sprachwandel wie den von der OT angenommenen. Nach Archangeli 1997:31 impliziert Sprachwandel eine veränderte Gewichtung der Beschränkungen, was voraussetzt, dass für eine neue Generation eine der bisherigen Beschränkungen nicht mehr robust genug ist. Auf diese Weise kann die Entstehung des er-Plurals im Fnhd erklärt werden, für den durch Wegfall der mhd Stammbildungssuffixe und die oberdt e-Apokope ein Bedarf bestand. Das nur temporäre Auftreten und der Abbau des s-Plurals zeigen dagegen gerade an, wie stabil die

\footnotetext{
${ }^{50}$ Die parallele Eindeutschung der Singularform ist tatsächlich eingetreten bei Datscha > Datsche, ein Beleg für den von mir angenommenen Vorsprung ostdeutscher Sprecher, ist aber offensichtlich keine Bedingung: Drama, Villa, Thema, Primadonna etc., heute alle mit en-Plural.
} 
Beschränkungen sind, die zu den nativen Pluralformen führen, insbesondere FUSS und NC, nicht immer FK, wie der genusunabhängige Stammflexionsplural auf -en zeigt.

Die Präferenz für dieses -en könnte durch ein Uniformitätsprinzip erklärt werden, das allerdings FK-widrig und fürs Deutsche daher wenig sinnvoll wäre. Sollte das Deutsche irgendwann aber doch einen Einheitsplural entwickeln, so hat -(e)n sehr viel bessere Chancen als -s. Mit der Genusunabhängigkeit teilt -en als Stammflexionsplural noch die andere Eigenschaft mit -s, dass es bei nichtnativen Wörtern auftritt, die von den Pluralregeln nicht erfasst werden. Somit hätten wir im Deutschen zwei Defaultplurale - was der Definition des Defaultplurals natürlich widerspräche und damit Zweifel aufkommen lässt, ob es im Deutschen überhaupt einen Defaultplural gibt, cf. hierzu 3.

Man mag sich fragen, ob der Übergang zur Stammflexion natürlichen Sprachwandel darstellt oder nicht vielmehr den regulierenden Eingriff des gebildeten Sprechers, d.h. der Schule zeigt. Tatsächlich werden die meisten dieser Pluralformen erst in der Schule gelernt, weil sie nicht zum Alltagswortschatz gehören. 1. ist das aber kein prinzipieller Unterschied, auch das Vorbild des gebildeten Sprechers kann einer der Faktoren natürlichen Sprachwandels sein. 2. würden sich solche Formen nicht durchsetzen, wenn sie unnatürlich wären. 3. erfüllen enPluralformen die meisten der für die deutsche Pluralbildung relevanten Beschränkungen, insbesondere FUSS sowie das universale Constraint NC, eben weit besser als die sPluralformen, was sie hinreichend motiviert. 4. zeigt sich, dass auch hier natürlich die Frequenz eine entscheidende Rolle spielt: In Fachsprachen, wo bestimmte Items hochfrequent sind, erfolgt der Übergang früher, wie Hibisken, Reseden in der Fachsprache der Gärtner (cf. Harnisch 1994:105), Konten, Salden, Disagien in der Fachsprache der Banker zeigt. ${ }^{51} \mathrm{Ob}$ diese Formen in die Alltagssprache übergehen, ist natürlich eine offene Frage. Der Notplural zweiter Stufe dürfte aber, da er wesentlich weniger Beschränkungen verletzt als der s-Plural, stabiler sein als jener.

Wenn der s-Plural im heutigen Deutsch nicht der Regelplural, sondern nur ein Notplural ist, so stellt sich angesichts der zahlreichen Entlehnungen aus dem Englischen doch die Frage, ob er genau wie dort zum Regelplural werden kann. Wie gerade die Geschichte seines Vorgängers, des er-Plurals, zeigt, kann ein Außenseiter sehr wohl zum "Renner", eventuell auch zum Regelfall werden, wie die skandinavischen Sprachen zeigen, cf. Braunmüller 1991. Da der s-Plural im Gegensatz zu -er aber NC und FK verletzt, bei endbetonten Wörtern außerdem nicht zum Trochäus führt, also FUSS verletzt, ist eine solche Entwicklung im heutigen Deutsch äußerst unwahrscheinlich. Wie gezeigt, wird NC-Verletzung nur dann toleriert, wenn dadurch Haplologie vermieden oder FK realisiert wird. Der s-Plural könnte also allenfalls bei Wörtern, die auf Vollvokal auslauten, toleriert werden: Kontos, Pizzas. Aber selbst hier wird er abgebaut, weil mit -en ein besserer Trochäus gebildet werden kann, der den Unterschied zwischen Haupt- und Nebensilbe deutlicher anzeigt, weil auch die auf einfaches -s auslautenden Silben mit Vollvokal hochgradig markiert sind und weil -en zumindest für Feminina und schwache Maskulina FK-spezifisch ist, -s aber nicht.

Die Untersuchung der heutigen Pluralformen und insbesondere der Fremdwörter ergibt, dass wir im Deutschen drei produktive Pluralsuffixe haben: -e, -en und -s. Das erste dient der Pluralisierung von starken Maskulina und Neutra, das zweite der von schwachen Maskulina und Feminina und zur Stammflexion bei Fremdwörtern aller drei Genera, -s dient zur Pluralisierung von markierten Substantiven wie Onomatopoetika, (Familien)Namen und neu

\footnotetext{
${ }^{51}$ In ähnlicher Weise führt hohe Frequenz in der Fachsprache zum umgelauteten Sortenplural von Stoffnamen: Sände, Stähle.
} 
entlehnten Fremdwörtern, d.h. von Wörtern, für die die Treuebeschränkungen höher gewichtet sind als die anderen Beschränkungen, so dass diese, v.a. FUSS und NC sowie FK verletzt werden dürfen. Das Auftreten des s-Plurals lässt sich in allen Fällen durch die phonologische Struktur des Stamms und/oder die kategoriale Eigenschaft "gehört zur Klasse der Onomatopoetika, Familiennamen, Fremdwort etc" erklären; der Abbau durch die im Zuge der Assimilierung wirksamer werdenden Beschränkungen, die für den nativen Wortschatz gelten und die nun auch, wenn die Fremdwörter aufhören, Fremdwörter zu sein, für diese gelten. Das sind v.a. die Beschränkungen auf einen Trochäus sowie auf Flexionsklassen. Die Veränderungen der Pluralformen zeigen also keinen generellen Sprachwandel an, sondern beweisen ganz im Gegenteil die Stärke der prosodischen Beschränkungen und der die nativen Pluralformen bewirkenden Regeln.

Zwischen -s und -e bzw -en besteht ein komplementäres Verhältnis. Das zeigen die Varianten unter den Pluralformen, die für Familiennamen vs Produktnamen bzw Appellativa bestehen, ebenso wie die, die zum selben (fremden) Stamm zu unterschiedlichen Zeitpunkten seiner Anpassung ans deutsche Flexionssystem bestehen. Dass es hier zu fließenden Übergängen und zu Schwankungen kommt und dass das Auftreten des Notplurals oder der nativen Form nicht nach starren Regeln vorhersagbar ist, ist eine Folge des Assimilierungsprozesses. Auch für das Auftreten der markierten Pluralformen, insbesondere der umgelauteten, lassen sich eher Tendenzen denn Regeln angeben, Tendenzen aber, die zeigen, dass diese Formen der Genusdifferenzierung dienen und/oder durch besonders hohe Distinktivität für den hochfrequenten Nahbereichwortsschatz motiviert sind, weshalb sie auch für den Spracherwerb und die Sprachverarbeitung kein Problem darstellen. Sie sind also keine Ausnahmen, die den Sprachgebrauch belasten.

Gegen Janda 1990, der meint: "-s as the dominant plural-ending of NHG seems extremely likely" (zit. nach Marcus et al. 1995:242, ähnlich Wunderlich 1999), möchte ich die These aufstellen: Der s-Plural kann aus prosodischen Gründen in der akzentzählenden Sprache Deutsch nicht zum Regelplural werden. Diesen Status könnte er nur dann gewinnen, wenn das Deutsche 1. seinen Charakter als akzentzählende Sprache mit der Präferenz für den Trochäus, 2. seine Genus- und Flexionsklassen aufgeben würde. Letzteres würde eine Änderung eines der nach Wurzel 1984:82 angesetzten Hauptparameter der Substantivmorphologie bedeuten, ersteres die Änderung eines der wichtigsten Parameter der Wortprosodie des Deutschen. Für beides gibt es innerhalb der Phonologie und Morphologie des heutigen Deutsch aber keinerlei Anhaltspunkte. ${ }^{52}$

\footnotetext{
${ }^{52}$ Für manche Beobachter der deutschen Sprache stellen die derzeitigen massiven Entlehnungen aus dem Englischen eine Gefahr dar. Es sei daran erinnert, was Voltaire 1750 aus Potsdam schrieb: "Ich befinde mich hier in Frankreich. Man spricht nur unsere Sprache, das Deutsche ist nur für die Soldaten und die Pferde." (zit. nach von Polenz 1978:108).
} 


\section{Plural und kognitive Linguistik}

\subsection{Konnektionistische und symbolistische Modelle}

Die deutschen Pluralsuffixe erfüllen also mehr Aufgaben als nur die Anzeige von Mehrzahligkeit, sie tragen auch zur Strukturierung des Lexikons bei: Sie zeigen Genus- und Flexionsklassen an und sie kennzeichnen phonologisch und/oder kategoriell markierte Substantive als solche. Deshalb ist das Pluralsystem komplexer als im Englischen oder Spanischen, zugleich aber nach bewundernswert klaren und funktionalen Prinzipien geordnet.

Der deutsche Plural mit drei produktiven Pluralsuffixen und neun Pluralklassen stellt für die Kognitive Linguistik eine Herausforderung dar und spielt deshalb in der gegenwärtigen Debatte zwischen konnektionistischen und symbolistischen Modellen eine Rolle.

Konnektionistische Modelle, siehe Elman et al. 1996, gehen davon aus, dass Flexionssysteme und ihr Erwerb bzw. ihre Verarbeitung in Form von assoziativen Netzwerken dargestellt werden können, bei denen traditionelle linguistische Regeln keine Rolle spielen. Die Netzwerke der Computersimulationen sind frequenzbasiert, besonders häufige Assoziationen zwischen Input und Output eines morphologischen Prozesses führen zu produktiven Verknüpfungen mit "Übergeneralisierungen", die in Form und Zahl tatsächlich den beim Spracherwerb beobachteten ähneln. Der Flexionserwerb ist somit in einem neuronalen Netzwerk modellierbar, wobei ein einheitlicher Lern- und Verarbeitungsmechanismus sowohl für reguläre als auch für irreguläre Formen angenommen wird. Regularität ist in diesen Modellen ein Effekt der Frequenz.

Duale Routen-Modelle nehmen dagegen an, dass ein Teil der Formen (die sog. Ausnahmen) gespeichert und dann beim Gebrauch abgerufen wird, ein anderer nach produktiven symbolischen Regeln gebildet wird. Experimentelle Untersuchungen, die unterschiedliche Reaktionszeiten für reguläre vs. irreguläre Formen und somit Frequenzeffekte der Pluralformen zeigen, werden als Beweis für das Duale Routen-Modell angeführt. Für Formen, die nicht nach einer oder mehreren produktiven Regeln gebildet sind und auch nicht als irregulär gespeichert gelten, wird ein Defaultplural angenommen (Kiparsky 1982), ein Defaultplural also, der in etwa unserer Definition von Notplural entspricht.

\subsection{Der s-Plural = the exception that proves the rule?}

Aus zunächst nur schwer verständlichen Gründen nehmen Wiese 1988, 1996, Clahsen et al. 1992, 1995, 1996, 1997, Marcus et al.1995, Niedeggen-Bartke 1999 nicht nur an, der s-Plural sei der Defaultplural des Deutschen, der dann auftrete, wenn keine andere Regel greife bzw kein Lexikoneintrag für einen irregulären Plural vorliege, sondern vertreten die sehr viel weitergehende These, der s-Plural sei der einzige reguläre Plural des Deutschen. Die Autoren setzen also Defaultplural = regulärer Plural, noch dazu mit Ausschließlichkeitsanspruch. Da dies offensichtlich im Gegensatz zu seiner Frequenz steht, wird diese Annahme damit begründet, dass dieser Plural weniger restringiert sei als die anderen Pluralflexive. Er sei

- bei allen drei Genera möglich,

- phonologisch nicht restringiert,

- es gebe Übergänge von -e zu -s, aber nur tentativ von -s zu -e,

- bei Fremdwörtern und Neologismen trete nur der s-Plural auf,

- bei schwankenden Pluralformen laute stets eine der Formen auf -s,

- er komme im Spracherwerb bei Übergeneralisierungen besonders häufig vor, 
- er trete bei Kunstworttests besonders häufig auf,

- er trete innerhalb von Komposita nicht auf.

Es bedarf kaum der Erwähnung, dass die Vertreter dieser These von der Annahme eines arbiträren, ja chaotischen Pluralsystems des Deutschen ausgehen - diese Annahme ist ja geradezu Voraussetzung für ihre These. Die Arbitraritätsthese wird begründet mit Behauptungen wie, es gebe eine große Zahl von Pluralflexiven, von denen keines statistisch dominant sei (siehe dagegen die Tabellen oben), ihre Verteilung sei arbiträr - Genus und Flexionsklassen werden von den Autoren überhaupt nicht berücksichtigt, nicht einmal der zu 100 \% regelmäßige Plural der schwachen Maskulina! Zu den anderen Punkten ist zu sagen:

1. Sämtliche Pluralflexive außer -er treten (in sehr unerschiedlicher Gewichtung) bei allen Genusklassen auf, dies ist also keine Besonderheit des s-Plurals.

2. Auch der s-Plural ist phonologisch restringiert: So wenig ein schwahaltiges Pluralflexiv auf eine Schwa-Silbe folgen kann, so wenig kann der s-Plural auf ein auslautendes -s oder -z folgen, -s und Schwa-Pluralformen sind also komplementär verteilt (cf. v.a. 2.3.1, 2.4).

3. Ein Blick in eine historische Grammatik oder auch nur in ein etwas älteres Wörterbuch zeigt, dass es kaum Übergänge von -(e) zu -s, aber zahlreiche von -s zu -(e) bzw. -(e)n gibt. Gerade bei der Assimilierung von Fremdwörtern sind -s und die nativen Formen komplementär verteilt, beide folgen bestimmten, aber unterschiedlichen Restriktionen. Schwankungen schließlich sind bei komplexen Systemen natürlich.

4. Bei Schwankungen tritt in süddeutschen Varianten neben -(e) eher der n- oder der erPlural auf (siehe oben). Die Autoren argumentieren einseitig aus norddeutscher Sicht.

5. Bei Neologismen, Eigennamen und Fremdwörtern tritt nicht generell der -s Plural auf (Gangster, Bosse), aber er ist eindeutig präferiert. Es konnte gezeigt werden, dass dies gerade darauf beruht, dass 1. diese Wörter noch neu sind und somit der generellen Akzeptanz bedürfen, oder dass sie phonologisch hochgradig markiert sind, weswegen Treuebeschränkungen hier ähnlich wie bei Onomatopoetika einen besonders hohen Rang einnehmen, und dass 2. der s-Plural für diese Wörter besonders geeignet ist, weil er genau diese Treuebeschränkungen weniger oder gar nicht verletzt.

6. Nach den Spracherwerbsdaten von Clahsen u. a. 1992 wird der s-Plural tatsächlich besonders häufig übergeneralisiert. Nach Untersuchungen von Mugdan 1977, SchanerWolles 1989 und Park 1978, Gawlitzek-Maiwald 1994 und meinen eigenen Untersuchungen (Wegener 1992, 1994, 1995 a) gilt dies so nicht, cf. auch den Überblick in Mills 1985. Schaner-Wolles und Park finden mehr n-Übergeneralisierungen, ${ }^{53}$ nach meinen Daten zum kindlichen DaZ-Erwerb gilt folgende Hierarchie der übergeneralisierten Pluralflexive (Wegener 1995a:202):

$-(e) n>-e>-s>U L>-e r$.

Der s-Plural bereitet den Kindern sogar besondere Schwierigkeiten (cf. ebenso SchanerWolles 1989): Kinder (und Ausländer), die natürlich die Phonologie des Deutschen noch

\footnotetext{
${ }^{53}$ Das Übergewicht des n-Plurals in den Wiener und Berner Daten, das des s-Plurals in den Düsseldorfer Daten könnte m. E. auf regionaler Variation beruhen, die den Input der Kinder beeinflußt. In Wien aufwachsende Kinder hören mehr n-Plurale als solche in Nordwestdeutschland, allerdings hören auch sie Fremdwörter und Neologismen mit dem s-Plural.
} 
nicht beherrschen, können nicht erkennen, dass T-Shirt, Cola untypisch sind und bilden für sie die Pluralformen *T-Shirte, *Colen. Insgesamt ist eher die geringe Zahl von Übergeneralisierungen in den Spontandaten bemerkenswert: Nach Clahsen et al. 1995:126 sind es im L1-Erwerb zwischen $3 \%$ und $10 \%$, nach meinen Daten, cf. Wegener 1992:56, sind es bei den russisch- und polnischsprachigen Aussiedlerkindern durchschnittlich 5,4 $\%$, bei den türkischen Kindern durchschnittlich 9,1\%.

7. Zu den Kunstworttest ist zunächst zu sagen, dass Kunstwörter eine Art von Neologismen darstellen, so dass eine Präferenz für den s-Plural bei den Probanden zu erwarten ist. Umso erstaunlicher ist die Tatsache, dass bei diesen Tests, cf. Mugdan 1977, Köpcke 1987, Wegener 1995:44,

- der s-Plural keine besonders hohen Werte aufweist, auch bei den Items auf Vollvokal wie Kafti, Ziro nicht generell gilt,

- dass vielmehr der genusspezifische Regelplural im Allgemeinen eindeutig präferiert wird: -(e)n für Feminina, -(e) für Maskulina etc., -er erringt besonders hohe Werte bei den Neutra.

Die Testergebnisse zeigen also ein Flexionsklassenbewusstsein der Probanden, womit die Annahme genus- bzw. flexionsklassenspezifischer Pluralbildung bestätigt wird.

$\mathrm{Zu}$ bedenken ist, dass diese Tests nicht zur Überprüfung der $\mathrm{s}=$ Default-These konzipiert wurden, sondern zur Überprüfung der psychologischen Realität der angenommenen Pluralregeln bzw. -schemata. Für die Frage, ob -s der Defaultwert des Deutschen ist, sind die Items nicht distinktiv: Sie müssten dann -s ebenso oft zulassen wie ausschließen. Wo letzteres der Fall ist, so wird, wie Mugdans Einzelauswertung zeigt, auch kein s-Plural gebildet (cf. Mugdan 1977:154 zu den Items Broos, Floos, Rondatsch).

Keiner der Tests, die von Clahsen, Marcus, Wiese u.a. zum Nachweis des Defaultstatus für den s-Plural durchgeführt wurden, bringt überzeugende Ergebnisse dafür, dass der s-Plural der einzig reguläre Plural des Deutschen ist.

Wenn Probanden den s-Plural bei Familiennamen eher akzeptieren als bei Appellativa (Marcus et al. 1995), so zeigt das nur, dass sie die Regel für die Pluralisierung von Familiennamen beherrschen, es sagt nichts über den Status der anderen Pluralflexive aus. Wenn Probanden auf irreguläre n-Pluralformen wie Muskeln anders reagieren als auf s-Plurale (Weyerts et al. 1997), so beweist das nicht, dass dies der einzig reguläre ist, und ebensowenig, dass alle n-Plurale irregulär sind.

Berücksichtigt man auch den n-Plural bei Feminina, wie es Penke und Krause 1999:313 in einer Studie bei Aphatikern tun, so zeigt sich, wie nicht anders zu erwarten, dass dieser regulär ist. Das ist zwar ein wenig überraschendes Ergebnis, interessant ist aber, dass der feminine en-Plural von aphatischen Störungen weniger betroffen ist als die selbe Form bei starken Maskulina.

Wenn sich schließlich Frequenzeffekte beim er-Plural im Unterschied zum s-Plural zeigen (Clahsen et al. 1996), so ist das ein wenig überraschendes Ergebnis angesicht der aus dem Spracherwerb seit langem bekannten Tatsache, dass der er-Plural lexikalistisch gelernt wird, cf.2.3.2. Auch dies sagt nichts über den Status der anderen Pluralsuffixe aus. Konkurrenten des s-Plurals sind -e und -en, nicht -er. 


\subsection{Das s-Suffix in Komposita}

Am interessantesten sind die Behauptungen zum s-Suffix in Komposita, auf die ich hier näher eingehen will. Dabei muss zwischen Fugen-s oder Genitiv-s und Plural-s unterschieden werden, denn nur für das letztere wird behauptet, es trete innerhalb von Komposita nicht auf. Dafür werden die ungrammatischen Beispiele *Autosbahn, *Sozistreffen angeführt. Diese Behauptung wird durch folgende Beispiele widerlegt:

Kuckucksinsel $^{54}$, Sheriffsfahndung ${ }^{55}$, Clownsgewerkschaft, Shrimpscocktail, Chipstüte, Pumpsverkauf, Ohrclipsverkäufer.

Bei einem Teil dieser Wörter ist die Pluralform häufiger als der Singular und erklärt ihr Auftreten in einfachen Komposita, aber da die Informanten ${ }^{56}$ gleichzeitig in Singular fordernden Kontexten ("der eine....") die Formen Shrimp, Chip, Pump, Clip benutzen, und da eine Genitiv Singular-Interpretation ausscheidet, ist gesichert, dass es sich hier um Pluralformen handelt. Das widerlegt die Annahme, der s-Plural trete nicht in Komposita auf, weil er der einzig reguläre Plural des Deutschen sei, und schwächt die viel weitergehende These, das mentale Lexikon sei in drei Ebenen gegliedert, auf denen flexivische, derivationelle und kompositionelle Prozesse nacheinander ablaufen, so dass die irreguläre Pluralflexion vor der Komposition, die reguläre aber danach erfolge, da der Output der jeweils vorhergehenden Ebene als Input der folgenden diene. Deswegen gilt innerhalb des Ebenenmodells der s-Plural trotz seiner von den Autoren anerkannten geringen Frequenz als Default i.S. des einzig regulären Plurals des Deutschen. Für den Spracherwerb würde das bedeuten, dass $97 \%$ aller Pluralformen gelistet und einzeln zu lernen wären, sofern sie nicht durch Ableitungssuffixe lizensiert sind.

Es ist offensichtlich, dass hier eine von Kiparsky 1982 fürs Englische entwickelte Theorie blind, d.h. ohne Berücksichtigung der empirischen Fakten, aufs Deutsche übertragen wird.

Tatsächlich scheint eine zu einem auf Vollvokal auslautenden Wort gebildete s-Pluralform in Komposita nicht aufzutauchen: *Autosbahn, *Sozistreffen. Dies bedarf der Erklärung. Sie liegt in der Funktion der Fugenelemente und lässt sich in Beschränkungen der OT fassen.

Für die Erstglieder in Komposita gelten ähnliche Beschränkungen wie für Pluralformen, teilweise gelten sie hier strikter, v.a. die folgende: Sie dürfen die Treuebeschränkungen hinsichtlich der Morphemgrenze nicht verletzen.

Die Funktion der Fugenelemente ist es (cf. Fuhrhop 1998),

die Morphemgrenze zu markieren,

mehrgliedrige Komposita zu strukturieren,

teilweise auch: trochäische Füße im Erstglied zu bilden, was für das nicht-silbische -s natürlich ausscheidet, aber nicht-pluralische Schwa-Silben in der Fuge erklärt.

den Genitiv anzuzeigen, was bei Pluralformen wegen deren $\emptyset$-Genitiv ebenfalls ausscheidet.

\footnotetext{
${ }^{54}$ In Analogie zur Berliner Pfaueninsel von sämtlichen der von mir befragten Studenten (= Informelle Befragung von ca. 30 Potsdamer Germanistikstudenten) vorgeschlagen.

${ }^{55}$ In der Lesart 'Fahndung nach Sheriffs' von 50\%, in der Lesart 'Fahndung durch Sheriffs' von 60\% meiner Studenten akzeptiert.

${ }^{56}$ Informelle Befragung von ca. 30 Potsdamer Germanistikstudenten.
} 
Die beiden letzten Funktionen sind für das Verständnis und die Entstehung von Fugenelementen wichtig.

Funktion 3 erklärt, warum wir scheinbare Pluralflexive an Erstgliedern ohne Pluralbedeutung finden: Hundehütte, Eierschale, Hühnerei, Bilderrahmen, Hahnenkampf, Küchenfenster, Frauenherz. Es handelt sich meist um Genitivflexive, auch die der früher schwach flektierten Nomen, ${ }^{57}$ bzw. um das alte Stammbildungssuffix $-\mathrm{er}^{58}$ (s.o.). Mit ihrer Hilfe gelingt es, trochäische Erstglieder zu bilden. $\mathrm{Zu}$ untersuchen wäre, ob diese Beschränkung dann besonders wirksam ist, wenn auch das Zweitglied trochäisch ist, so dass wir ein vier- oder sechssilbiges, zwei- oder dreifüßiges Kompositum mit regelmäßig alternierender Betonung erhalten: Professorentitel - Doktortitel.

Pluralmarkierung ist am Erstglied nicht notwendig, der unmarkierte generische Singular genügt i.a. trotz pluralischer Bedeutung: Buchhändler, Bildband, Haarfarbe, Hutmacher, Schuhgeschäft, Skiverleih etc.

Funktion 4 erklärt die Fugenelemente diachron und synchron: Komposita entstehen aus Genitivphrasen: ${ }^{59}$ des Apfels Kern > Apfelkern, mit zunehmender Lexikalisierung kann das Genitivsuffix wegfallen, ${ }^{60}$ wenn es nicht aus phonologischen Gründen notwendig ist, oder zu einem Fugenelement umfunktioniert werden, d.h. die o.g. Funktionen ausüben. Sie erklärt auch die Beschränkung auf paradigmische Flexive, die nur bei Feminina verletzt wird (Geburtstag), siehe unten. *Kindengarten, wie von Clahsen et al. 1995:128 erwogen, ist daher ein morphologisch unmögliches Wort des Deutschen!

Pluralität anzuzeigen ist offensichtlich nicht die primäre Funktion der Fugenelemente, ist aber auch nicht ausgeschlossen, wie Städtereisen - Stadtbummel, Schwesternschule Schwesterschule zeigen.

Die erste Funktion entspricht der von mir definierten Treubeschränkung IDENT $\mu$ : im Gegensatz zu Flexions- und zu Derivationsformen darf bei Kompositionen die Morphemgrenze nicht verdunkelt und nicht verschoben werden. Wir haben Zei.ten, Zei.tung, aber Zeit.reise, Zeit.alter, obwohl nach Vennemanns Silbenkontaktgesetz ein Silbenauslaut von niedriger Sonorität in den Silbenanfangsrand der nächsten Silbe gezogen werden müsste und bei Derivation und Flexion auch gezogen würde. Genau dies verhindert das Fugenelement, wie *Kalbbraten, *Kalbleber vs Kalbfleisch zeigen: die Gefahr falscher Syllabierung *Kal.braten, *Kal.bleber wird durch Kalbsbraten, Kalbsleber gebannt.

\footnotetext{
${ }^{57}$ Da die Klasse der schwachen Substantive aller drei Genera früher wesentlich größer war und bei ihnen Genitiv- und Pluralsuffix formgleich sind, kommt es häufig zu Fehlinterpretationen dieser Suffixe als Pluralflexive. Auch in Hahnenkamm, Sternenbanner, Greisenalter, Frauenherz, Ohrenweh und sogar in Gänsebraten liegen Genitivformen vor. Nur selten, cf. Sinnenreiz, ist -en unparadigmisch (cf. Wellmann et al. 1974: 373). Die e-Fuge verwendet den Genitiv Plural: Hundehütte. Da die meisten Substantive nur eine Kompositionsstammform ausbilden (cf. genauer Fuhrhop 1998), wird diese (singularische oder pluralische Form) dann auch in allen Komposita verwendet, unabhängig von einer singularischen oder pluralischen Bedeutung des Erstglieds. Widersprüche ergeben sich daraus nur, wenn man wie Clahsen et al., Marcus et al. Fugenelemente für Morpheme hält.

${ }^{58}$ Interessanterweise taucht die er-Fuge in 5\% der kindersprachlichen Bildungen auf (Schrauberfresser), s. Niedeggen-Bartke 1999:219, ein Phänomen, für das die Autorin keine Erklärung hat, da sie die Fugen als Morpheme deutet.

${ }^{59}$ Die Interpretation als Genitivsuffix wird ex negativo bestätigt durch die Tatsache, dass Kopulativkomposita, denen ja kein Genitivverhältnis zugrunde liegt, keine Fugen haben: Prinzgemahl, Strichpunkt. Sie wird durch Scheinkomposita wie Lieblingsbluse, Hauptsache, Riesenhunger, Mordskerl nicht widerlegt: hier handelt es sich im Erstglied um intensifikatorische Affixoide.

${ }^{60}$ Hermann Paul (1917) spricht z.B. noch von "umlautsfähigen" Vokalen.
} 
Natürlich verstößt die Kompositionsstammform Kalbs gegen NC, die Treuebeschränkung IDENT $\mu$ ist hier aber höher gewichtet. Bei Kalbfleisch besteht diese Gefahr nicht, da anlautendes f- nur mit einem einzigen anderen Konsonanten einen Anfangsrand bilden kann, nämlich p-, aber intervokalisch von diesem getrennt wird: Trop.fen. Ein -s wäre hier afunktional, ein damit verbundener Verstoß gegen NC nicht motiviert. Bei Identität des auslautenden Konsonanten des Erstglieds mit dem anlautenden Konsonanten des Zweitglieds ist bei Obstruenten die Gefahr falscher Syllabierung und sogar Tilgung eines der Segmente wegen Geminatentilgung besonders groß: Sie wird vermieden durch -s, das sogar unparadigmisch an Feminina tritt: *Gebur.ttag, *Hochzei.ttraum, Abfahrtszeit - Fahrzeit (!)Fahrtdauer, Mondschein - Montag (!). Nicht-obstruente Konsonanten können dagegen gelängt und zum Silbengelenk werden: Stalllaterne, Schifffahrt.

Lautet das Erstglied nun auf Vollvokal aus, so besteht keine Gefahr falscher Syllabierung, da nach NC und dem universalen Silbenkontaktgesetz *Aut.obahn gar nicht syllabiert werden kann. Ein hochsonoranter Endrand kann nicht in den Anfangsrand der Folgesilbe gezogen werden. Ein Fugenelement wäre hier also afunktional und verstieße in nicht motivierter Weise gegen NC! *Autosbahn, *Sozistreffen sind folglich unmögliche Wörter des Deutschen.

Es ist nun natürlich problematisch, wenn die Autoren zur Überprüfung ihrer These und der Frage, ab wann Kindern die angenommene Ebenenstrukturierung des Lexikons zur Verfügung steht, Elizitationstests durchführen, bei dem Komposita ausgerechnet mit einem auf f- anlautenden Zweitglied (Fresser) gebildet werden sollen. Es gibt gar keinen Grund, Formen wie *Autosfresser, *Federsfresser oder *Federnfresser zu bilden, wie auch Federbett mit zweifellos pluralischer Bedeutung von Feder zeigt, da das Erstglied bereits einen Trochäus darstellt und die Morphemgrenze nicht in Gefahr ist. ${ }^{61}$ Wenn die Kinder hier also kein Pluralsuffix, genauer: kein Fugenelement einsetzen, so zeigen sie, dass sie das universale Silbengesetz No Coda beherrschen, nicht mehr und nicht weniger. ${ }^{62}$ Über die angenommene Ebenenstrukturierung und über den angeblichen Defaultstatus oder gar die Regularität des sPlurals sagen diese Testergebnisse nichts aus, sie sind durch die Testitems provoziert. Denn gefragt, wie jemand heißt, der Shrimps oder Chips frisst, wurden die Kinder nicht. Da ein Fugenelement bei einfachen Komposita vor anlautendem f- höchst unwahrscheinlich ist, bringt das Testdesign hier das erwartete Ergebnis. ${ }^{63}$

Angesichts der Tatsache, dass 72,8\% der N+N-Komposita überhaupt kein Fugenelement haben (Ortner et al.1991:54), und dass es für das Auftreten der Fugenelemente nur Tendenzen, aber keine Regeln zu geben scheint (cf. Rathaus - Ratsherr, Bildband Bilderbuch bei sonst gleichen Bedingungen!), scheint es fraglich, ob Fugenelemente bei Kindern sinnvoll elizitierbar sind bzw. ob die Tatsache, dass Kinder wenige bilden, etwas über ihre interne Grammatik aussagt.

\footnotetext{
${ }^{61}$ Nach Erstgliedern, die auf -el oder -er enden, steht fast nie ein Fugenelement, cf. Wellmann et al. 1974: 364, es erstaunt daher denn doch, dass für das Erstglied Testitems gewählt wurden, die zu fast einem Drittel genau dieser Struktur entsprechen, Fugenelemente also nahezu ausschließen!

${ }^{62}$ Es ist bekannt, dass Kinder in der Testsituation wesentlich mehr Übergeneralisierungen produzieren als im freien Gespräch, wo sie auch unmittelbar zuvor produzierte Pluralsuffixe auslassen. Das reduziert die Wahrscheinlichkeit, dass sie Komposita damit bilden, weiter.

${ }^{63}$ Damit soll hier nicht unterstellt werden, die Autoren hätten die Ergebnisse manipuliert. Auch das Testdesign wurde aus einer amerikanischen Studie kopiert. Testergebnisse sind aber abhängig von den Testitems, hier sind sie dessen Artefakte. Das gilt zumindest für das in Clahsen et al. 1995, Niedeggen-Bartke 1999 beschriebene 1. Experiment mit "Fresser" als Zweitglied. Auch das 2. Experiment mit variablen Zweitgliedern enthält aber wenig fugenfreundliche Items und elizitiert v.a. nur zweigliedrige Komposita, bei denen eine Fuge aber selten ist.
} 
Die 2. Funktion, nämlich mehrgliedrige Komposita zu strukturieren, (s. schon Zepic 1970:53), erklärt, warum ein Fugenelement umso eher auftritt, je komplexer das Kompositum ist: Zeitreise, aber Hochzeitsreise, Hofmauer - Friedhofsmauer, Werkzeug - Handwerkszeug, Turmuhr - Kirchturmsuhr. Bei dreigliedrigen Komposita ist grundsätzlich die Lesart AB+C oder A+BC möglich, das Fugenelement schafft hier Klarheit und sichert in den Beispielen die Lesart $A B+C{ }^{64}$ ) In dieser Funktion müsste nun auch ein -s nach Vollvokalauslaut möglich sein, und es lassen sich auch unschwer Beispiele finden: Spielzeugautosfresser, Umweltautosentwicklung, Liebhaberautosverkauf, Firmenchefsautos und eventuell sogar Firmenchefsautosversteigerung, mit zwei s-Fugen, die pluralische Bedeutung haben.

Das stimmlose -s ist im Deutschen das ideale Segment zur Wahrung und Anzeige der Morphemgrenze: im Wortanlaut wird es vor Vokal stimmhaft (Sache), vor Konsonant zum sch-Laut (Stein), intersyllabisch stets getrennt: Mus.kel, Fens.ter. Als Fuge bleibt es stimmloses -s und zeigt somit die Morphemgrenze an. Die Tatsache, dass im Englischen weder Sonorisierung vor Vokal (safe) noch Palatalisierung vor Konsonant (stone) auftritt, erklärt zugleich, warum das -s dort diese Funktion nicht erfüllen kann und es folglich fast keine s-Fugen gibt. Das Deutsche ist dem Englischen in diesem Teil seiner Phonologie nicht einmal ähnlich.

Die Annahme, der s-Plural sei "the exception that proves the rule" und der einzig reguläre Plural des Deutschen, wirft natürlich die Frage auf, welche Evidenz für das Kind für diesen Status im Input besteht. Das (angebliche) Nichtvorkommen in Komposita wäre dann KontraEvidenz. Da die Frequenz im Input gegen diesen Status spricht, nehmen Marcus et al. 1995:245 an, Onomatopoetika, Eigennamen und Fremdwörter seien cues für den Defaultplural, aus denen das Kind den Status des s-Plurals als regulär erkennen könne. Wenn das Kind tatsächlich aus derart hochmarkierten Formen auf den Default schließen soll, was es, wie Fehler an Fremdwörtern zeigen, glücklicherweise nicht tut (da es diese ggf. auch gar nicht als Fremdwörter erkennt, siehe oben), dann müsste es auch Reduplikation für das Defaultprinzip der Wortbildung im Deutschen halten!

Das Duale-Routen-Modell, das den s-Plural als Default i.S. eines Notplurals ansieht, der dann appliziert wird, wenn keine andere Regel greift bzw. kein Lexikoneintrag vorliegt, ist durch diese Komposita natürlich nicht widerlegt. Baayen et al. 1997 zeigen, dass Duale-RoutenModelle nicht implizieren, dass nur die irregulären Pluralformen gespeichert werden. Psycholinguistische Tests zeigen, dass auch reguläre Formen, sofern sie frequent sind, schneller verfügbar sind als weniger frequente, so dass angenommen werden kann, dass auch sie gespeichert sind. Es scheint plausibel anzunehmen, dass hochfrequente Formen gespeichert und somit schneller verfügbar sind als niedrig frequente. Angesichts dieser Ergebnisse löst sich die Frage, ob es im Deutschen einen oder mehrere Regelplurale gibt und ob dies der s-Plural oder ein anderer ist, in ein Scheinproblem auf.

\footnotetext{
${ }^{64}$ Mädchenhandelsschule scheint hier ein Gegenbeispiel, erklärt sich aber aus der weiteren Funktion des Fugenelements, Verbableitungen als Substantiv zu kennzeichnen, cf. Eisenberg (1998).
} 


\subsection{Ausblick und offene Fragen}

Da Duale-Routen-Modelle nicht implizieren, dass nur ein Pluralsuffix produktiv und regulär ist, wie Baayen et al. 1997 am Holländischen zeigen, ist der deutsche Plural mit konnektionistischen und symbolistischen Modellen in gleicher Weise kompatibel. Auch die eher geringe Zahl von Übergeneralisierungen in den Spontandaten der Kinder (siehe oben), die Spracherwerbsforscher immer wieder zu dem Schluss geführt haben, dass zumindest "die Pluralformen gebräuchlicher Wörter eher auswendig gelernt werden" (Schaner-Wolles 1989:173), womit ja noch nichts über die Herausbildung eines Flexionsklassenbewusstseins gesagt ist, schließt keines der Modelle aus.

Für konnektionistische Ansätze, die Grammatik einer natürlichen Sprache als Netzwerk zu implementieren und den Spracherwerb zu simulieren, stellt das komplexe System der Pluralbildung im Deutschen eine Herausforderung dar.

Da semantische Restriktionen bei der Pluralbildung kaum eine Rolle spielen, scheint ein solches Vorhaben nicht unmöglich. Und wenn Netzwerke Spracherwerbsprozesse modellieren können, so müsste es schließlich sogar möglich sein, die Sprachentwicklung zu modellieren, wie der Versuch von Hare und Elman 1995 für englische past tense-Formen im Altenglischen zeigt. Hier eröffnet sich ein weites Feld und eine faszinierende Aufgabe für die Computerlinguistik und den Konnektionismus. 


\section{Literatur}

\section{Wörterbücher}

Duden 1989: Deutsches Universalwörterbuch, Mannheim: Duden

Grimm 1873: Deutsches Wörterbuch.Leipzig: Hirzel

Sachs-Villatte 1900: Encyclopädisches Wörterbuch.Bd II: Dt-Frz, Berlin: Langenscheidt

Wahrig 1968/1975: Deutsches Wörterbuch. Gütersloh: Bertelsmann

\section{Wissenschaftliche Werke}

Archangeli, Diana (1997): "Optimality Theory: An Introduction to Linguistics in the 1990s". In: Archangeli, Diana/Langendoen, Terence (eds..): 1-32.

Archangeli, Diana/Langendoen, Terence (eds.) (1997): Optimality Theory: An Overview. Oxford: Blackwell.

Augst, Gerhard (1979): Neuere Forschungen zur Substantivflexion. In: ZGL 7, 220-232.

Baayen, Harald R./Dijkstra, Ton/Schreuder, Robert (1997): "Singulars and Plurals in Dutch: Evidence for a Parallel Dual-Route Model". In: Journal of Memory and Language 37: 94117.

Baayen, Harald, et al. (1999): "Dutch inflection: The rules that prove the exception". In: Nooteboom, S. /Weerman, F./Wijnen, F. (eds.): Storage and computation in the language faculty. Dordrecht: 1-29.

Bech, Gunnar (1963): "Zur Morphologie der deutschen Substantive". In: Lingua 12: 177-189.

Becker, Thomas (1994): "Die Erklärung von Sprachwandel durch Sprachverwendung am Beispiel der deutschen Substantivflexion". In. Köpcke, K.M. (ed.): Funktionale Untersuchungen zur deutschen Nominal- und Verbalmorphologie, Tübingen: 45-64.

Bornschein, Matthias/Butt, Matthias (1987): "Zum Status des s-Plurals im gegenwärtigen Deutsch." In: Abraham, Werner/Arhammar, Rita (Hgg): Linguistik in Deutschland. Tübingen: 135-153.

Bybee, Joan L. (1985): Morphology, A Study of the relation between meaning and form. Amsterdam/Philadelphia.

Chapman, Carol (1995): "Perceptual salience and affix order: noun plurals as input to word formation." In: Booij, G./van Marle, J.(eds): Yearbook of Morphology1995. Dordrecht: 175-184.

Clahsen, Harald/Rothweiler, Monika/Woest, Andreas (1990): "Lexikalische Ebenen und Morphologische Entwicklung: Eine Untersuchung zum Erwerb des deutschen Pluralsystems im Rahmen der Lexikalischen Morphologie". In: M. Rothweiler (ed.): Spracherwerb und Grammatik. Linguistische Untersuchungen zum Erwerb von Syntax und Morphologie. (= Ling. Berichte, Sonderheft 3): 105-126.

Clahsen, Harald, et al. (1992): "Regular and irregular inflection in the acquisition of German noun plurals." In: Cognition, 45 (1992): 225-255.

Clahsen, Harald, et al. (1995): "Compounding and inflection in German child language" ${ }^{1}$. In: Yearbook of Morphology 1995: 115-142.

Clahsen, Harald/Eisenbeiss, Sonja/ Sonnenstuhl-Henning, Ingrid (1996): "Morphological structure and the processing of inflected words". In: Essex research reports in linguistics 13: 1-53.

Corbett, Greville (1991): Gender. New York: Cambridge UP.

Dittmar, Norbert (1997): Grundlagen der Soziolinguistik - ein Arbeitsbuch mit Aufgaben. Tübingen

Eisenberg, Peter (1991): "Syllabische Struktur und Wortakzent: Prinzipien der Prosodik deutscher Wörter". Zeitschrift für Sprachwissenschaft 10: 37-64. 
Eisenberg, Peter ( $\left.{ }^{3} 1994\right)$ : Grundriss der deutschen Grammatik. Stuttgart: Metzler.

Eisenberg, Peter (1998): Grundriss der deutschen Grammatik. I: Das Wort. Stuttgart: Metzler. Elman, Jeffrey L. et al. (1996): Rethinking Innateness. Cambridge (Mass).

Engelen, Bernhard (1991): "Über das Verhältnis von Auslautkonsonant und Pluralumlaut bei den einsilbigen Nomina". Zielsprache Deutsch 22: 25-37.

Féry, Caroline (1997): "Uni und Studis: die besten Wörter des Deutschen". Linguistische Berichte 172: 461-489.

Fleischer, Wolfgang / Barz, Irmhild (1995): Wortbildung der deutschen Gegenwartssprache, 2. Auflage, Tübingen.

Fuhrhop, Nanna (1998): Grenzfälle morphologischer Einheiten. Tübingen: Stauffenburg.

Golston, Chris / Wiese, Richard (1995): "Zero morphology and constraint interaction: subtraction and epenthesis in German dialects." In: Booij, G. /van Marle, J. (eds): Yearbook of Morphology 1995. Dordrecht: 143-159.

Hare, M., Elman, J.L. (1995): "Learning and morphological change." Cognition 56: 61-98.

Harnisch, Rüdiger (1990): "Die Pluralbildung des Substantivs im Deutschen - Ein Fall von 'Grundformflexion'?". Linguistische Studien A 208: 37-55.

Harnisch, Rüdiger (1994): "Stammerweiterung im Singular - Stammflexion im Plural. Zum Bautyp der deutschen Substantivdeklination". In: Köpcke, K. M. (ed.): Funktionale Untersuchungen zur deutschen Nominal- und Verbalmorphologie, Tübingen: 97-114.

Heine, Bernd (1982): "African noun class-systems". In: Seiler, Hansjakob/ Lehmann, Christian (eds.): Apprehension. Das sprachliche Erfassen von Gegenständen. Tübingen: 189-216.

Kiparsky, Paul (1982): "From Cyclic Phonology to Lexical Phonology." In: van der Hulst, H./ Smith, N. (eds): The Structure of Phonological Representations. Dordrecht: 131-175.

Kloeke, Wus van Lessen (1982): Deutsche Phonologie und Morphologie. Tübingen.

König, Werner (1989): Atlas zur Aussprache des Schriftdeutschen in der Bundesrepublik Deutschland. 2 Bände. Ismaning.

Köpcke, Klaus-Michael (1987): "Die Beherrschung der deutschen Pluralmorphologie durch muttersprachliche Sprecher und L2-Lerner mit englischer Muttersprache". In: Ling. Berichte 107, 23-43.

Köpcke, Klaus-Michael (1988): "Schemas in German Plural Formation". In: Lingua 74, 303335.

Köpcke, Klaus-Michael (1994): "Zur Rolle von Schemata bei der Pluralbildung monosyllabischer Maskulina". In: Köpcke, K.M. (ed.): Funktionale Untersuchungen zur deutschen Nominal- und Verbalmorphologie, Tübingen: 81-96.

Lüdtke, Helmut (1980): "Sprachwandel als universales Phänomen". In: H. Lüdtke (ed.): Kommunikationstheoretische Grundlagen des Sprachwandels. Berlin: 1-19.

Marcus, Gary F. et al. (1995): "German inflection: the exception that proves the rule". Cognitive Psychology 29: 189-256.

Mayerthaler, Willi (1981): Morphologische Natürlichkeit. Wiesbaden.

Meier, Helmut (1964): Deutsche Sprachstatistik. Hildesheim.

Mills, Anne E. (1985): "The Acquisition of German". In: Slobin, Dan I. (ed.): The Crosslinguistic Study of Language Acquisition, Bd 1, Hillsdale, London:141-254.

Müller, Gereon (1997): "Beschränkungen für Binomialbildungen im Deutschen". Zeitschrift für Sprachwissenschaft 16: 5-51.

Mugdan, Joachim (1977): Flexionsmorphologie und Psycholinguistik. Tübingen.

Neef, Martin (1998): "Reduced syllable plural in German." In: Fabri, R./Ortmann. A./Parodi, T.(eds): Models of Inflection, Tübingen: Niemeyer: 244-265.

Niedeggen-Bartke, Susanne (1999): "Flexion und Wortbildung im Spracherwerb". In: Meibauer, J./ Rothweiler, M. (eds): Das Lexikon im Spracherwerb. Tübingen: 208-228.

Ortner, Lorelies, et al. (1991): Deutsche Wortbildung. Bd. IV: Substantivkomposita. Berlin. 
Park, Tschang-Zin (1978): "Plurals in child speech". Journal of Child Language 5: 237-250.

Paul, Hermann (1880/1975): Prinzipien der Sprachgeschichte. 9. Auflage. Tübingen.

Paul, Hermann (1917) Deutsche Grammatik. Band II,: Flexionslehre. Tübingen.

Pavlov, Vladimir (1995): Die Deklination der Substantive im Deutschen. Sychronie und

Diachronie. Frankfurt/Main.

Penke, Martina /Krause, Marion (1999): "Broca's aphasia and German plural formation".

Brain + Language 69: 305-318.

von Polenz, Peter (1978): Geschichte der deutschen Sprache. Berlin.

Ramge, Hans 1975: Spracherwerb. Grundzüge der Sprachentwicklung der Kinder. Tübingen.

Russ, Charles (1989): "Die Pluralbildung im Deutschen." ZGL 17: 58-67.

Russell, Kevin (1997): "Optimality Theory and Morphology". In: Archangeli, Diana/Langendoen, Terence (eds.), 134-170.

Schaner-Wolles, Chris (1989): "Plural- vs Komparativ-Erwerb im Deutschen - Von der Diskrepanz zwischen konzeptueller und morphologischer Entwicklung". In: Günther, Hartmut (ed.): Experimentelle Studien zur deutschen Flexionsmorphologie, Hamburg: 155186.

Schluroff, Michael (1974): "Flexionsklassen von Substantiven und ihre Häufigkeitsverteilung". Ling. Berichte 31: 19-30.

Schmidt-Wilpert, Gabriele (1980): "Zur Substantivflexion, Grammatik und Sprachnorm um 1750." Zs f. Dt. Philologie 99: 410-429.

Stegmann von Pritzwald, Kurt (1969): "Die Pluralumwälzung im Deutschen". In: Moser, Hugo (ed.): Das Ringen um eine neue deutsche Grammatik. Darmstadt: 89-100.

Vennemann, Theo (1988): Preference laws for syllable structure and the explanation of sound change. Berlin.

Vennemann, Theo (1991): "Skizze der deutschen Wortprosodie". In: Zeitschrift für Sprachwissenschaft 10, 86-111.

Vennemann, Theo (1993): "Language change as language improvement". In: Jones, Charles (ed): Historical Linguistics. London/New York: 319-344.

Wegener, Heide (1992): Kindlicher Zweitspracherwerb. Untersuchungen zur Morphologie des Deutschen und ihrem Erwerb durch Kinder mit polnischer, russischer und türkischer Erstsprache. Eine Längsschnittuntersuchung. Habilitationsschrift, Universität Augsburg.

Wegener, Heide (1992a): "Pluralregeln und mentale Grammatik". In: A. Strigin/I. Zimmermann (eds.) Fügungspotenzen. Festschrift für M. Bierwisch. Studia grammatica 34, Berlin:, 225-249.

Wegener, Heide (1994): "Variation in the acquisition of German noun plurals". In: Tracy, R./Lattey, E. (eds.): How Tolerant is Universal Grammar? Problems of Learnability and Variation in Language Acquisition. Tübingen: 267-294.

Wegener, Heide (1995): Die Nominalflexion des Deutschen, verstanden als Lerngegenstand. Tübingen. (=Reihe Germanistische Linguistik 151).

Wegener, Heide (1995a): Generative Morphologie und Deutsch als Fremd- und Zweitsprache, Der deutsche Plural und sein Erwerb durch kindliche L2-Lerner - ein Beispiel für Natürliche Morphologie und Grade von Markiertheit im Deutschen. Jahrbuch Deutsch als Fremdsprache 21:185-208.

Wegener, Heide (1999): "Syntaxwandel und Degrammatikalisierung im heutigen Deutsch? Noch einmal zu weil - Verbzweit." Deutsche Sprache 27: 3-24.

Wegera, Klaus-Peter (1984-85): "Morphologie des Frühneuhochdeutschen, Morphologie des Neuhochdeutschen". In: Besch, W./Reichmann, O./Sonderegger, S. (eds.): Sprachgeschichte. Ein Handbuch zur Geschichte der deutschen Sprache und ihrer Erforschung. Berlin/New York: 1313-1322 und 1501-1510.

Wegera, Klaus-Peter (1987): Flexion der Substantive. (Bd 3 von Moser, Hugo/ Stopp, Hugo/Besch, Werner (eds): Grammatik des Frühneuhochdeutschen. Heidelberg. 
Wellmann, Hans, Reindl, Nikolaus, Fahrmaier, Anemarie (1974): "Zur morphologischen Regelung der Substantivkomposition im heutigen Deutsch. In: ZfdPh 93: 358-378.

Werner, Otmar (1969): "Das deutsche Pluralsystem. Strukturelle Diachronie". In: H. Moser (ed.): Sprache, Gegenwart und Geschichte. Düsseldorf: 92-128.

Weyerts, Helga, Clahsen, Harald (1994): "Netzwerke und symbolische Regeln im Spracherwerb: Experimentelle Ergebnisse zur Entwicklung der Flexionsmorphologie". Linguistische Berichte 154/1994: 430-460.

Weyerts, Helga, et al. (1997): "Brain potentials indicate differences between regular and irregular German plurals." NeuroReport 8: 957-962.

Wiese, Richard (1996): The phonology of German. Oxford.

Wunderlich, Dieter / Fabri, Ray (1995) "Minimalist Morphology: An approach to inflection." Zeitschrift für Sprachwissenschaft 14: 236-294.

Wunderlich, Dieter (1999): "German noun plural reconsidered", Düsseldorf: Ms.

Wurzel, Wolfgang U. (1970): Studien zur deutschen Lautstruktur, Berlin: Akademie.

Wurzel, Wolfgang U. (1984): Flexionsmorphologie und Natürlichkeit. Ein Beitrag zur morphologischen Theoriebildung. Berlin.

Wurzel, Wolfgang U. (1985): "Deutsch der Funke zu der Funken: ein Fall für die natürliche Morphologie". In: Ling. Studien A 127, 129-145.

Wurzel, Wolfgang U. (1990): "The mechanism of inflection: lexicon representations, rules, and irregularities". In: Dressler, W. U., et al. (eds): Contemporary Morphology, Berlin, New York: 203-216.

Zehetner, Ludwig (1985): Das bairische Dialektbuch. München.

Zepic, Stanko (1970): Morphologie und Semantik der deutschen Nominalkomposita. Zagreb. 


\section{Anhang: Pluralvarianten}

\section{Semantisch motivierte Variation}

1a) Unterscheidung von Homonymen:

$\begin{array}{llll}\text { (e)n - (e) } & \text { Muttern } & - & \text { Mütter } \\ & \text { Banken } & - & \text { Bänke } \\ & \text { Leitern } & - & \text { Leiter } \\ & \text { Steuern } & - & \text { Steuer } \\ \text { (e) - er } & \text { Bände } & - & \text { Bänder } \\ & \text { Worte } & - & \text { Wörter } \\ & \text { Schilde } & - & \text { Schilder } \\ \text { s - (en) } & \text { Koteletts } & - & \text { Koteletten }\end{array}$

1b) Unterscheidung von Appellativen bzw. Produktnamen und Eigennamen:

$\begin{array}{llrl}\text { er - s } & \text { Männer } & - & \text { Manns } \\ & \text { Holzmänner } & - & \text { Holzmanns } \\ & \text { Mannesmänner } & \text { - } & \text { Mannesmanns } \\ \text { (e) - s } & \text { Schmiede } & - & \text { Schmieds } \\ & \text { Bäcker } & - & \text { Beckers } \\ \text { o - s } & \text { Opel } & - & \text { Opels } \\ & \text { Duden } & - & \text { Dudens } \\ \text { "(e) - s } & \text { Vögel } & - & \text { Vogels } \\ \text { "(e) - ens } & \text { Käuze } & - & \text { Kauzens } \\ \text { en - ens } & \text { Katzen } & - & \text { Katzens } \\ & \text { Schulzen } & - & \text { Schulzens } \\ \text { "er - ens } & \text { Klötzer } & - & \text { Klotzens }\end{array}$

\section{Stilistische Variation:}

Die Varianten gehören unterschiedlichen Sprachschichten ${ }^{67}$ an.

$\begin{array}{llll}\text { (e) - er } & \text { Grabmale } & - & \text { Grabmäler } \\ & \text { Denkmale } & - & \text { Denkmäler } \\ \text { Worte } & - & \text { Wörter } \\ & \text { Bande } & - & \text { Bänder } \\ \text { Eilande } & - & \text { Länder }\end{array}$

\footnotetext{
${ }^{65}$ Inforadio 01.12.1999.

${ }^{66}$ Die Zeit 02.12.1999: 16.

${ }^{67}$ In diesen Fällen ist der er-Plural die jüngere Form, die ältere gilt als erhaben. Zum Teil ist die ältere Form noch in Ortsnamen erhalten: Niederlande, Burghausen, Rheinfelden.
} 
3. Diastratische Variation:

a) Süden ${ }^{68}$ - Norden

$\begin{array}{llll}\text { er - (e) } & \text { Skier } & - & \text { Ski } \\ & \text { Beiner } & - & \text { Beine } \\ & \text { Steiner } & - & \text { Steine } \\ & \text { Bröter } & - & \text { Brote } \\ \text { "(e) - (e) } & \text { Wägen } & - & \text { Wagen } \\ & \text { Ärm } & - & \text { Arme } \\ & \text { Täg } & - & \text { Tage } \\ \text { (e)n - (e) } & \text { Onkeln } & - & \text { Onkel } \\ & \text { Mädeln } & - & \text { Mädel } \\ & \text { Spiegeln } & - & \text { Spiegel } \\ \text { "(e) - s } & \text { Pärke } & - & \text { Parks } \\ & \text { Karusselle } & - & \text { Karussells } \\ \text { (e) - s } & \text { Onkel } & - & \text { Onkels } \\ \text { en - s } & \text { Jungen } & - & \text { Jungs }\end{array}$

b) Osten - Westen

$\begin{array}{llll}\text { (e) }-\mathrm{s} & \text { Parke }^{70} & - & \text { Parks } \\ & \text { Pointe } & - & \text { Points } \\ & \text { PKW } & - & \text { PKWs } \\ & \text { Taxen } & - & \text { Taxis } \\ \text { (e) } n-\mathrm{s} & \text { LPGen } & - & \text { LPGs }\end{array}$

\section{Diachrone Variation}

a) Veränderungen im Fnhd - Entstehung eines neuen Pluralsuffixes:

(e) $>$ er

\begin{tabular}{lll}
\multicolumn{2}{l}{ (Ebers)Walde - } & Wälder \\
(Burg)Hausen - & Häuser \\
Worte & - & Wörter \\
Bande & - & Bänder \\
Geiste & - & Geister \\
Sträuche & - & Sträucher \\
Wichte & - & Bösewichter \\
Lichte & - & Lichter \\
Gesichte & - & Gesichter \\
Dinge & - & Dinger \\
Manne & - & Männer
\end{tabular}

\footnotetext{
${ }^{68}$ Schwäbisch, bairisch.

${ }^{69}$ Schweizerisch.

${ }^{70}$ Junge Welt 17./18. Juli 1999: Service Pointe.
} 
b) Abbau dieses Notplurals:

$\begin{array}{llll}\text { er }>(e) \quad & \text { Sträußer } & - & \text { Sträuße } \\ & \text { Complimenter - } & \text { Komplimente } \\ & \text { Lazaretter } & - & \text { Lazarette } \\ & \text { Testamenter } & - & \text { Testamente } \\ & \text { Kameler } & - & \text { Kamele } \\ & \text { Kabinetter } \quad- & \text { Kabinette } \\ \text { er }>\text { s } & \text { Departementer }- & \text { Departements } \\ & \text { Buketter } & - & \text { Buketts }\end{array}$

c) Assimilierung von Fremdwörtern:

$\begin{array}{lll}\mathrm{s}>(\mathrm{e}) \quad \text { Generals } & - & \text { Generäle }^{71} \\ \text { Barons } & - & \text { Barone } \\ \text { Onkels } & - & \text { Onkel } \\ \text { Balkons } & - & \text { Balkone } \\ \text { Hurricans } & - & \text { Hurrikane } \\ \text { Lifts } & - & \text { Lifte } \\ \text { Fracks } & - & \text { Fräcke } \\ \text { Kostüms } & - & \text { Kostüme } \\ \text { Kaftans } & - & \text { Kaftane } \\ \text { Turbans } & - & \text { Turbane } \\ \text { Defizits } & - & \text { Defizite } \\ \text { Tunichtguts } & - & \text { Tunichtgute } \\ \text { Vergissmeinnichts } & \text { Vergissmeinnichte }\end{array}$

$\begin{array}{llll}\text { e }>\text { as } & \text { Pizze } & - & \text { Pizzas } \\ & \text { Ville } & - & \text { Villas } \\ \text { i }>\text { os } & \text { Motti } & - & \text { Mottos } \\ & \text { Conti } & - & \text { Kontos } \\ & \text { Celli } & - & \text { Cellos } \\ & \text { Saldi } & - & \text { Saldos } \\ & \text { Mensas } & - & \text { Mensen } \\ & \text { Basilikas } & - & \text { Basiliken } \\ & \text { Divas } & - & \text { Diven }\end{array}$

$\begin{array}{llll}\text { ta }>\mathrm{s} & \text { Themata } & - & \text { Themas } \\ & \text { Schemata } & - & \text { Schemas } \\ & \text { Kommata } & - & \text { Kommas } \\ & & & \\ \text { as }>\text { en } & \text { Primadonnas } & - & \text { Primadonnen } \\ & \text { Schemas } & - & \text { Schemen } \\ & \text { Themas } & - & \text { Themen } \\ & \text { Pizzas } & - & \text { Pizzen } \\ & \text { Aromas } & - & \text { Aromen }\end{array}$

\footnotetext{
${ }^{71}$ Nach Paul 1917 waren dies die Pluralformen im 18. Jahrhundert.

${ }^{72}$ Diese und die folgenden Pluralformen noch bei Curme 1922: 93.

${ }^{73}$ Sachs/Villatte 1900, Wahrig 1968 auch: Mensae.
} 


\begin{tabular}{|c|c|c|c|}
\hline & Villas & - & Villen \\
\hline & Verandas & - & Veranden \\
\hline & Astas & - & Asten $^{74}$ \\
\hline \multirow[t]{6}{*}{ os $>$ en } & Kontos & - & Konten \\
\hline & Saldos & - & Salden \\
\hline & Disagios & - & Disagien \\
\hline & Freskos & - & Fresken \\
\hline & Risikos & - & Risiken \\
\hline & Folios & - & Folien \\
\hline is $>$ en & Sozis & - & Sozen \\
\hline usse $>$ en & Globusse & - & Globen \\
\hline \multirow[t]{2}{*}{ ums > en } & Albums & - & Alben \\
\hline & Ultimatums & - & Ultimaten \\
\hline \multirow[t]{2}{*}{$\varnothing>(\mathrm{e})$} & Keks $^{75}$ & - & Kekse \\
\hline & Straps & - & Strapse \\
\hline \multirow[t]{3}{*}{$a>$ en } & Fakta & - & Fakten \\
\hline & Data & - & Daten \\
\hline & Vota & - & Voten \\
\hline
\end{tabular}

\section{Synchrone Variation}

$\begin{array}{llll}\text { en }- \text { ens } & \text { Jungen } & - & \text { Jungens } \\ \text { en }-\mathrm{s} & \text { Jungen } & - & \text { Jungs } \\ \text { (e) }-\mathrm{s} & \text { Onkel } & - & \text { Onkels } \\ & \text { Mädel } & - & \text { Mädels } \\ & \text { Fräulein } & - & \text { Fräuleins } \\ & \text { Mädchen } & - & \text { Mädchens } \\ & \text { Bräutigame } & - & \text { Bräutigams } \\ & & & \\ \text { s-(e) } & \text { Lifts } & - & \text { Lifte } \\ & \text { Labors } & - & \text { Labore } \\ & \text { Scheichs } & - & \text { Scheiche } \\ & \text { Fracks } & - & \text { Fräcke } \\ & \text { Karussells } & - & \text { Karusselle } \\ & \text { Balkons } & - & \text { Balkone }\end{array}$

\footnotetext{
${ }^{74}$ Zum maskulinen (!) Akronym für Allgemeiner Studentenausschuß, Zeitungsbelege bei Harnisch 1994: 107, Fn 11.

${ }^{75}$ Duden 1915, 1934,1989 als Pluralform, s. genauer 2.4.3.1.
} 